EDUARDO MILTON RAMOS SANCHEZ

\begin{abstract}
AVALIAÇÃO DO MODELO DE HAMSTER PARA DETECÇÃO DAS ALTERAÇÕES LIPÍDICAS E CARDIOTOXICIDADE ASSOCIADAS À TERAPIA CONTRA O VÍRUS DA IMUNODEFICIÊNCIA HUMANA
\end{abstract}

Tese apresentada ao Programa de Pós-Graduação em Imunologia do Instituto de Ciências Biomédicas da Universidade de São Paulo, para obtenção do Título de Doutor em Ciências (Imunologia).

São Paulo

2009 
EDUARDO MILTON RAMOS SANCHEZ

\section{AVALIAÇÃO DO MODELO DE HAMSTER PARA DETECÇÃO DAS ALTERAÇÕES LIPÍDICAS E CARDIOTOXICIDADE ASSOCIADAS À TERAPIA CONTRA O VÍRUS DA IMUNODEFICIÊNCIA HUMANA}

Tese apresentada ao Programa de Pós-Graduação em Imunologia do Instituto de Ciências Biomédicas da Universidade de São Paulo, para obtenção do Título de Doutor em Ciências (Imunologia).

Área de concentração: Imunologia

Orientador: Prof. Dr. Magnus Ake Gidlund

São Paulo

2009 


\section{Certificado}

Certificamos que o protocolo registrado sob $\mathrm{n}^{\circ} \mathbf{9 3}$ nas fls. 49 do livro 2 para uso de animais em experimentação, sob a responsabilidade de Mgnus Ake Gidlund Coordenador(a) da Linha de pesquisa "Avaliação do modelo de hamster para a deteç̧ão das alterações lipídicas e cardiotoxicidade associadas à terapia contra HW' do qual participou(aram) o(s) alunos Eduardo Milton Ramos Sanchez e o pesquisador Hiro Goto, está de acordo com os Principios Éticos de Experimentação Animal adotado pelo Colégio Brasileiro de Experimentação Animal (COBEA) e foi aprovado pela COMISSÃO DE ÉTICA EM EXPERIMENTAÇÃO ANIMAL (CEEA) em 22.10.2007.

São Paulo, 23 de outubro de 2007.

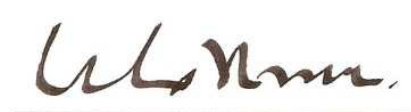

Prof. Dr. Wothan TAVARES DE Lima Coordenador CEEA - ICB/USP

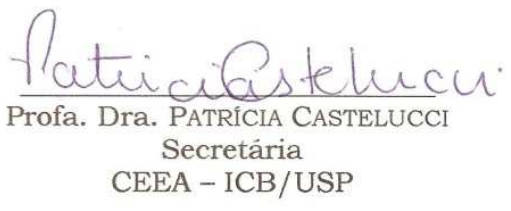


Dedico este trabalho a minha tia Nelly Marta Sanchez Hurtado (in memorian) pelo incentivo, princípios, apoio, dedicação e amor em minha vida. 


\section{AGRADECIMENTOS}

Ao Prof. Dr. Magnus Ake Gidlund pela orientação na realização desta tese, por todos os ensinamentos durante esta caminhada, pela amizade construída e pela confiança depositada em mim.

À Profa. Dra. Hiro Goto por todas as contribuições no desenvolvimento da tese, por permitir a utilização do biotério do Instituto de Medicina Tropical para a realização da parte experimental, por sua confiança e amizade.

A minha família em especial a minhas irmãs pelo apoio e amor.

À Stella por ser cheia de saúde, por ser sempre tão contente e por fazer parte da minha vida.

Ao amigo Fernando Nogueira Souza pelo convívio diário, pela ajuda na elaboração desta tese, por colocar no papel as minhas idéias e pela nossa amizade.

À Luiza por estar sempre presente, por ter me dado tranqüilidade e amor num dos momentos mais difíceis na minha vida.

Aos amigos do laboratório de Imunofisiopatologia: Andrea Monteiro, Gabriela, Silvana Silva, Francisco Rios, Ronald pelo convívio, apoio e pela amizade.

À Andrea Monteiro por toda ajuda sempre que precisei e pela grande amizade conquistada.

Ao Francisco Rios pelo convívio e pela ajuda em algumas fases deste trabalho. 
À Dra. Dolores Helena por ter permitido o uso de equipamentos para realização dos eletrocardiogramas.

À Dra.Thais Mauad pela ajuda na realização das análises dos cortes histopatológicos.

À Dra. Denise Schwartz, cardiologista veterinária, pelas análises dos eletrocardiogramas.

Ao Andre Gimenez pela colaboração na parte prática e pela realização dos eletrocardiogramas.

As técnicas Clara e Marli do laboratório de veterinária pela realização das técnicas bioquímicas.

Ao Fernando por ter me dado orientações e ajuda sempre mesmo na distância.

Aos amigos do laboratório de Soroepidemiologia e Imunobiologia: Maria das Graças Prianti, Wesley, Beatriz, Sandra, Juliana, Mussya, Edite, Carmen, Célia, Márcia, Angelo pela convivência,conselhos e pelas horas de discontração.

Ao Renato Racickas pelo apoio na parte experimental.

A todos do laboratório de Soroepidemiologia e Imunobiologia do IMT pelo convívio e auxílio sempre que foi preciso.

A todos os constituintes da chamada máfia Peruana aqui em São Paulo pelo apoio e convivência.

A todos do departamento de Imunologia do ICB.

À secretaria da Pós-Graduação do Departamento de Imunologia pela assistência sempre que foi preciso. 
Aos professores que fizeram parte da minha banca de qualificação pelas considerações sobre esta Tese.

À CAPES, FAPESP, FINEP, CNPq, CNPq-Milênio, LIM-38 e Pró-Reitoria de Pós Graduação pelo suporte financeiro.

Enfim, a todos que me ajudaram direta ou indiretamente para a conclusão deste trabalho. 
"Acerca das Virtudes"

Nietzsche

"God is dead" (Nietzsche)

"Nietzsche is dead" (God)

(Desconhecido) 


\section{RESUMO}

RAMOS-SANCHEZ, E.M. Avaliação do modelo de hamster para detecção das alterações lipídicas e cardiotoxicidade associadas à terapia contra o vírus da imunodeficiência humana. 2009. 116 f. Tese (Doutorado em Imunologia) - Instituto de Ciências Biomédicas, Universidade de São Paulo, São Paulo, 2009.

Com a introdução de uma nova classe de antiretrovirais integrantes da terapia anti-retroviral altamente ativa (HAART) para o tratamento das infecções pelo vírus da imunodeficiência humana, começaram a ser descritos inúmeros efeitos secundários. $\mathrm{Na}$ tentativa de se estabelecer um modelo animal para $\mathrm{O}$ estudo destes efeitos buscou-se uma espécie com similaridade no perfil e metabolismo lipídico. Iniciou-se estudo em Mesocricetus auratus. Foram avaliados o perfil lipídico e glicêmico,função hepática e renal, níveis de autoanticorpos anti ox-LDL, perfil eletrocardiográfico, alterações histopatológicas renais e cardíacas nos animais sob dieta hiperlipídica e normal,tratados com Indinavir, inibidor de protease utilizado na HAART. Observou-se uma diminuição da sobrevida nos animais tratados com indinavir, aumento do nível sérico de triglicérides e glicose, redução de auto-anticorpos anti oxLDL,aumento do segmento QRS no eletrocardiograma, presença de fibrose renal e cardíaca, hipercelularidade glomerular nos animais tratados com a droga com ou sem dieta hiperlipídica quando comparados com os controles. Concluimos que Mesocricetus auratus se apresenta como um bom modelo para o desvendamento dos mecanismos patológicos observados na HAART.

Palavras-chave: Inibidor de protease. Terapia HAART. HIV. 


\begin{abstract}
RAMOS-SANCHEZ, E.M. Evaluation of the hamster model for the detection of lipidic and cardiotoxicity alterations associated to therapy against human immunodeficiency virus. 2009. 116 p. Ph. D. Thesis(Immunology) Instituto de Ciências Biomédicas, Universidade de São Paulo, São Paulo, 2009.

With the introduction of a new antiretroviral class use, integrants of highly active anti-retroviral therapy (HAART) for the treatment of infections by human immunodeficiency virus, several side effects started to be described.To establish an animal model for the study of these side effects, was chosen specie that have similarities in the lipidic profile and metabolism. A study in Mesocricetus auratus was started. It was evaluated the lipidic and glicemic profile ,hepatic and renal function, the levels of auto-antibodies against oxLDL, electrocardiographic profile and renal and cardiac histopathological alterations in these animals under hyperlipidic and normal diets, treated with Indinavir, a protease inhibitor used in HAART.It was observed a decrease in the survival rate in the animals treated with Indinavir; an increase of the triglycerides and glucose serum level; reduction of anti ox-LDL auto-antibodies; increased QRS segment in the electrocardiogram; presence of renal and cardiac fibrosis; glomerular hypercellularity in the animals treated with the drug, with or without hyperlipidic diet when compared with the controls. We conclude that the Mesocricetus auratus is a good model for disclosure of the pathological mechanisms generated by HAART.
\end{abstract}

Key-Words: Proteases inhibitor. HAART therapy. HIV. 


\section{LISTA DE ABREVIATURAS E SIGLAS}

3TC - Lomivudina

ABC - Abacavir

ADN - ácido desoxirribomucléico

ALT - alanina transaminase

AMP - Amprenavir

Apo - Apolipoproteina

ARN - ácido ribonucléico

AST - aspartato transaminase

ATV- Atazanavir

AVF, AVL, AVR - derivações eletrocardiográficas

AZT - zidovudina

C - colesterol

CCR - receptores celulares de quimiocinas

$\mathrm{CuSO}_{4}$ - sulfato de cobre

D4T - Estavudina

DDI - Didanosina

DI, DII, DII - derivações eletrocardiográficas

DMSO - Dimetilsulfóxido

EFV - Efavirenz

$E C G$ - eletrocardiograma

ELISA - ensaio imunoenzimático (Enzyme-linked Immunosorbent Assay)

GLUT-4 - proteína transportadora de glicose - 4

gp - gligoproteína

$\mathrm{H}_{2} \mathrm{O}_{2}$ - água oxigenada

HAART - Terapia anti-retroviral potente ou altamente ativa

HDL - lipoproteína de alta densidade

HIV - "human immunodeficiency vírus" (vírus da imunodeficiência humana)

Hsp - proteínas de choque térmico 
IDV - Indinavir

Ig - Imunoglobulina

IL - Interleucina

IP - inibidores de protease

ITR - inibidores da transcriptase reversa

ITRNN - inibidores da transcriptase reversa não análogos de nucleosídeos

$\mathrm{KBr}$ - brometo de potássio

$\mathrm{kDa}$ - kilo Dalton

LDL - lipoproteína de baixa densidade

LPV/R - Lopinavir/Ritonavir

MCP-1 - proteína quimioatraente de macrófagos-1

MDA - malondialdeído

MHC - complexo de histocompatibilidade princicpal

NFV - Nelfinavir

NO - óxido nítrico

NVP - Nevirapina

ox - oxidada

PAF - fator de ativação plaquetária

PBS - solução salina tamponada com fosfato

$\mathrm{RO}$ - radicais livres

RTV - Ritonavir

SIDA - Sindrome da Imunodeficiência Adquirida

SQV - Saquinavir

TAG - triacilgliceróis

TMB - tetrametilbenzidina

TNF- $\alpha$ - fator de necrose tumoral- $\alpha$

VCAM-1 - vascular cell adhesion molecule-I

VLDL - Lipoproteína de densidade muito baixa 


\section{SUMÁRIO}

1INTRODUÇÃO....................................................................... 14

1.1 Infecção pelo Vírus da Imunodeficiência Humana.........................................14

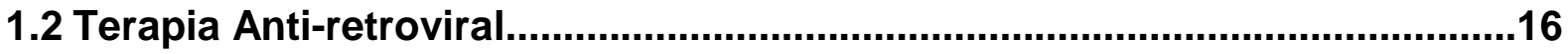

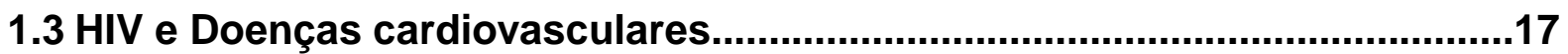

1.4 Efeitos colaterais causados pela HAART .................................................18

1.5 Alterações no metabolismo lipídico do paciente infectado pelo HIV............20

1.6 Efeitos colaterais observados com o uso de Indinavir....................................

1.7 Sistema Imune e doença cardiovascular........................................................22

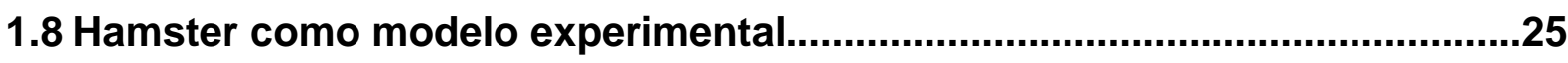

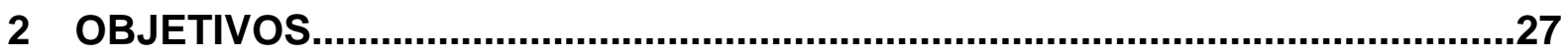

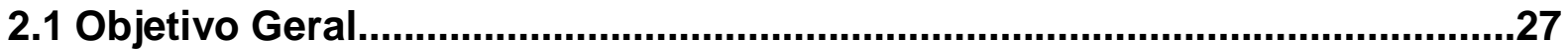

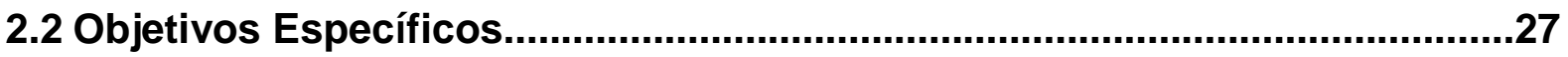

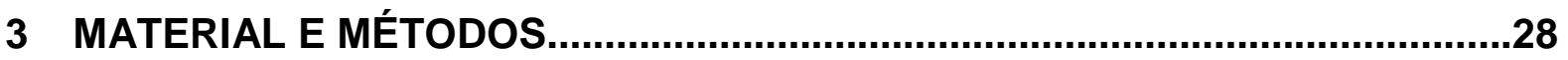

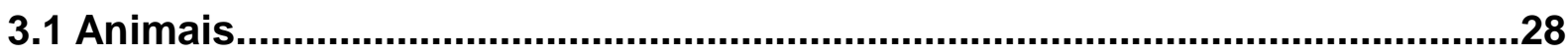

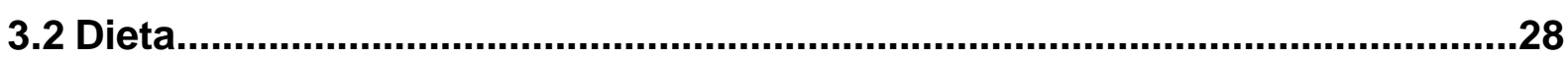

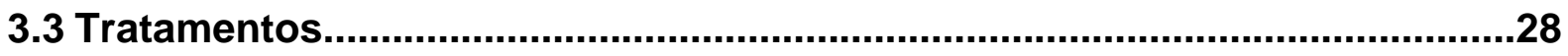

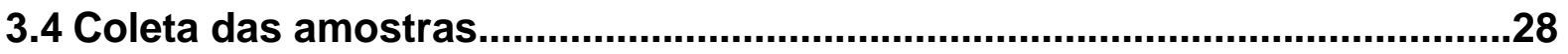

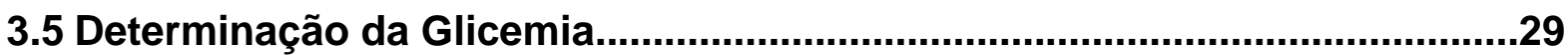

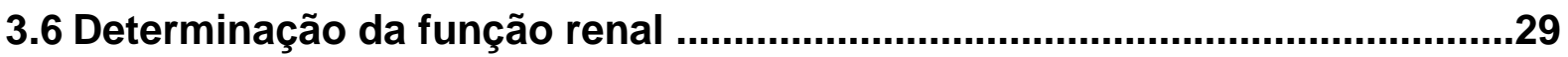

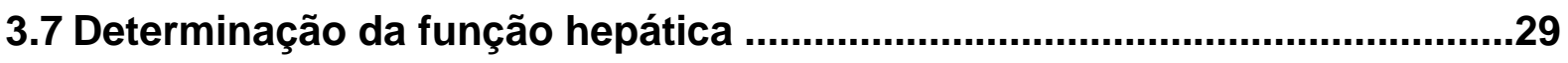

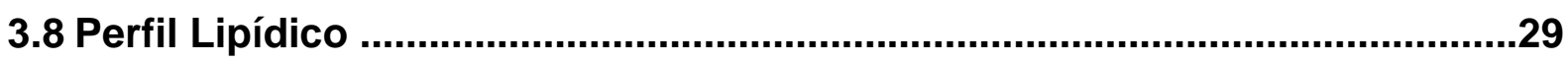

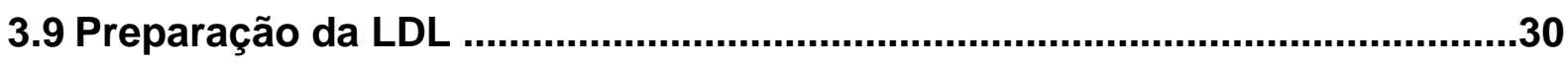

3.10 Isolamento e modificação de lipoproteínas ............................................30

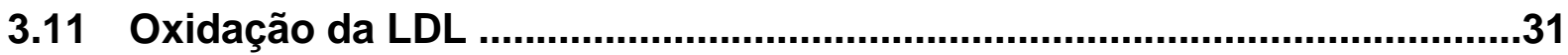

3.12 Avaliação do processo de oxidação da LDL ..............................................31

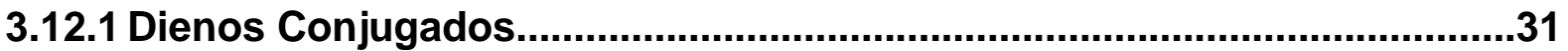

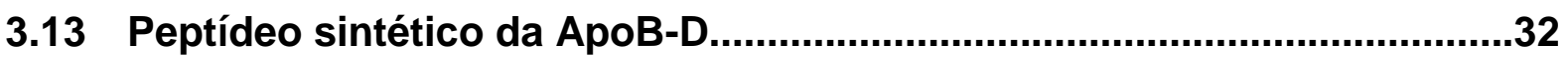

3.14 Detecção de auto-anticorpos contra ox-LDL e anti-ox-pepD....................32 


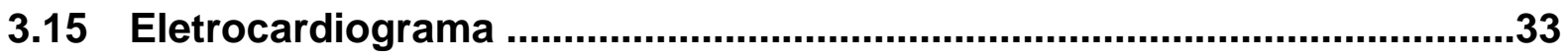

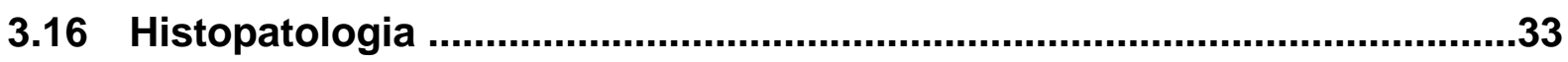

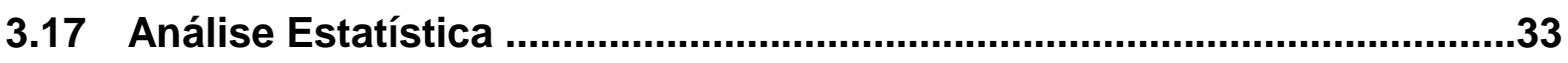

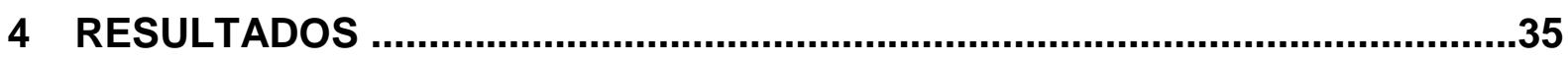

4.1 Análise da formação de substâncias reativas ao ácido tiobarbitúrico

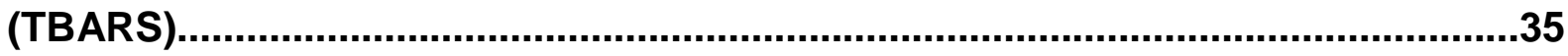

4.2 Análise da formação de dienos conjugados ..............................................36

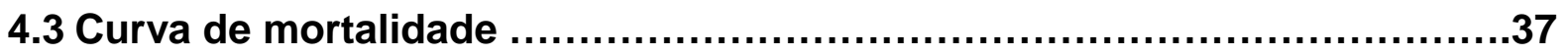

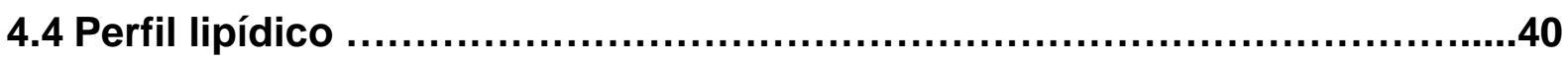

4.5 Níveis de HDL e LDL plasmáticos.............................................................50

4.6 Análise da glicemia......................................................................................65

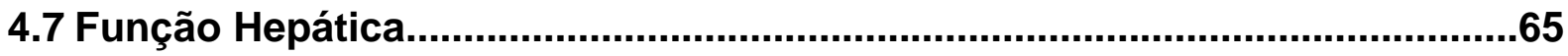

4.8 Função Renal...............................................................................................61

4.9 Detecção de anticorpos anti-ox-LDL e apo-B-D ........................................65

4.10 Análise das concentrações plasmáticas...................................................74

4.11 Alteração cardíaca.............................................................................79

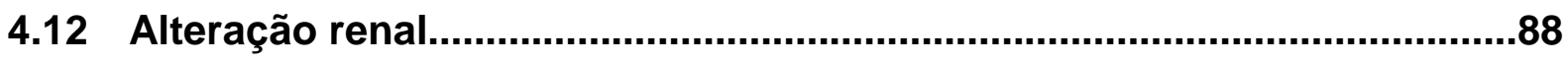

5 DISCUSSÃO..............................................................................................92

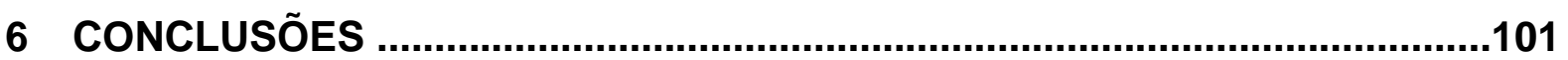

REFERÊNCIAS BIBLIOGRÁFICAS ..........................................................103 


\section{INTRODUÇÃO}

No início da década de 80 , os centros para controle e prevenção de Doenças (CCPD) em Atlanta, Estados Unidos, relataram aumento no número de casos de pneumonia por Pneumocystis carinii e de sarcoma de Kaposi entre homossexuais jovens e previamente saudáveis. Até então, estas afecções eram relativamente raras e quase que restritas a indivíduos imunocomprometidos. Observações clínicas e achados laboratoriais posteriores, bem como relatos do acometimento de indivíduos que haviam recebido transfusões de sangue e/ou hemoderivados, sugeriram uma causa infecciosa para esta nova entidade clínica, inicialmente denominada Gay Related Immunodeficiency Disease (GRID) e mais tarde síndrome da imunodeficiência Adquirida (SIDA).

\subsection{Infecção pelo Vírus da Imunodeficiência Humana}

O vírus da imunodeficiência humana ("human immunodeficiency vírus"=HIV) é um retrovírus do grupo lentivírus que foi isolado em 1983/1984 por grupos diferentes de pesquisadores, e identificado como 0 agente etiológico da SIDA (LEVY, 1984). A patogênese foi posteriormente elucidada, onde foi reportada a infecção de linfócitos T CD4 ${ }^{+}$. A molécula de CD4 é uma glicoproteína monomérica de 58 kDa composta por 370 aminoácidos que é detectada na superfície de aproximadamente $60 \%$ dos linfócitos $\mathrm{T}$, e ainda em precursores de linfócito $T$ dentro da medula óssea e do timo, monócitos e macrófagos, eosinófilos, células dendríticas e células da microglia do sistema nervoso central. Os aminoácidos 40 ao 55 da cadeia protéica do marcador de superfície celular CD4 servem de sítio de ligação para a glicoproteína 120 (gp 120) no HIV, que é parte do capsídeo viral (KLATZMANN et al., 1984; EDWARDS et al., 2001). Além disso, o vírus interage pela glicoproteína (gp 41) com os receptores celulares de quimiocinas como CCR5 e CXCR4 
principalmente, e outros como os CCR3, CCR2, CCR8, CCR9, STRL33, Gpr 15, Gpr 1 (DENG et al., 1997; LIAO et al., 1997), o que é crucial para a infecção celular (KILBY et al., 1998), etapa fundamental para o término da fusão, sendo que posteriormente o ARN (ácido ribonucléico) de fita dupla ingressa na célula do hospedeiro, que é convertido em ácido desoxiribonucléico (ADN) no citoplasma da célula do hospedeiro mediante uma trancriptase reversa do vírus a qual pode ser inibida por inibidores de nucleosídeos que são análogos de nucleotídeos, gerando HIV-ADN que é exportada para o núcleo (ZACK et al., 1990). No núcleo inicia-se a replicação do vírus e a produção de suas proteínas, uma destas é a gp 120, que é sintetizada como moléculas maiores de gp160-precursoras que são clivadas pela HIV-protease em gp120 e em gp 41. As proteínas “gag” (p24, p17, p9 e p7) são derivadas de uma molécula precursora de $53 \mathrm{kDa}$, que é clivada pela protease do HIV. A clivagem das moléculas protéicas precursoras pela protease HIV-1 é necessária para a geração de partículas virais infecciosas, e conseqüentemente a protease viral representa alvo interessante para fins terapêuticos (KOHL et al., 1988). Subsequentemente, o vírus é montado e exportado para membrana citoplasmática, onde ocorre a exocitose das novas partículas virais, que levam consigo fosfolipídeos de membrana celular, proteínas de membrana e colesterol sendo capaz de infectar qualquer célula $\mathrm{CD}^{+}$(KOHL et al., 1988).

Com o intuito de melhorar a qualidade de vida dos portadores do HIV ou até mesmo buscar a cura, dada por antiretrovirais, inúmeras pesquisas foram desenvolvidas até a liberação da primeira droga anti-retroviral em 1987, a zidovudina $(\mathrm{AZT})$, análogo de nucleosídeo que inibe a transcriptase reversa do HIV (FISCHL et al., 1987;1990). Sucessivamente, outras drogas pertencentes a este grupo de inibidores da transcriptase reversa (ITR) foram sendo desenvolvidas e testadas (CONCORDE, 1994; VOLBERDING et al., 1994; DELTA, 1996; ERON et al., 1995; KATLAMA et al., 1996; KATZENSTEIN et al., 1996; MIRELES-VIEYRA et al., 1996), mas somente a partir de 1996, 
observou-se redução significativa na incidência das infecções oportunistas e da mortalidade com o uso de novo grupo de drogas que inibem a protease (IP) do HIV (EGGER et al., 1997; MOCROFT et al., 1998; MOORE, 1998; PALELLA et al., 1998; VITTINGHOFF et al., 1999; MOCROFT et al., 2000). A combinação dos IP e ITR passou então a ser utilizado e denominado terapia anti-retroviral potente ou altamente ativa (HAART) (BARTLETT; MOORE, 1996; BARTLETT et al., 1998; MINISTÉRIO DA SAÚDE, 1999; GALLANT, 2000).

\subsection{Terapia Anti-retroviral}

A necessidade emergencial de tratamentos que pudessem deter os elevados índices de mortalidade que envolvia a SIDA levou a aceleração de pesquisas para se obter novas drogas que tivessem efeito anti-retroviral. Quando uma nova droga sob investigação é aprovada, e o medicamento correspondente alcança o estágio de teste em humanos, certamente já foi desenvolvida extensa avaliação de sua farmacocinética, farmacodinâmica e propriedades tóxicas in vitro e em diversas espécies animais. Nos EUA, os ensaios de medicamentos em humanos geralmente são conduzidos em três fases que devem estar concluídas antes que a nova aplicação medicamentosa seja aprovada (MELMON, 1983). No entanto, a pressão social para liberação de drogas anti-retrovirais e suas aplicações imediatas no tratamento do HIV resultaram na liberação precoce das drogas recém desenvolvidas que foram liberadas ainda na segunda fase do ensaio clínico pelo órgão norte-americano que regula a administração de alimentos e medicamentos dos Estados Unidos da América (EUA) ("Food and Drug Administration"), e que estabelece regulamentos e orientações que direcionam o tipo e a extensão dos testes préclínicos.

Em junho de 1999, os CCPD registraram pela primeira vez entre 1996 e1997 diminuição de 18\% na incidência da SIDA, e 42\% na mortalidade devido 
ao HIV, acarretando em taxa de sobrevivência $10 \%$ maior dos pacientes com SIDA em 1998. No entanto, salienta-se que a diminuição na mortalidade foi anterior á redução da incidência, pois o tratamento foi inicialmente aplicado nos pacientes com SIDA, e posteriormente nos pacientes infectados pelo HIV mesmo sem o desenvolvimento da síndrome (CDC,1999).

Apesar do impacto positivo causado pela nova terapia anti-retroviral, nos anos seguintes foram surgindo algumas preocupações relacionadas com a liberação precoce das drogas anti-retrovirais. A terceira fase do teste é tipicamente um amplo ensaio clinico que exige amostragem estatisticamante representativa de pacientes para determinar a eficácia da droga e a segurança durante seu uso. Como as drogas anti-retrovirais foram liberadas precocemente, é de se esperar que alguns efeitos colaterais importantes possam surgir em uma população maior e em observação por um período mais longo.

Atualmente são 15 os medicamentos anti-retrovirais disponíveis e aprovados para prescrição no Brasil que são divididos em três classes, e vários outros se encontram ainda em investigação e em estudos clínicos. Estas classes são dadas pelos inibidores da transcriptase reversa análogos de nucleosídeos (ITRN) representados pela Zidovudina (AZT), Didanosina (DDI), Lomivudina (3TC), Estavudina (D4T), Abacavir (ABC); e mais recente, pelo primeiro representante análogo de nucleotídeo o Tenofovir; pelos inibidores da transcriptase reversa não análogos de nucleosídeos (ITRNN) representados pela Nevirapina (NVP) e Efavirenz (EFV), ainda pelos inibidores de protease (IP) como o Saquinavir (SQV), Ritonavir (RTV), Indinavir (IDV), Nelfinavir (NFV), Amprenavir (AMP), Lopinavir/Ritonavir (LPV/R) e Atazanavir (ATV) (MINISTÉRIO DA SAÚDE , 2004).

\subsection{HIV e doenças cardiovasculares}

Em pacientes infectados pelo HIV são frequentemente observadas 
complicações cardíacas quer pelos efeitos diretos ou indiretos (ARSHAD et al., 2000). Assim, alterações cardíacas são correlacionadas com o HIV como exemplo a dislipidemia decorrente do aumento dos níveis de triglicérides e/ou redução dos níveis da lipoproteína de alta densidade (HDL) (SPOSITO et al., 1997), a pericardite mais comumente descrita em pacientes com SIDA (LEWIS 1989; HEIDENREICH et al., 1995; HARMON et al., 2002), o derrame do pericárdio descrito em 8 a 27\% dos pacientes (HEIDENREICH et al., 1995; GALLI; CHELTLIN, 1992), a miocardite e as miocardiopatias que são responsáveis por uma das principais causas de morte em pacientes com SIDA (15 a $50 \%)$.

Ademais, são citadas alterações valvulares, neoplasias cardíacas, hipertensão pulmonar, arritmias e enfermidades tromboembólicas (COHEN et al., 1990; BECKER, 1992), que apenas são encontradas em exames ecocardiográficos ou em autópsias, já que são geralmente alterações subclínicas. A etiopatogenia da miocardite e miocardiopatias é incerta, e existe controvérsia sobre a possibilidade do efeito direto do vírus, sendo considerado sua possibilidade como agente etiológico destas enfermidades, ou até mesmo associado a agentes oportunistas (MORENO et al., 1995).

Em amplo estudo prospectivo envolvendo 1.254 pacientes infectados com HIV, onde 373 pacientes que já recebiam tratamento com inibidores de tratamento por 17 meses foram avaliados por 171 dias, e 951 indivíduos não tratados foram observados por 526 dias, foi reportado que o tratamento com os IPs apresentaram como fator de risco para infarto do miocáridio (JUETTE et al., 1999).

\subsection{Efeitos colaterais causados pela HAART}

A síndrome da lipodistrofia resulta em perda periférica do tecido adiposo e redistribuição anormal de gordura com aumento da gordura visceral (MILLER 
et al., 1998b; VIRABEN et al., 1998; HENGEL et al., 1997; HERRY et al., 1997; LO et al., 1998; MILLER et al., 1998), dorso-cervical (giba de búfalo) (LO et al., 1998), lipomatose (HENGEL et al., 1997), hipertrofia da mama (HERRY et al., 1997), e lipoatrofia associada a perdas de gordura periférica da face, couro cabeludo, glúteos e extremidades.

A hiperlipidemia resultante, além de favorecer o depósito de gordura central, contribui também para a resistência à insulina, e à susceptibilidade individual para o desenvolvimento do diabetes mellitus tipo 2 (CARR, 1998).

Esta síndrome está relacionada com a hipertrigliceridemia, hipercolesterolemia e resistência periférica à insulina (BARBARO, 2002; MULLIGAN et al., 2000). Estas alterações metabólicas levam a disfunção de diversos tipos celulares como células endoteliais, células musculares lisas e plaquetas provocando vasoconstrição, inflamação e trombose (BECKMAN et al., 2002).

Todas essas modificações metabólicas vêm acometendo indivíduos que fazem o uso dos antiretrovirais, tais como os IPs (VIRABEN, 1998; CARR et al., 1998; MADGE et al., 1999; SAINT-MARC et al., 1999). Os primeiros sinais clínicos da lipodistrofia em presença de IPs são observados geralmente de um a sete meses após o início do tratamento (GRAHAM, 2000). Contudo, outros estudos relataram uma média de dez meses para o aparecimento da síndrome (CARR et al., 1998). Esses componentes da lipodistrofia e de outras síndromes metabólicas podem ser revertidos após terapia descontínua do IPs (GRAHAM, 2000).

Os pacientes sob tratamento com IPs apresentam hipertrigliceremia como foi demonstrado em estudo com indinavir em pessoas HIV negativas (HUI, 2003; CALZA et al., 2008 ). Em pacientes sob terapia com IP têm se observado concentrações elevadas de triacilgliceróis (TAG) e colesterol ligado à LDL e à HDL (MULLIGAN et al., 2000). Ademais, têm-se demostrado a indução de apoptose de adipócitos (DOMINGO et al.,1999) e inibição da proliferação de preadipócitos in vitro em células tronco murinas mesenquimais 
C3H10T1/2, preadipócitos 3T3-L1 e preadipócitos humanos expostos a IPs (BASTARD et al., 2002).

Adicionalmente a isto, as mudanças acima mencionadas têm relação com resistência à insulina e tolerância a glicose (HADIGAN et al., 2001, MYNARCIK et al., 2000). Recentemente tem demostrado em estudo com 3T3L1 adipócitos em que os IPs podem agir diretamente sobre o transporte de glicose mediado por insulina e GLUT-4, de fato isso poderia levar ao desenvolvimento de dibetes ou complicar ainda mais a diabetes (MURATA et al., 2000).

Além disso, deve-se considerar que todos os fatores acima citados são marcadores para risco cardíaco. Por exemplo, HENRY et al., em 1998, detectaram o desenvolvimento de doença coronariana prematura em pacientes portadores de SIDA que faziam uso de IP. Posteriormente, estudos mostraram que a incidência do infarto do miocárdio aumentou em pacientes sob tratamento com IP por certo período. O risco de infarto do miocárdio parece aumentar duas a três vezes nos pacientes sob tratamento em relação a indivíduos sadios (MARY-KRAUSE et al., 2003; SHIKUMA, 1999). Mais recentemente em um estudo prospectivo mais extenso incluindo mais de 23000 indivíduos infectados foi relatado um aumento de $26 \%$ na incidência de infarto do miocárdio a cada ano de terapia HAART (FRIIS-MOLLER et al., 2003).

\subsection{Alterações no metabolismo lipídico do paciente infectado pelo HIV}

Diversas alterações no metabolismo de lipídeos em pacientes HIV positivos foram observadas antes do tratamento com inibidores de protease, onde se observou aumento das concentrações plasmáticas de TAG, redução do colesterol ligado à LDL e HDL, aumento das concentrações plamáticas de ácidos graxos livres, diminuição da lipase lipoproteíca e na velocidade de depuração dos TAG (GRUNFELD, 1992), tendência à elevação da velocidade 
da lipólise corporal e da eliminação de lipídeo não oxidado, além do aumento da velocidade da lipogênese hepática (HOMMES, 1991; MULLIGAN, 1993).

Todas essas desordens metabólicas são fatores de risco no desenvolvimento da aterosclerose e estão ligados a outras patologias como lipodistrofia, resistência à insulina, acúmulo de gordura central, e outras patologias (BARBARO, 2002).

O próprio vírus do HIV pode interferir no metabolismo de lipides, o que dificulta o estabelecimento de uma correlação entre o tratamento com IPs e o aumento na incidência de doenças cardiovasculares e demais efeitos colaterais. Recentemente (MUJAWAR et al., 2006), foi descrito possíveis mecanismos pelo qual o HIV pode interferir no metabolismo de lípides. Por exemplo, foi demontrado o sequestro de colesterol pelo HIV através da proteína citoplasmática Nef, proteína integrante do HIV que seqüestra partículas de colesterol pela supressão pós-transcricional da proteína ABCA1 e pela relocalização da mesma proteína para a membrana celular. A ABCA1 citoplasmática participa no efluxo celular de colesterol e fosfolípides inserindo lípides na apoA-1, que é a porção protéica da HDL, e como consequência a lipidificação do HDL é afetada juntamente com o efluxo de fosfofolípides em macrófagos e linhagens celulares (HeLa). Deste modo, ocasionaria a formação de células espumosas, que explicaria o aumento dos casos de aterosclerose e doenças cardiovasculares em pacientes infectados pelo HIV. Isto também pode explicar a redução da HDL nos pacientes com HIV dependente da carga viral. Enfatiza-se neste caso, que o tratamento em pacientes infectados com o HIV ocasiona simultameamente redução da carga viral, e consequentemente ocasiona concomitamente aumento dos níveis de HDL.

\subsection{Efeitos colaterais observados com o uso de Indinavir}

Muitos estudos têm demonstrado que nefrolitíase é um dos eventos adversos mais freqüentes na terapia com indinavir, o que acontece com uma 
incidência de 5- 25\% dos pacientes (MERAVIGLIA, 2002), nefropatia devido à presença de cristais de indinavir no rim, cristalúria (GAGNON et al., 2006;2007) e necrose tubular aguda (SAID et al., 2007). É também relatado nefrolitíase aguda que é dependente da concentração sérica da droga (COLLIN et al., 2007). Estes efeitos podem ser notados mesmo em pacientes que receberam indinavir e outros IPs associados (CHEUNG et al., 2007). Num estudo prospectivo envolvendo 93 centros distribuídos pela Europa, incluindo ainda Israel e Argentina realizado pelo grupo EuroSIDA, relataram aumento na tendência para desenvolver insuficiência renal crônica em pacientes sob tratamento com Indinavir (MOCROFT et al., 2007).

Adicionalmente a isto, já foram reportados diminuição na sensibilidade à insulina em ratos e humanos (NOOR et al., 2001;2002; HRUZ et al., 2002) e aumento nos níveis séricos de fibrinogênio que foi associado ao uso de ritonavir e indinavir (MADDEN et al., 2008). Além disso, é relatado aumento no grau de relaxamento do endotélio dos vasos sangüíneos que está correlacionado com disfunção endotelial (JIANG et al., 2006), que não foi associado a altos níveis séricos de lípides. Contudo, os resultados são sob o efeito do indinavir sob os níveis séricos de triglicérides e colesterol contraditórios, já que alguns estudos apontam para maior alteração no metabolismo de lípides, enquanto outros estudos demonstram o maior envolvimento do metabolismo de glicose. No entanto, estudos mais recentes apontam para que o indinavir afeta mais o metabolismo de glicose (LEE et al., 2004; ROSENKRANZ et al., 2007).

\subsection{Sistema Imune e doença cardiovascular}

Diversas evidências em modelos experimentais de aterosclerose e em estudos clínicos sobre a mesma, mostram que o sistema imune possui um papel importante no seu desenvolvimento, podendo ainda, em certas circunstâncias, alterar o seu curso (HANSSON, 1997; LIBBY, 200; WITZTUM; 
PALINSKI, 1999).

O processo aterosclerótico tem início quando o endotélio dos vasos sofre alguma lesão, ocorrendo alterações na permeabilidade vascular, que resulta no influxo de macromoléculas e monócitos para a região sub-endotelial (ROSS; GLOMSET, 1976; YOKOTA; HANNSON, 1995). Posteriormente a entrada, estes monócitos diferenciam-se em macrófagos. Diferentemente dos monócitos, que apresentam receptores LDL, os macrófagos passam a expressar menos destes receptores em sua membrana, que modificam para expressar receptores "scavengers" (HARA et al., 1987; HASSALL, 1992). As características destes receptores "scavengers" são diferentes da dos receptores LDL que são regulados pelo acúmulo de colesterol. Os receptores "scavengers" que ligam-se com alta especificidade a macromoléculas polianiônicas incluindo polissacarídeos e lipopolissacarídeos bacterianos e LDL modificadas (BROWN et al., 1980; KRIEGER, 1992), não são regulados negativamente como os receptores LDL com o acúmulo de colesterol e conseqüentemente levam a formação de células espumosas, repletas de colesterol, passo este considerado inicial para o desenvolvimento da lesão aterosclerótica (LIU et al., 1996; LUSIS, 2000).

Além disso, no local onde ocorre a lesão, instala-se um processo inflamatório que contribui para o desenvolvimento da aterosclerose. Vários estudos mostram a participação de mecanismos imunes/inflamatórios:

1. presença de Interferon $\gamma$ e IL-2 em placas ateroscleróticas (GENG et al., 1995);

2. TNF- $\alpha$ e IL-1 são capazes de modular as funções endoletiais, aumentar expressão de moléculas de adesão (ex. VCAM-I) e quimiocinas (p.ex. MCP-I) acelerando o processo de formação da placa aterosclerótica (LIBBY et al., 1995);

3. presença de mediadores lipídicos como o fator de ativação de plaquetas (PAF) em placa ateroscleróticas (BROCHERIOU et al., 2000); 
4. camundongos linfócitos $\mathrm{T} \mathrm{CD}^{+}$e $\mathrm{CD} 8^{+}$Knock-out apresentam redução da formação das estrias de gordura (EMESON et al., 1996);

5. transferência de linfócitos $\mathrm{T} \mathrm{CD}^{+}$de camundongos imunocompotentes para imunodeficientes aumentam a área da lesão em cerca de $170 \%$ (ZHOU et al., 2000).

Uma das explicações para esta resposta inflamatória é a ocorrência de resposta contra neo-antígenos formados durante as modificações sofridas pela partícula de LDL, principalmente as modificações oxidativas (STEINBERG et al., 1989). Estão relacionados abaixo os principais achados que corroboram para estas afirmações: a ox-LDL pode tornar os macrófagos mais imunoestimulados, modificando a expressão das moléculas de classe II do complexo de histocompatibilidade principal (MHC-II) (FROSTEGARD et al., 1990; STEMME et al., 1995); presença de linfócitos $\mathrm{T} \mathrm{CD4}^{+}$na placa de ateroma (MATSUMURA et al., 1999; STEMME et al., 1995); expansão oligoclonal e reconhecimento da ox-LDL pelos Linfócitos T (STEMME et al., 1995 ;PAULSSON et al., 2000 ); presença de anticorpos contra ox-LDL na circulação e na placa (SHOENFELD et al., 2000; SOHMA et al., 1995; YLAHERTTUALA, 1998); a ox-LDL pode estimular as células $T$ via macrófagos (FROSTEGARD et al., 1992; JONASSON et al., 1986); a oxLDL pode induzir nos macrófagos a expressão de proteínas do choque térmico (heat shock protein $=$ Hsp) $($ FROSTEGARD et al., 1996).

A resposta imune juntamente com a hiperlipidemia podem ser apontados como os fatores de risco mais importantes no desenvolvimento da aterosclerose. Diversos trabalhos sugerem grande número de antígenos potenciais que podem ser encontrados na lesão aterosclerótica e que poderiam ser responsáveis pela ativação do sistema imune. Nesta lista estão incluídos: antígenos virais e bacterianos (LIBBY et al., 1997); proteínas de choque térmico (WICK et al., 1999); componentes da parede dos vasos ou lipoproteínas (PALINSKI et al., 1995; REAVEN et al., 1997), e principalmente 
as lipoproteínas modificadas e as lipoproteínas de baixa densidade oxidada.

A partícula de LDL é constituída por lipídios, vitaminas lipossolúveis (inclusive a vitamina $E$ e outros antioxidantes) e uma parte protéica que é a apolipoproteína B-100 (apoB-100) (HAVEL, 1984).

Sabe-se que estas partículas podem sofrer várias modificações in vivo, sendo que a mais comumente estudada é a modificação oxidativa que resulta no aparecimento da oxLDL (STEINBRECHER et al., 1989). In vivo, a geração de oxLDL está associada a resposta inflamatória caracterizada pela presença de células imunologicamente ativas (linfócitos e monócitos/macrófagos) e seus produtos com potencial oxidante como óxido nítrico (NO), água oxigenada $\left(\mathrm{H}_{2} \mathrm{O}_{2}\right)$ e radicais livres $(\mathrm{RO})$. O fato mais importante é que in vivo a geração de ox-LDL está associada a processos inflamatórios que produzem espécies reativas de oxigênio (STEINBERG et al., 1989, HALLIWELL et al., 1992 ).

\subsection{Hamster como modelo experimental}

O hamster sírio dourado - Mesocricetus auratus- foi usado como modelo para estudar o metabolismo de lipídeos e a aterosclerose experimental induzida por dieta desde principios da década de 80 (SPADY; DIETSCHY, 1985).

O hamster foi selecionado, pois a composição de lipídeos no plasma nesta espécie é similar àquela dos seres humanos (SPADY; DIETSCHY, 1985). Adicionalmente a isto, há semelhanças muito bem estabelecidas com humanos no metabolismo de lipídeos e ácidos biliares (SPADY et al., 1983). Entre tais semelhanças, tem-se também que o turnover de LDL é predominantemente dependente do receptor; e o fígado é o principal local da eliminação de LDL do plasma, sendo de $73 \%$ no hamster e de 56 a $80 \%$ no homem (SPADY; DIETSCHY, 1988). A captação de LDL mediada pelo receptor de LDL é superior a $90 \%$ em ambas as espécies.

Estudos demonstram também efeitos do colesterol e triglicerídeos 
dietéticos sob as taxas do transporte receptor-dependente e receptorindependente da LDL no fígado do hamster.

Assim, estes animais sob dietas enriquecidas com $0,1,0,25$, ou de $1 \%$ de colesterol, o transporte receptor-dependente de LDL no fígado foi suprimido por 43,63 , e $77 \%$, respectivamente, e com concomitante mudança nas concentrações da LDL plasmáticas. Estes estudos demonstram o papel importante da dieta no aumento da supressão da atividade do receptor de LDL hepático, e acréscimo dos níveis do LDL (SPADY; DIETSCHY, 1988). Além disso, mediante dieta pode-se induzir níveis elevados de lípides similares aos encontrados em humanos com alterações lipídicas.

Há ainda estudos recentes em hamsters que sugerem que o colesterol da dieta e os ácidos graxos saturados das dietas poderiam ter efeito no desenvolvimento da aterosclerose, além de seu papel em afetar os níveis de lipoproteínas plasmáticas, podem também induzir um aumento na produção de citocinas que causam inflamação na parede arterial, favorecendo o desenvolvimento da aterosclerose.(ALEXAKI et al., 2004).

Este modelo animal também foi utilizado satisfatoriamente na replicação do fenômeno do escape observado pela administração de estatinas em humanos, onde se observa que os níveis de colesterol plasmáticos estão inicialmente reduzidos retornando aos níveis anteriores ao tratamento (UGAWA et al., 2002). Por estas semelhanças entre o metabolismo de lipídeos, a formação de lesões ateroscleróticas e fenômenos que acontecem com algumas drogas que são utizadas para o controle de níveis altos de colesterol, a utilização do hamster como modelo animal foi considerado como um candidato para fazer estudos com inibidores de proteases que afetam o metabolismo de lipídeos. 


\section{OBJETIVOS}

\subsection{Objetivo Geral}

Avaliação do hamster dourado Mesocricetus auratus como modelo para estudo dos possíveis efeitos secundários do inibidor de proteases indinavir, utilizado no tratamento do HIV, e o efeito de uma dieta hiperlipídica associado à droga.

\subsection{Objetivos Específicos}

- Determinar as concentrações plasmáticas de colesterol, triglicérides, LDL e HDL dos animais tratados com o inibidor de protease Indinavir nas doses de 6,12 e $30 \mathrm{mg} / \mathrm{dia}$;

- Determinar os auto-anticorpos anti ox-LDL e peptídeo apoBd dos animais tratados com o inibidor de protease Indinavir nas doses de 6, 12 e 30 $\mathrm{mg} / \mathrm{dia}$;

- Realizar análise histopatológica no coração e rim nos animais sob tratamento do inibidor de proteases Indinavir nas doses de 6, 12 e $30 \mathrm{mg} / \mathrm{dia}$;

- Avaliar possíveis correlações entre o perfil lipídico e autoanticorpos contra a ox-LDL, o anti-peptídeo ApoBd, e a histopatologia renal e cardíaca nos animais tratados com diferentes doses $(6,12$ e $30 \mathrm{mg} / \mathrm{dia})$ do inibidor de protease Indinavir.

- Verificar a presença de alterações cardíacas dado pelo eletrocardiograma nos animais tratados com $30 \mathrm{mg} /$ dia do inibidor de protease Indinavir.

- Determinar a glicemia dos animais tratados com $30 \mathrm{mg} / \mathrm{dia}$ do inibidor de protease Indinavir.

- Avaliar possíveis alterações na função hepática e renal nos animais tratados com $30 \mathrm{mg} / \mathrm{dia}$ do inibidor de protease Indinavir. 


\section{MATERIAL E MÉTODOS}

\subsection{Animais e Dieta}

Hamsteres (Mesocricetus auratus) não isogênicos, machos, de 6-8 semanas de idade foram fornecidos pelo Centro de Bioterismo da Faculdade de Medicina da Universidade de São Paulo e mantidos no Biotério Experimental do Instituto de Medicina Tropical de São Paulo da Faculdade de Medicina da Universidade de São Paulo. Os animais foram mantidos em ambiente com ventilação controlada a temperatura de $23^{\circ} \mathrm{C}$ no ciclo claroescuro de 12 horas com ração (Nuvilab-Brasil) e água à vontade.

\subsection{Dieta}

Os animais foram subdivididos em dois grupos a saber: dieta normal onde os animais foram alimentados com ração balanceada (Nuvilab, Brasil);e dieta hiperlipídica no qual os animais receberam ração balanceada (Nuvilab, Brasil) com adição de $20 \%$ gordura saturada de coco e 0,4\% colesterol (Sigma) na dieta conforme estabelecido por Alexaki et al. (2004).

\subsection{Tratamentos}

Os animais foram separados em quatro grupos: dieta normal, dieta normal mais Indinavir 6,12 ou $30 \mathrm{mg} / \mathrm{dia}$, dieta hiperlipídica, dieta hiperlipídica mais droga 6,12 ou $30 \mathrm{mg} /$ dia por 90 dias.

\subsection{Coleta das amostras}

A coleta das amostras sangüíneas foi realizada por via retroorbital 
utilizando capilar previamente heparinizado. Ressalta-se que o fornecimento de água para os animais se manteve á vontade, no entanto, os animais foram submetidos a jejum alimentar de 16 a 18 horas.

\subsection{Determinação da Glicemia}

A concentração plasmática de glicose foi quantificada por método enzimático colorimétrico utilizando kit comercial (Reflotron, Roche, Suiça) conforme instruções do fabricante.

\subsection{Determinação da Função Renal}

A determinação da função renal se deu pela quantificação plasmática de uréia e creatinina. As concentrações plasmáticas de uréia e creatinina foram quantificadas por métodos enzimáticos colorimétricos utilizando kits comerciais (Reflotron, Roche, Suiça) de acordo com as recomendações do fabricante.

\subsection{Determinação da Função Hepática}

A determinação da função hepática se deu pela quantificação plasmática das enzimas aspartato transaminase (AST), alanina transaminase (ALT) e gama glutamil transferase (GGT). As concentrações plasmáticas de ALT, AST e GGT foram quantificadas por métodos enzimáticos colorimétricos utilizando kits comerciais (Reflotron, Roche, Suiça) utilizando as informações do fabricante.

\subsection{Perfil Lipídico}

A concentrações plasmática de triglicérides (TG), de colesterol (C) e da lipoproteína de alta densidade (HDL) foram quantificadas por métodos 
enzimáticos colorimétricos utilizando kits comerciais (Reflotron, Roche, Suiça) conforme recomendações do fabricante. A concentração da lipoproteína de baixa densidade $(L D L)$ foi calculada pela equação de Friedewald: [ $L D L-C=$ (total - C) - (HDL - C) - (TG/5,0)] como descrito por Anastos et al. (2007).

\subsection{Preparação da LDL}

Amostras de sangue foram colhidas via retroorbital de animais de 6-8 semanas de idade sob jejum $16-18$ horas. O sangue foi colhido num tubo com EDTA $1 \%(1 \mathrm{mg} / \mathrm{mL})$ e imediatamente centrifugado $\left(4{ }^{\circ} \mathrm{C}, 10 \mathrm{~min}, 1000 \mathrm{x}\right.$ g) para obtenção do plasma, em que foram acrescentados os seguintes conservantes: aprotinina $(0,1$ unidade $/ \mathrm{mL})$, benzamidina $(2 \mathrm{mM})$, gentamicina $(0,5 \%)$, cloranfenicol $(0,25 \%)$ e fluoreto de fenilmetilsulfonila $(0,5 \mathrm{mM})$.

\subsection{Isolamento e modificação de Lipoproteínas}

A LDL foi obtida por ultracentrifugação seqüencial (Havel;Eder; Gragdon, 1955), utilizando ultracentrífuga beckman e rotor $50 \mathrm{Ti}$. O plasma foi centrifugado $100.000 \times \mathrm{g}$ por 18 horas para a obtenção da VLDL (densidade $=1,006 \mathrm{~g} / \mathrm{mL}$ ). Após este período a fração do infranadante foi acertada para $1,063 \mathrm{~g} / \mathrm{mL}$ com adição de brometo de potássio $(\mathrm{KBr})$ e , em seguida centrifugado por 20 horas $(100.000 \times$ g), para obtenção da LDL (densidade $1,063 \mathrm{~g} / \mathrm{mL}$ ). A LDL presente no sobrenadante foi retirada e dialisada durante 48 horas, em solução PBS- Tampão fosfato $(\mathrm{NaCl} 0,9 \%$, $\mathrm{Na}_{2} \mathrm{HPO}_{4}$ 0,2\%, $\mathrm{NaOH} 0,38 \%$ e EDTA 0,01\%, $\left.\mathrm{pH}=7,4\right)$. As proteínas foram quantificadas por Kit BCA (Pierce), de acordo com as instruções do fabricante. O conteúdo de colesterol total e triglicérides foram realizadas por métodos enzimáticos colorimétricos (liquiform, LabTest-Diagnostica,Brasil), utlizando as informações do fabricante. Os valores de triglicérides na faixa de 160-220 mg/dL e colesterol na faixa de 90-130 foram aceitos como normais 
para a posterior utilização do plasma como fonte de LDL.

\subsection{Oxidação da LDL}

A LDL foi dializada em PBS por $24 \mathrm{~h}$ a $4{ }^{\circ} \mathrm{C}$ para reti rada do EDTA. Em seguida a LDL foi incubada com sulfato de cobre (CuSO $20 \mu \mathrm{M})$, como padronizado por 14 horas. Após este período a oxidação foi bloqueada com a adição de EDTA 1 mM segundo protocolo de Fernvick et al. (2004) modificado.

\subsection{Avaliação do processo de oxidação da LDL}

Para avaliar o grau de oxidação da preparação de oxLDL foi realizada a dosagem de TBARS, formados a partir da peroxidação lipídica da partícula. Foram incubados $50 \mu \mathrm{L}$ de amostra com $200 \mu \mathrm{L}$ de reagente de TBARS (1\% de ácido tiobarbitúrico , ácido clorídrico 562,5 $\mu \mathrm{M}$ e ácido tricloroacético $15 \%$ ). A mistura foi colocada sob fervura, a $100^{\circ} \mathrm{C}$, por $15 \mathrm{~min}$, centrifugada a 1.000 x g por $10 \mathrm{~min}$, e o sobrenadante lido a $540 \mathrm{~nm}$.Os resultados foram expressos baseando-se em uma curva padrão de amalondialdeído (MDA) (Malondialdeido, TOP, Merck, Alemanha).

\subsubsection{Dienos conjugados}

Durante o processo oxidativo da LDL ocorre a formação de dienos conjugados devido á geração de hidróxidos de colesterol e de hidroperóxidos. A formação destes produtos poder ser acompanhada pela absorção de luz UV a $234 \mathrm{~nm}$. Para dosagem de dienos conjugados, $50 \mu \mathrm{L}$ de cada preparação de oxLDL foram depositados em placas de 96 poços de Quarço e lidos a $234 \mathrm{~nm}$ por espectofotometria. 


\subsection{Peptídeo sintético da Apo B-D}

Foram desenvolvidos, em nosso laboratório, diversos peptídeos sintéticos baseado na seqüência de aminoácidos da ApoB. A seleção dos peptídeos foi realizada seguindo os parâmetros conhecidos de predição de peptídeos imunogênicos, presentes nos programas e bancos de dados encontrados no Expert Protein Analysis System (ExPASy), seguindo as etapas: a) presença de regiões anfipáticas, b) probabilidade de estar exposto em sua configuração terciária, c) presença de domínios com alta probabilidade de ligação a moléculas de $\mathrm{MHC}$, d) domínios relacionados á ligação com receptores para LDL, e) acessibilidade a Tripsina e f) solubilidade em água. Vinte e cinco seqüências de peptídeos foram sintetizadas em fase continua, cada uma com 18 a 25 resíduos de aminoácidos e grupamento amida na extremidade C-terminal. Destas 25 seqüências, uma foi selecionada, após ter sido confirmada a sua imunogenicidade por ELISA.

\subsection{Deteção de auto-anticorpos contra ox-LDL e anti-ox-pepD}

Para a dosagem de auto-anticorpos contra ox-LDL e peptídeo ApoBd, placas de 96 poços (Costar, EUA) foram sensibilizadas com $50 \mathrm{uL}$ de peptídeo ApoBd na concentração de 7,5 ug/mL ou 4,5 ug/mL de ox-LDL em tampão carbonato de sódio $0,1 \mathrm{M}, \mathrm{pH} 9,4$, durante 18 horas a $4{ }^{\circ} \mathrm{C}$. Após 4 ciclos de lavagens com 100uL de PBS, as placas foram bloqueadas com solução de gelatina a 2\% (Gibco, EUA) em temperatura ambiente, por 2 horas. Em seqüência, as placas foram lavadas 4 vezes com PBS e os poços receberam em triplicata $50 \mathrm{uL}$ das amostras de soro diluídas 1:400 em PBS. Após $2 \mathrm{~h}$ de incubação as placas foram lavadas 4 vezes com 100 uL de PBS$\mathrm{T}$ e incubadas com $50 \mathrm{uL}$ de conjugado por 2 horas em temperatura ambiente. Foi utilizado como conjugado IgG de cabra anti-lgG de Hamster marcada com peroxidase (Santa Cruz, EUA) na diluição 1:2000 para ox-LDL 
e para peptídeo ApoBd. Posteriormente, as placas foram submetidas a mais 4 ciclos de lavagem com PBS-T. O processo de revelação foi realizado com adição, em cada poço, de 75uL de solução de TMB (250 uL de 3,3'5,5'tetrametilbenzidina $6,5 \%$ em DMSO, $12 \mathrm{~mL}$ de tampão citrato $0,1 \mathrm{pH} 5,5 \mathrm{e}$ 10uL de $\mathrm{H}_{2} \mathrm{O}_{2}$ substrato para enzima peroxidase). A reação foi interrompida após 10 minutos do seu início com adição de $25 \mathrm{uL}$ de ácido sulfúrico (2 M) (Merck, Alemanha). Os resultados foram avaliados por leitura espectrofotométrica em $450 \mathrm{~nm}$ em leitor de ELISA multiskan Tecan.

\subsection{Eletrocardiograma}

O eletrocardiograma foi realizado após indução anestésica inalatória com isofluorano. Em seguida, foram colocados eletrodos na altura de cotovelos, joelho e costas, para cobrir todas as derivações bipolares DI, DII, DIII e derivações unipolares estendidas AVR, AVL e AVF. Posteriormente, procedeu-se o registro do eletrocardiograma no eletrocardiógrafo EGCPC (TEB Brasil), para posterior avaliação do intervalo QT e ST.

\subsection{Histologia}

Após o término do tratamento os animais foram sacrificados e os órgãos foram retirados e mantidos em formalina tamponada $10 \%$.

As colorações específicas Hematoxilina-Eosina (HE), PAM e Tricrômica de MASSON foram efetuadas com técnicas rotineiras do Departamento de Patologia da Faculdade de Medicina da USP.

\subsection{Análise Estatística}

Para a análise de variância foi utilizada o teste de ANOVA e pós-teste de TUKEY. Em todas as comparações considerou-se como significante a 
diferença quando $P<0,05$. Todos os processamentos foram realizados utilizando-se o programa GrapPad Prisma versão 5.00 para Windows (GraphPad Software, EUA) . 


\section{RESULTADOS}

Com o intuito de estudar os efeitos colaterais do inibidor de proteases indinavir utilizado no tratamento da infecção pelo HIV, desenvolveu-se o modelo experimental em hamster. Neste modelo, avaliaram-se alterações de perfil lipídico, da glicemia, da função renal e hepática, da oxidação da LDL e possíveis lesões no coração, aorta e rim.

\subsection{Análise da formação de substâncias reativas ao ácido tiobarbitúrico (TBARS)}

Inicialmente, verificamos se a oxidação ocorria nas frações lipídicas de hamster como nas outras espécies, utilizando duas abordagens metodológicas diferentes. No gráfico abaixo está apresentado o aumento exponencial da formação de TBARS (Figura 1). Os valores foram expressos em $\mu \mathrm{M}$ de MDA/mg de proteína em relação a absorbância e curva padrão de MDA. 


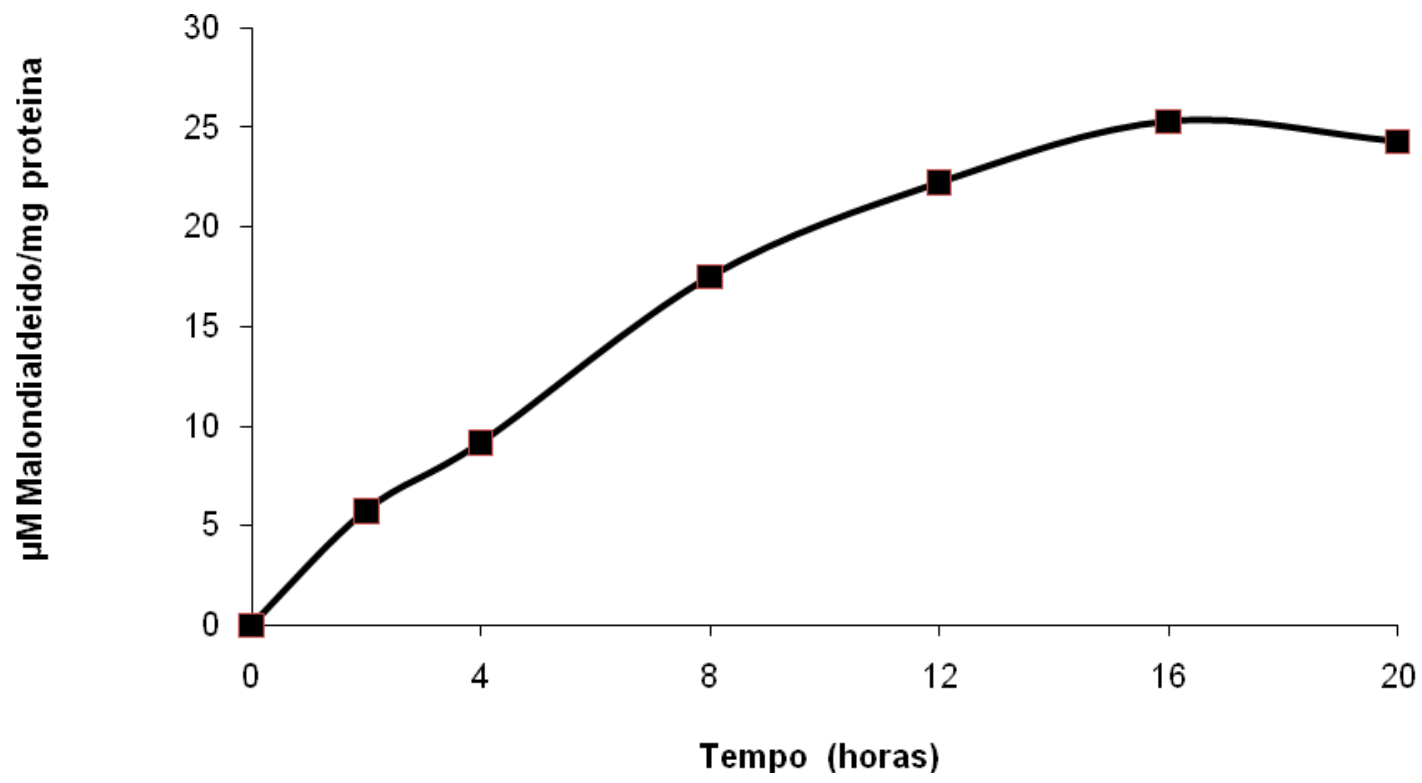

Figura 1: Cinética de formação de TBARS durante a oxidação da LDL. Preparações de LDL $(1 \mathrm{mg} / \mathrm{mL})$ foram incubadas em distintos tempos (0-18 horas) com $20 \mu \mathrm{M}$ de $\mathrm{CuSO}_{4}$.

\subsection{Análise da formação de dienos conjugados}

Pode-se observar que houve aumento exponencial de dienos conjugados com a concentração de $20 \mu \mathrm{M}$ de $\mathrm{CuSO}_{4}$ (Figura 2). O perfil cinético encontrado foi semelhante ao relatado na oxidação da LDL humana (FERNVICK et al., 2004). 


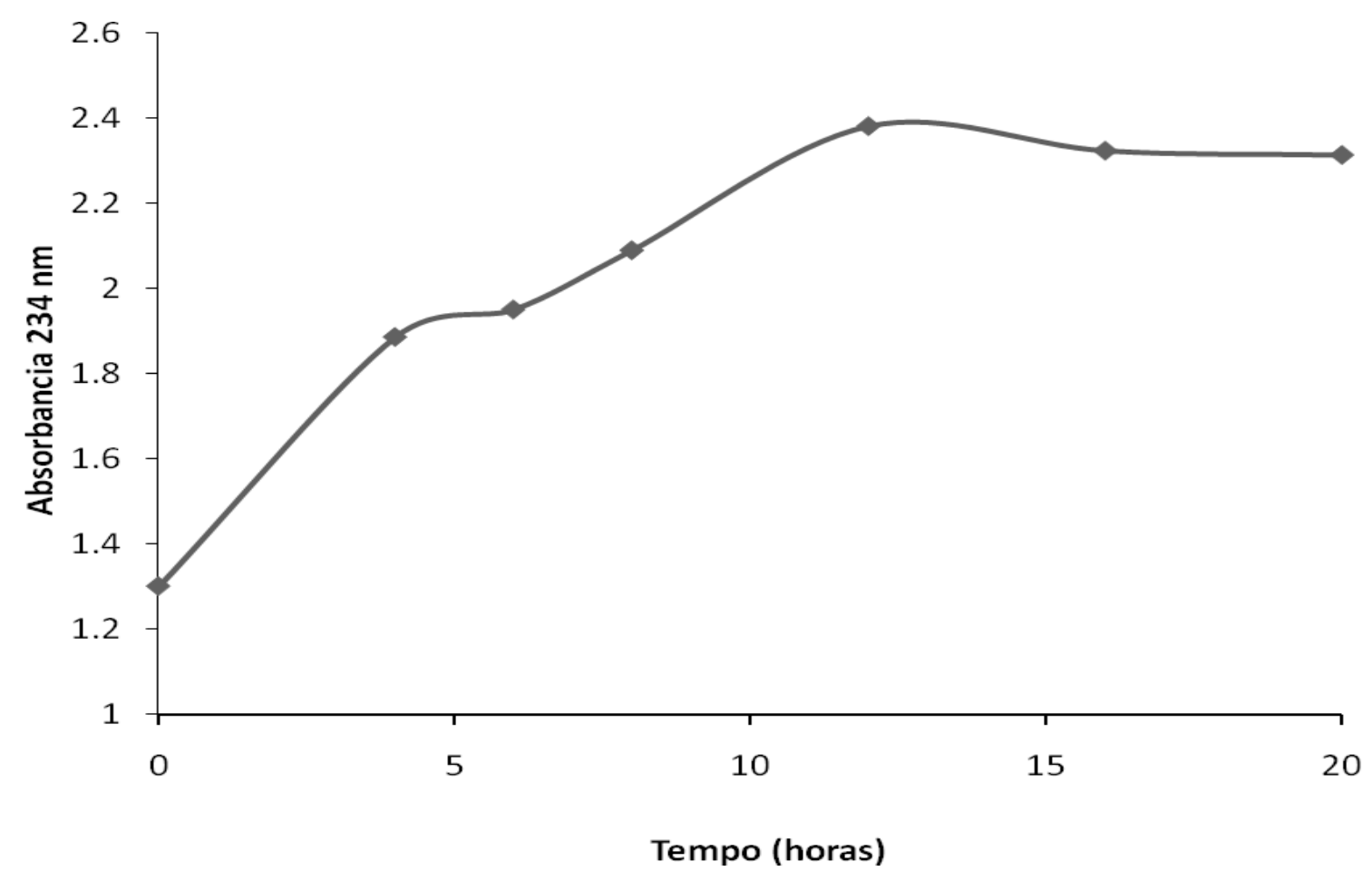

Figura 2: Cinética da formação de dienos conjugados. Preparações de LDL (1 $\mathrm{mg} / \mathrm{mL})$ foram incubadas em diferentes tempos (0-20 horas) com $20 \mu \mathrm{M}$ de $\mathrm{CuSO}_{4}$.

\subsection{Curva de mortalidade}

Inicialmente, para estabelecer o modelo do presente estudo dos efeitos colaterais da droga indinavir, avaliou-se a taxa de mortalidade de hamsteres submetidos a diferentes doses do inibidor de protease indinavir. Para tal, inicou-se o teste com doses próximas à utilizada no tratamento de pacientes, isto é três $\mathrm{mg} / \mathrm{dia}$ e seis $\mathrm{mg} / \mathrm{dia}$. Porém, não se observou morte dos animais no período de seis meses. Desta forma, com o fito de instituir um modelo onde o efeito da droga fosse mais facilmente visível, realizou-se o estudo utilizando 
doses maiores.

Ao utilizar a dose de $12 \mathrm{mg} / \mathrm{dia}$, os animais submetidos à dieta hiperlipídica e à droga começaram a morrer em torno de 60 dias, e aqueles sob dieta normal e com droga, em torno de 150 dias após o início do experimento. Observou-se taxa de mortalidade de mais de $50 \%$ nos animais alimentados com dieta hiperlipídica e tratados com a droga no final de cinco meses de experimento. Já os animais tratados com a droga e alimentados com dieta normal, a mortalidade foi aproximadamente de $20 \%$ no mesmo período (Figura 3A).

Mesmo diante do exposto, com o intuito de verificar o efeito da droga, buscou-se uma dose maior, no caso de $30 \mathrm{mg} /$ dia administrada durante todo o experimento. Os animais submetidos à dieta hiperlipídica e à droga começaram a morrer em torno de 60 dias e aqueles sob dieta normal e tratados com droga, em torno de 70 dias do experimento. Com essa dose, a mortalidade atingiu $70 \%$ dos animais tratados com a droga, tanto mantidos sob dieta normal ou hiperlipídica, já no final de três meses de experimento. Observou-se mortalidade discretamente maior nos animais tratados $\mathrm{e}$ submetidos a dieta hiperlipídica (Figura 3B). No final do experimento, foi também observado a morte súbita de alguns animais. 


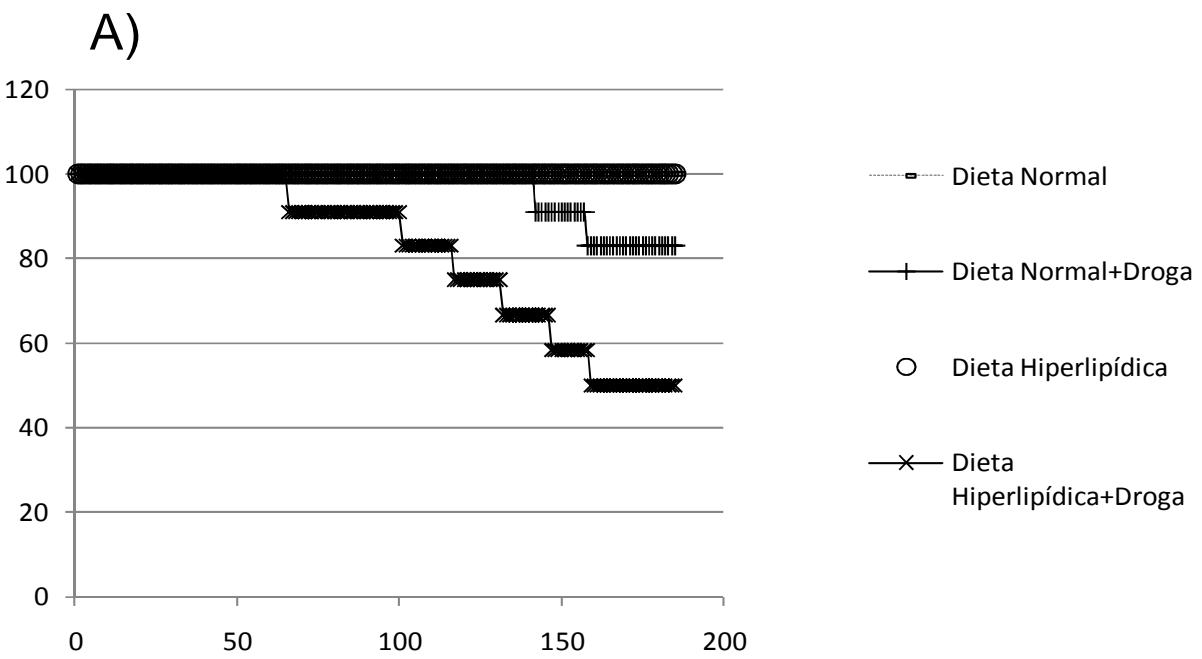

B)

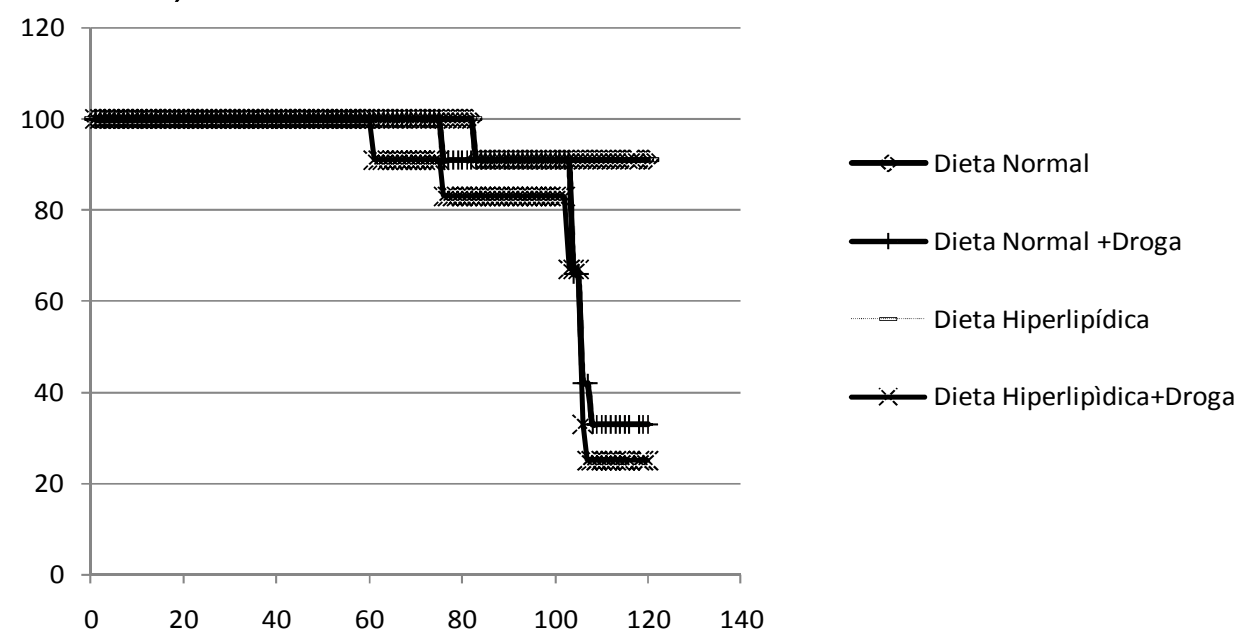

Figura 3. Taxa de sobrevivência de hamsteres submetidos a diferentes doses de inibidor de protease indinavir $(A-12 \mathrm{mg} / \mathrm{d}$ e $B-30 \mathrm{mg} / \mathrm{d}$ ) durante todo 0 período do experimento com dieta normal ou hiperlipídica $(\mathrm{n}=$ 12/grupo). 


\subsection{Perfil lipídico}

Embora não se detectasse morte de nenhum animal, nos animais do grupo que recebeu doses menores (6 e $12 \mathrm{mg} / \mathrm{dia}$ ), observaram-se alterações no perfil lipídico.

Ao utilizar a dose de 6mg/dia de indinavir encontrou-se, a partir do primeiro mês de tratamento, aumento significante do nível de colesterol nos animais submetidos à dieta hiperlipídica em relação aos grupos com dieta normal, apesar de não ter sido detectado alteração pelo uso da droga (Figura 4B, C, D e E). No segundo mês do tratamento, observou-se nível significantemente maior de colesterol no grupo sob dieta hiperlipídica e indinavir quando comparado ao controle com a dieta hiperlipídica sem a droga $(P<0,001)$ (Figura $4 C)$. Nos meses subseqüentes, não se observou diferença entre os animais que receberam a droga e seus respectivos controles (Figura $4 \mathrm{D}$ e $\mathrm{E})$. 

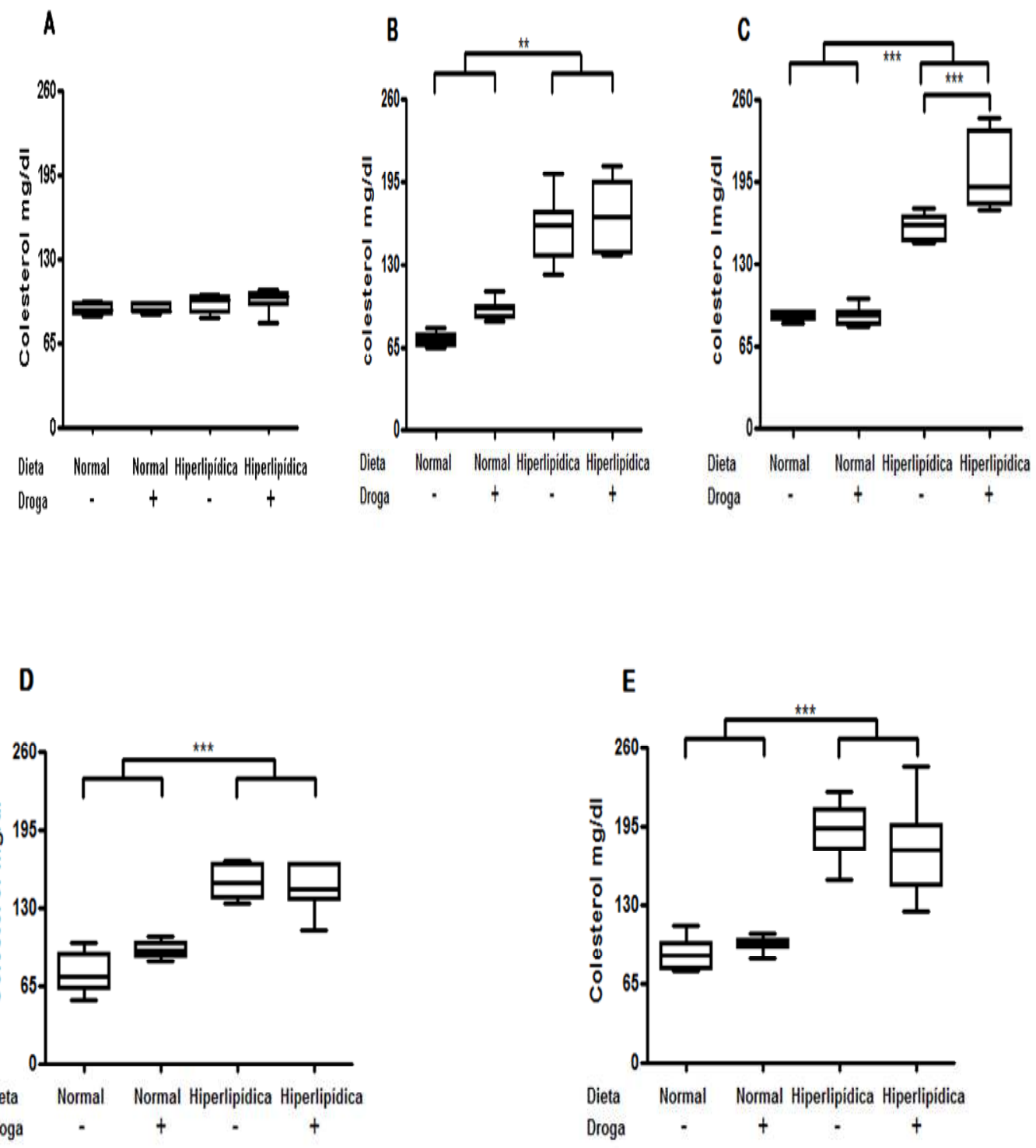

Figura 4. Níveis de colesterol plasmático em diferentes tempos de experimento em hamsteres submetidos a dieta normal ou hiperlipídica e com ou sem tratamento com a droga, inibidor de protease indinavir $(6 \mathrm{mg} / \mathrm{dia})$ mantidas durante todo o período do experimento. Tempos: A) zero; B) primeiro mês; C) segundo mês; D) terceiro mês; E) quarto mês. ${ }^{* *} \mathrm{P}<0.01,{ }^{* * *} \mathrm{P}<0.001$. 
No experimento com a dose de indinavir de seis $\mathrm{mg} / \mathrm{dia}$, os níveis de triglicérides plasmáticos em hamsteres tiveram aumento significante, a partir do primeiro mês de tratamento, nos animais submetidos a dieta hiperlipídica e á droga Indinavir $(p<0.001)$ em relação ao grupo com dieta normal, diferença que se manteve até $o$ final do experimento(Figura 5B,C,D e E).

Já no segundo mês de tratamento, observou-se aumento significante nos níveis de triglicérides nos animais submetidos à dieta hiperlipídica e tratados com Indinavir em relação àqueles sob dieta hiperlipídica sem a droga $(P<0.05) \quad$ (Figura $5 \mathrm{C}$ ) esta diferença desapareceu, no entanto, nos tempos posteriores (Figura 5D e E). Também foi observado diferença significante $(<0.01)$ entre os grupos submetidos a dieta normal e tratados com indinavir e dieta hiperlipídica tratados com indinavir que se manteve até o final do experimento (Figura 5C,D eE).

A partir do terceiro mês de tratamento observou-se diferença significativa entre os grupos submetidos a dieta normal e dieta hiperlipidica (Figura 5D e E) que se manteve até o final do experimento. Essa diferença significante pode ser atribuída ao efeito da dieta. 


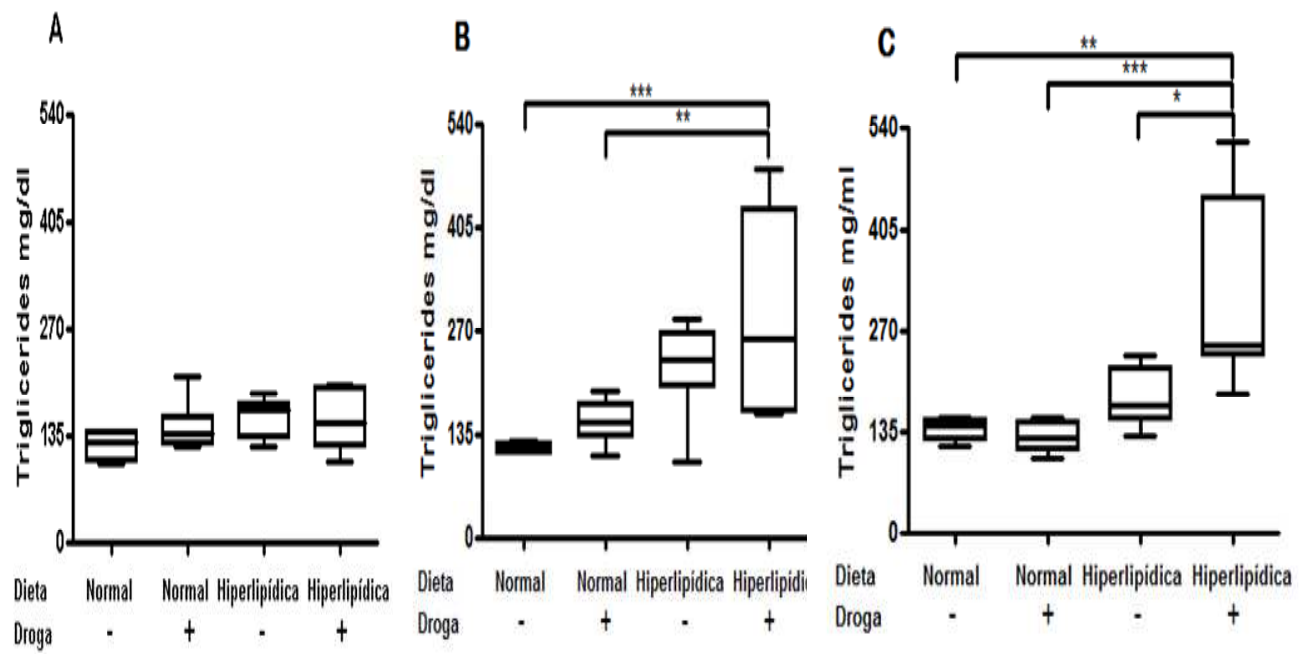

D

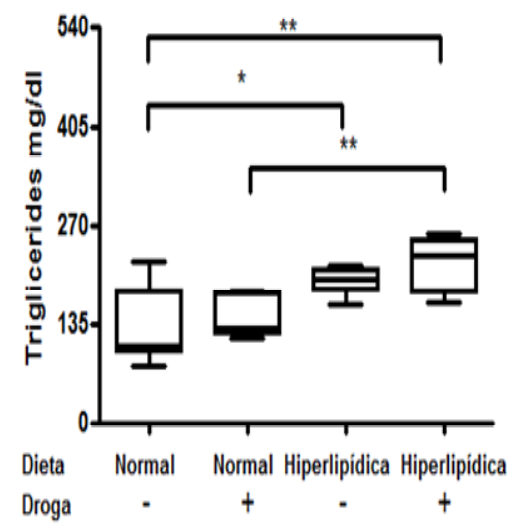

E

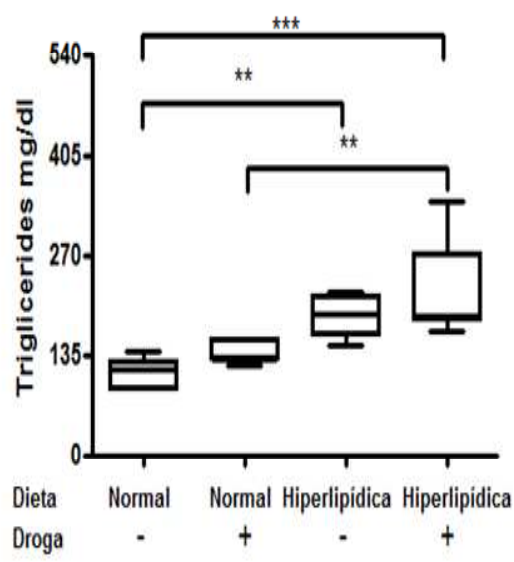

Figura 5. Níveis de triglicérides plasmáticos em distintos tempos de experimento, em hamsteres submetidos a dieta normal ou hiperlipídica e com ou sem tratamento com a droga, inibidor de protease indinavir $(6 \mathrm{mg} / \mathrm{dia})$, mantidas durante todo o período do experimento. Tempos: A) zero; B) primeiro mês;C) segundo mês;D) terceiro mês ; E) quarto mês. ${ }^{* * *} \mathrm{P}<0.001,{ }^{* *} \mathrm{P}<0.01,{ }^{* \star} \mathrm{P}<0.01$. 
No experimento com dose de $12 \mathrm{mg} /$ dia de indinavir, a partir do primeiro mês do tratamento notou-se aumento significante do nível de colesterol nos animais dos grupos submetidos a dieta hiperlipídica em relação aos grupos com dieta normal, independentemente do uso da droga (Figura 6B, C, D e E). Encontrou-se no terceiro mês de tratamento aumento significante dos níveis plasmáticos de colesterol nos animais mantidos com dieta normal e tratados com indinavir em relação aos que receberam somente dieta normal $(P<0.001)$ (Figura 6D). Já no quarto mês de tratamento, observou-se aumento significante nos níveis de colesterol nos animais sob dieta hiperlipídica e tratados com indinavir em relação aqueles mantidos apenas com a dieta hiperlipídica $(P<0.05)$ (Figura 6E).

Em experimento com $12 \mathrm{mg} / \mathrm{dia}$ de indinavir, no primeiro mês de tratamento, encontrou-se aumento significante de triglicérides plasmáticos nos animais dos grupos submetidos à dieta hiperlipídica e tratados com indinavir com respeito aos demais grupos (Figura 7B). Essa diferença pode ser atribuída ao efeito sinérgico de droga quando acompanhado de dieta hiperlipídica

Já no segundo e quarto mês do experimento, foi observado um aumento significante $(P<0.001$ e $P<0.05$, respectivamente) nos níveis de triglicérides nos animais sob dieta hiperlipídica em relação aos animas sob dieta normal (Figura 7C e E). No terceiro mês de tratamento, observou-se diferença significante entre o grupo submetido a dieta normal com respeito aos grupos submetidos a dieta hiperlipídica com $(P<0.001)$ ou sem tratamento com indinavir $(P<0.05)$. Também foi observado diferença significante entre o grupo submetido a dieta normal e tratados com indivanir em relação aos animais submetidos adieta hiperlipidica $(P<0.001)$ (Figura 7D) 

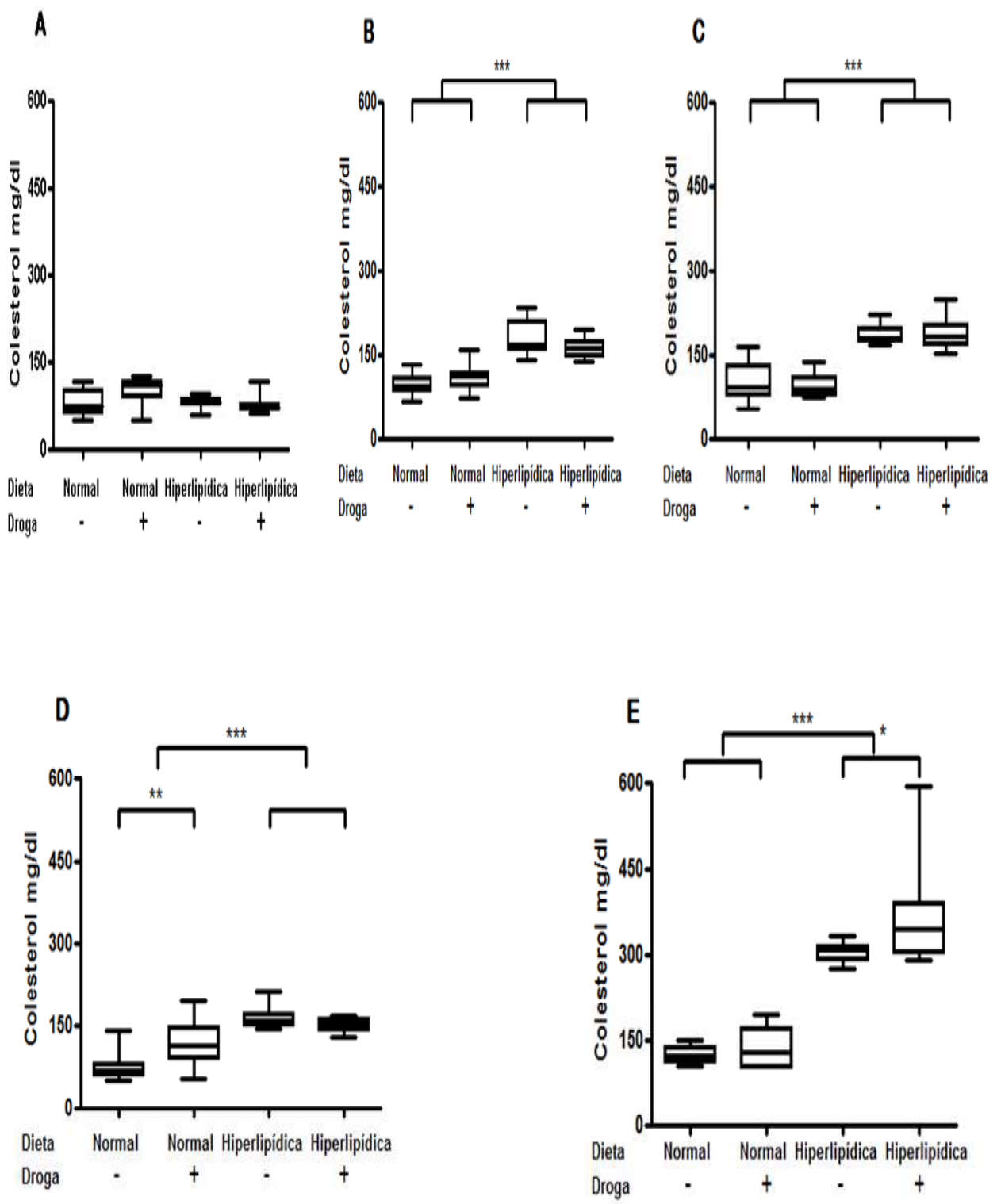

Figura 6. Níveis de colesterol plasmático em diferentes tempos de experimento em hamsteres submetidos a dieta normal ou hiperlipídica e com ou sem tratamento com a droga, inibidor de protease indinavir (12mg/dia) mantidas durante todo o período do experimento. Tempos: A) zero; B) primeiro mês; C) segundo mês; D) terceiro mês; E) quarto mês. ${ }^{*} P<0.05$, ${ }^{* *} \mathrm{P}<0.01,{ }^{* *} \mathrm{P}<0.001$. 

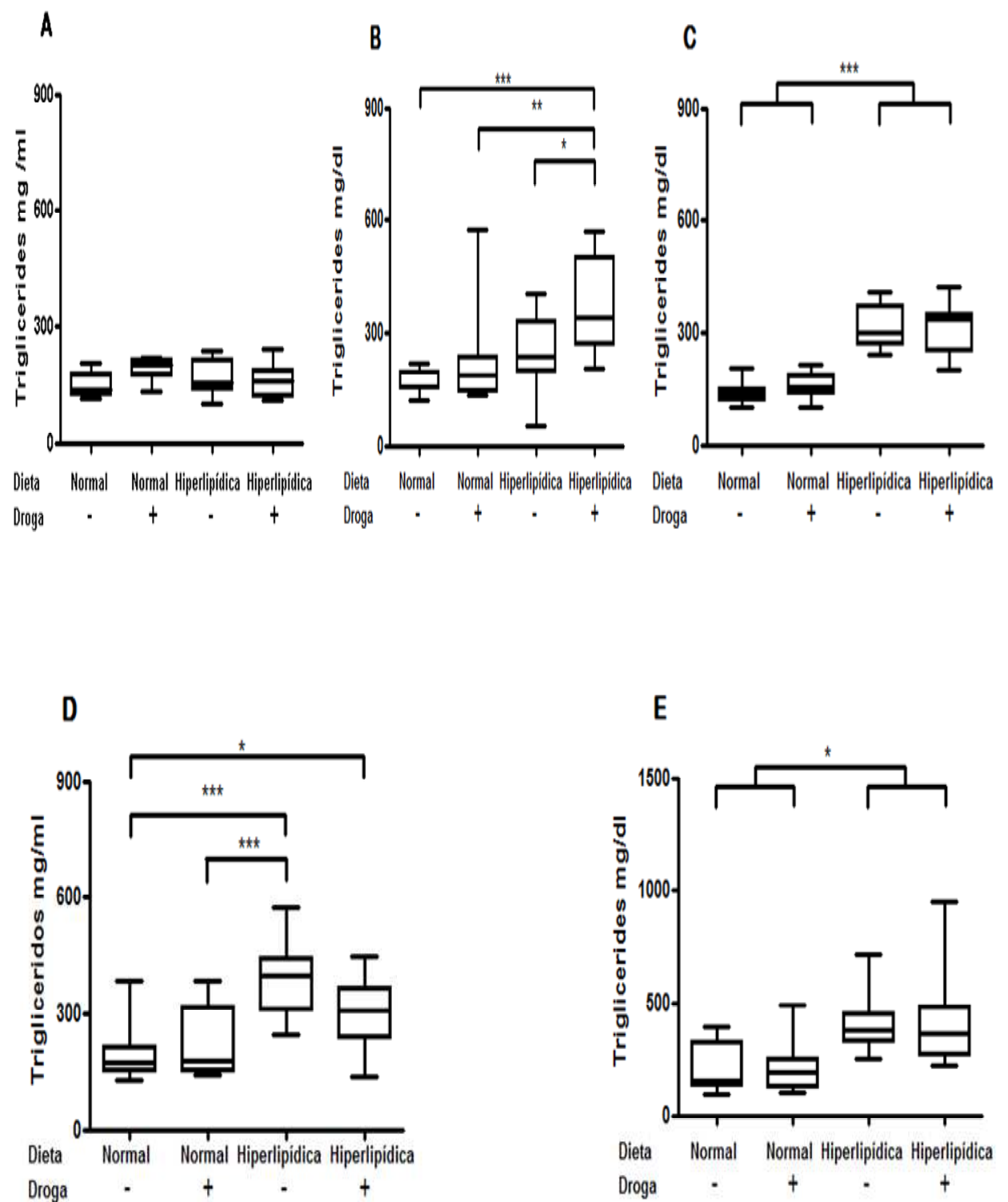

Figura 7. Níveis de triglicérides plasmáticos em diferentes tempos de experimento em hamsteres submetidos a dieta normal ou hiperlipídica e com ou sem tratamento com a droga, inibidor de protease indinavir (12mg/dia) mantidas durante todo o período do experimento. Tempos: A) zero; B) primeiro mês; C) segundo mês; D) terceiro mês; E) quarto mês. ${ }^{*} P<0.05$, ${ }^{* *} \mathrm{P}<0.01,{ }^{* *} \mathrm{P}<0.001$. 
Em experimento com $30 \mathrm{mg} / \mathrm{dia}$ de indinavir, a partir do primeiro mês do tratamento notou-se aumento significante do nível de colesterol nos animais dos grupos submetidos à dieta hiperlipídica em relação aos grupos com dieta normal, independentemente do uso da droga (Figura 8B, C e D). Já no terceiro mês foi observada diferença significativa entre os grupos submetidos à dieta hiperlipídica com e sem tratamento com a droga $(P<0.01)$ (Figura 8D).

$\mathrm{Na}$ avaliação dos níveis de triglicérides plasmáticos no experimento com $30 \mathrm{mg} / \mathrm{dia}$ de Indinavir, no segundo mês do tratamento, observou-se aumento significante de triglicérides nos animais dos grupos submetidos a dieta hiperlipídica e tratados com indinavir (Figura 9C ).Já o grupo submetido à dieta hiperlipídica e sem tratamento só teve diferença significante em relação ao grupo com dieta normal (Figura 9C). Ressalta-se, no entanto, que no terceiro mês de tratamento houve diferença signicante entre os grupos submetidos a dietas diferenciadas $(p<0.001)$ como também quando comparado os grupos tratados ou não com a droga $(P<0.05)$ (Figura 9D). 
A

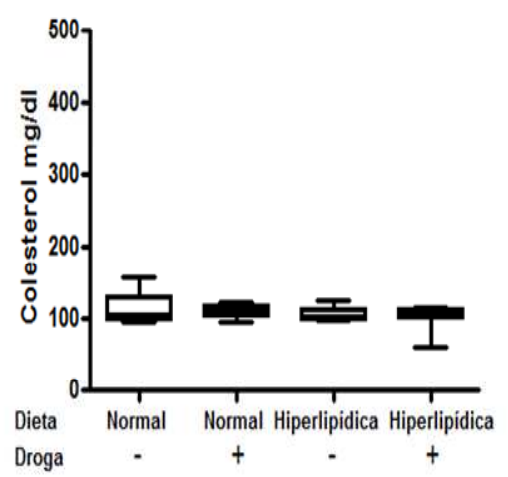

C

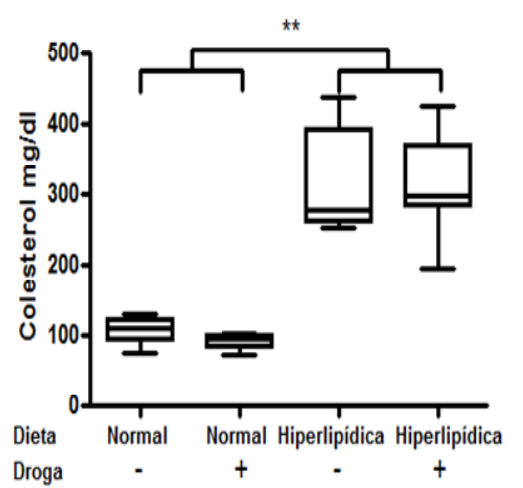

B

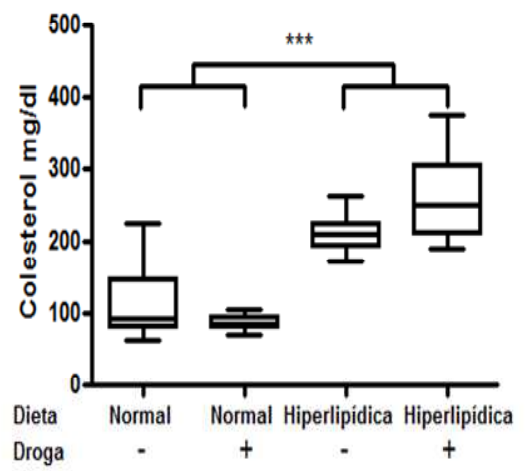

D

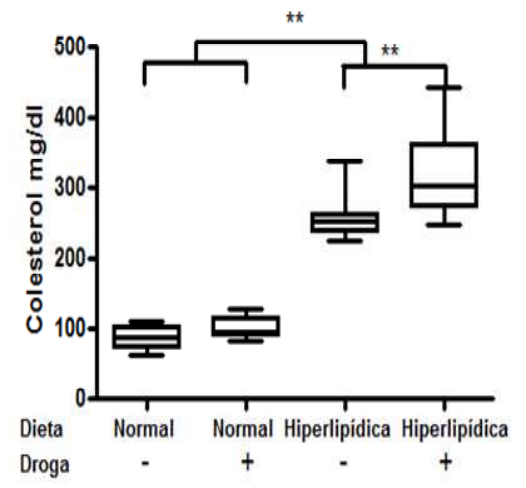

Figura 8. Níveis de colesterol plasmático em diferentes tempos de experimento em hamsteres submetidos a dieta normal ou hiperlipídica e com ou sem tratamento com a droga, inibidor de protease indinavir $(30 \mathrm{mg} / \mathrm{dia})$ mantidas durante todo o período do experimento. Tempos: A) zero; B) primeiro mês; C) segundo mês; D) terceiro mês. ${ }^{* \star} \mathrm{P}<0.01,{ }^{* \star *} \mathrm{P}<0.001$. 
A
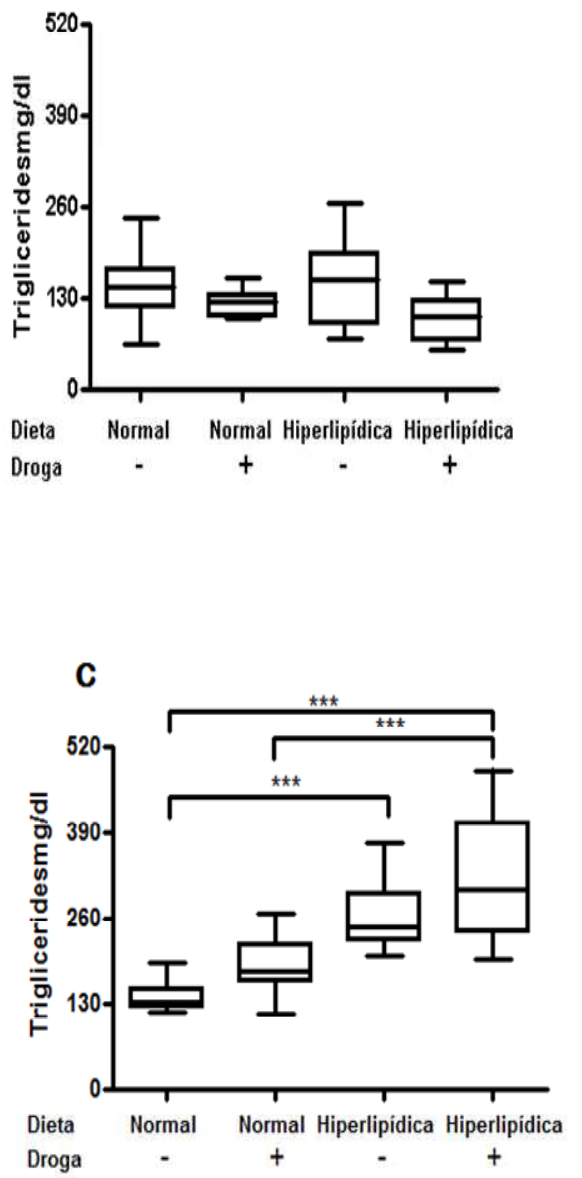

B
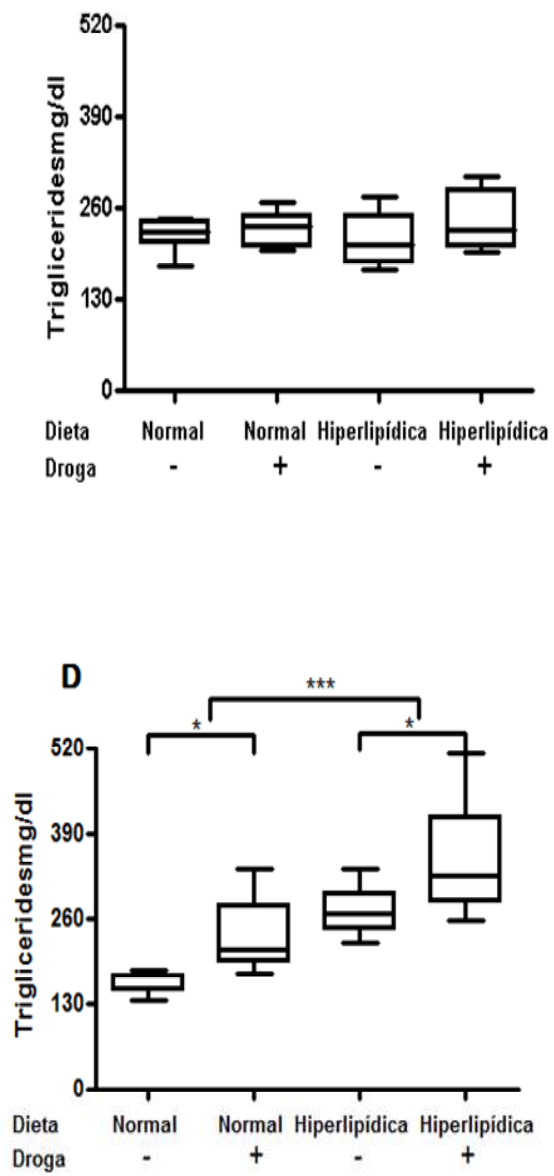

Figura 9. Níveis de triglicérides plasmático em diferentes tempos de experimento em hamsteres submetidos a dieta normal ou hiperlipídica e com ou sem tratamento com a droga, inibidor de protease indinavir $(30 \mathrm{mg} / \mathrm{dia})$ mantidas durante todo o período do experimento. Tempos: A) zero; B) primeiro mês; C) segundo mês; D) terceiro mês. ${ }^{*} \mathrm{P}<0.05$, ${ }^{* \star}{ }^{*} \mathrm{P}<0.001$. 


\subsection{Níveis de HDL e LDL plasmáticos}

A avaliação dos níveis de HDL e LDL foi realizada utilizando o protocolo experimental de $30 \mathrm{mg} / \mathrm{dia}$ de indinavir, concentração escolhida mediante padronização.

Os níveis de HDL apresentaram resultados significantes a partir do primeiro mês do tratamento nos animais dos grupos submetidos à dieta hiperlipídica em relação aos grupos com dieta normal, independentemente do uso da droga ( $p<0.001)$ (Figura 10B, C e D).

$\mathrm{Na}$ avaliação dos níveis de LDL plasmáticos,a partir do primeiro mês do tratamentofoi observado um aumento significante nos animais dos grupos submetidos a dieta hiperlipídica em relação aos grupos com dieta normal, independente do uso da droga $(p<0.001)$ e esta diferença significativa se manteve ate o final do experimento (Figura 11B,C e D). 
A

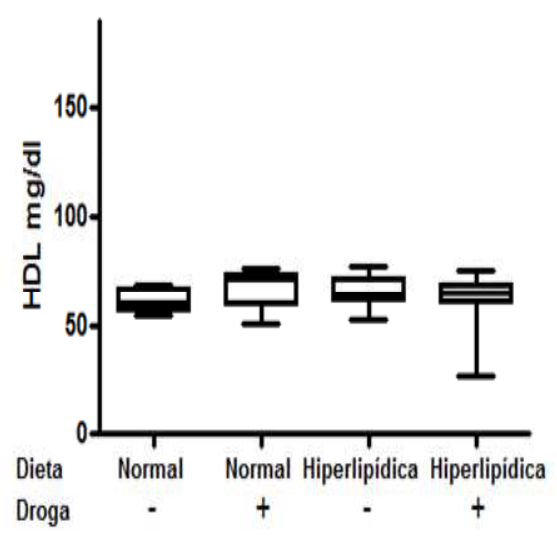

C

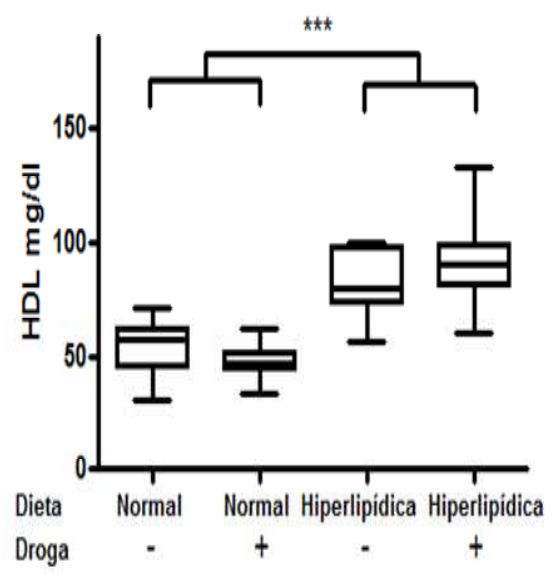

B

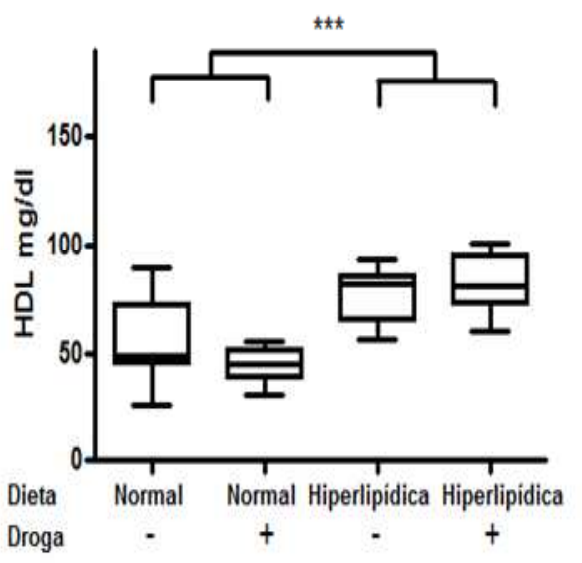

D

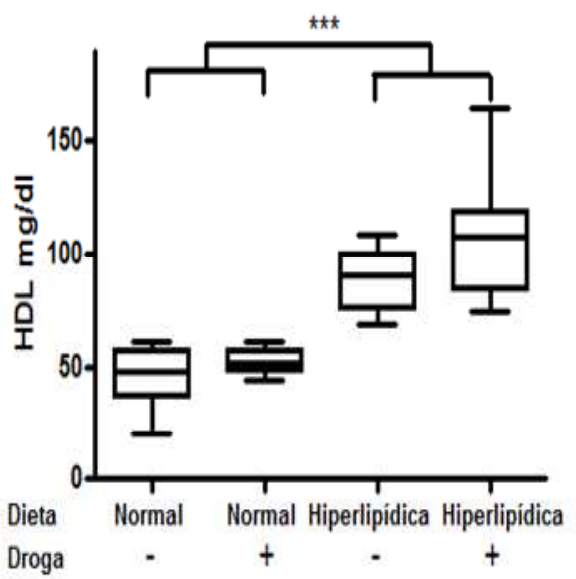

Figura 10. Níveis de HDL plasmático em diferentes tempos de experimento em hamsteres submetidos a dieta normal ou hiperlipídica e com ou sem tratamento com a droga, inibidor de protease indinavir $(30 \mathrm{mg} / \mathrm{dia})$ mantidas durante todo 0 período do experimento. Tempos: A) zero; B) primeiro mês; C) segundo mês; D) terceiro mês. ${ }^{* \star *} \mathrm{P}<0.001$. 


\section{A}

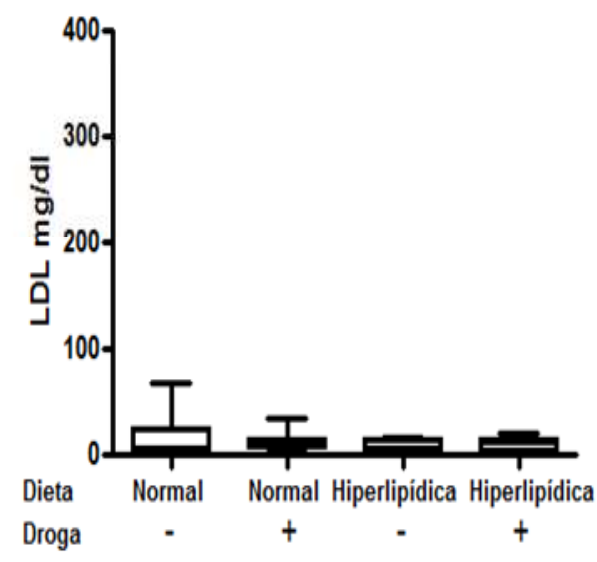

\section{C}

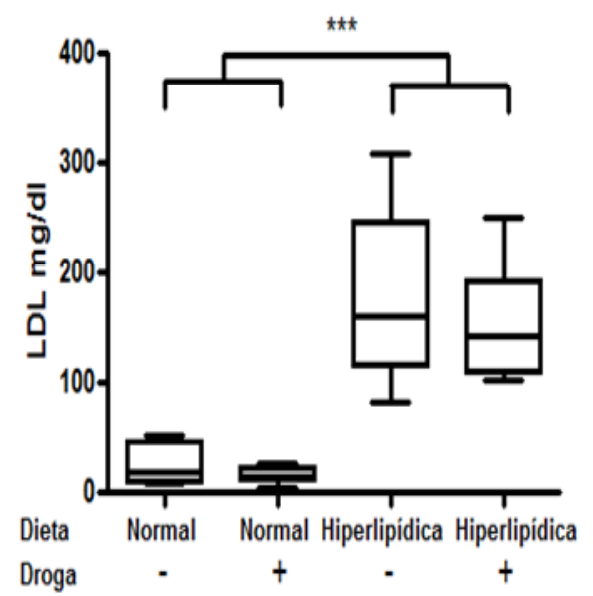

B

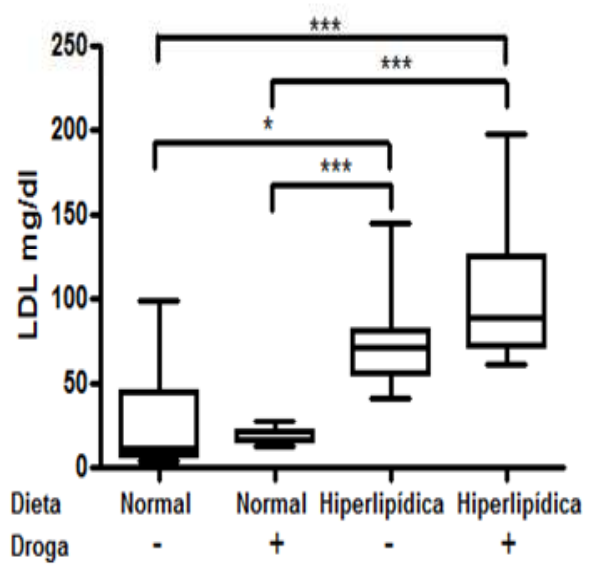

D

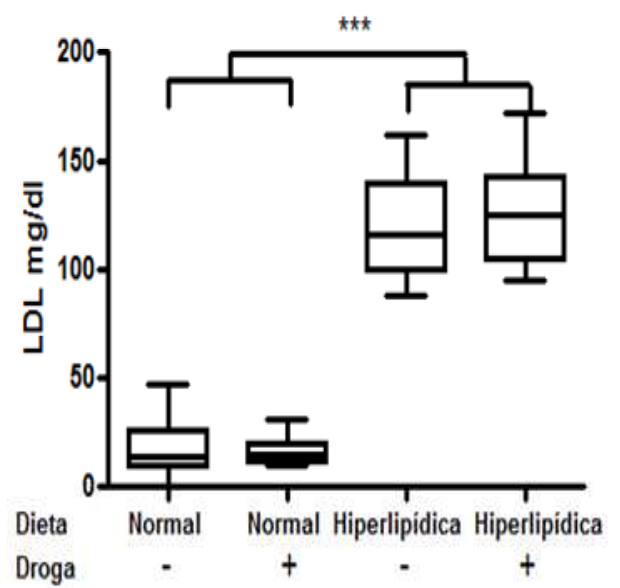

Figura 11. Níveis de LDL plasmático em diferentes tempos de experimento, em hamsteres submetidos a dieta normal ou hiperlipídica, com ou sem tratamento com a droga, inibidor de protease indinavir $(30 \mathrm{mg} / \mathrm{dia})$, mantidas durante todo o período do experimento. Tempos: A) zero; B) primeiro mês; C) segundo mês D) terceiro mês. ${ }^{*} P<0.05,{ }^{* * *} P<0.001$. 


\subsection{Análise da Glicemia}

Os níveis plasmáticos de glicose foram analisados em diferentes tempos de experimento com a utilização de $30 \mathrm{mg} / \mathrm{dia}$ de indinavir, conforme padronização.

No primeiro mês de tratamento, os níveis de glicose apresentaram um aumento significante nos animais submetidos à dieta hiperlipídica e tratados com indinavir em relação ao grupo submetido à dieta normal sem tratamento $(P<0.05)$. Também pôde ser observado um aumento significante em animais submetidos à dieta hiperlipídica e tratados com indinavir quando comparado com os animais submetidos à dieta normal e tratados com indinavir $(P<0.05)$ (Figura 12B).

No segundo mês de tratamento, encontrou-se uma maior significância, quando comparado com o primeiro mês, nos animais submetidos à dieta hiperlipídica e tratados com indinavir em relação ao grupo submetido à dieta normal sem tratamento $(P<0.01)$. Já nos grupos submetidos à dieta hiperlipídica, observou-se um aumento significante dos níveis de glicose nos animais tratados com indinavir quando comparados com os animais sem tratamento $(\mathrm{P}<0.05) \quad$ (Figura $12 \mathrm{C}$ ). Já no terceiro mês, as diferenças se mantiveram como relatado no primeiro e segundo mês de tratamento, porém com uma significância de $p<0.001$. E também, observou-se um aumento significante nos animais tratados com indinavir quando comparados aos animais sem tratamento, independente da dieta $(P<0.05)$ (Figura 12D). 
A

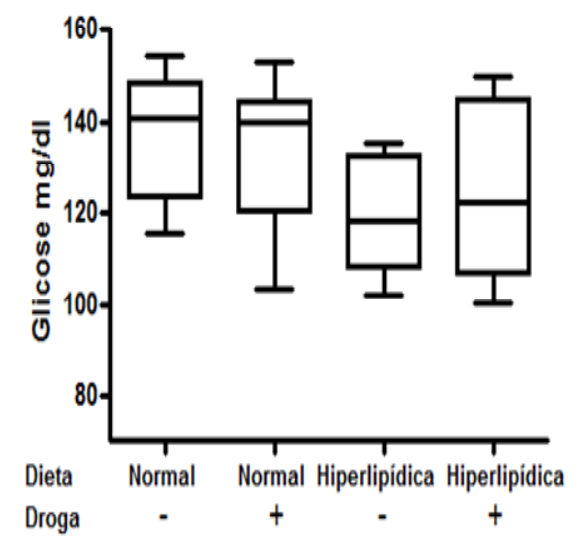

C

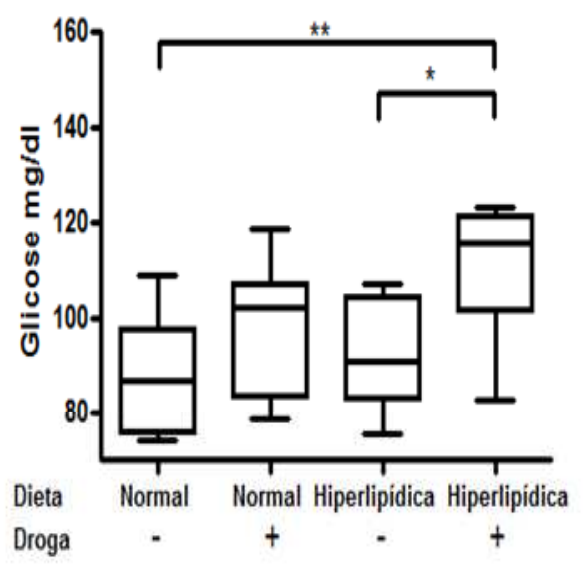

B

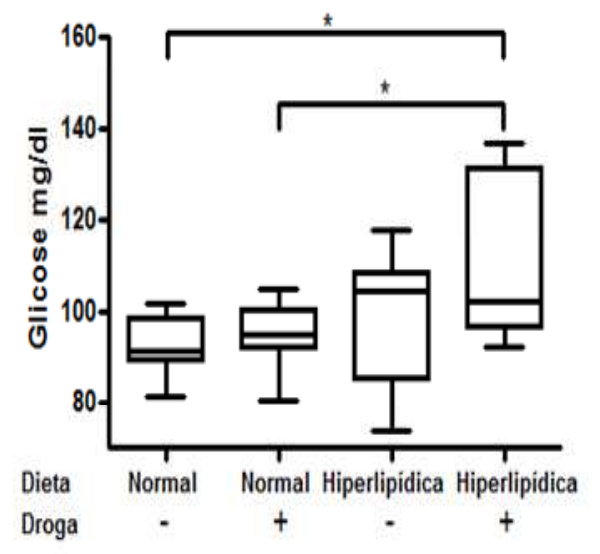

D

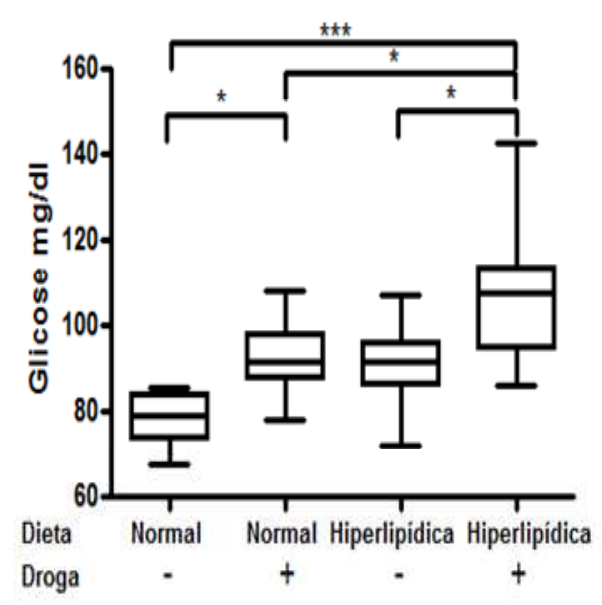

Figura 12. Níveis plasmáticos de glicose em diferentes tempos de experimento, em hamsteres submetidos a dieta normal ou hiperlipídica, com ou sem tratamento com a droga, inibidor de protease indinavir $(30 \mathrm{mg} / \mathrm{dia})$, mantidas durante todo o período do experimento. Tempos: A) zero; B) primeiro mês; C) segundo mês $D)$ terceiro mês. ${ }^{*} P<0.05,{ }^{* *} P<0.01$, ${ }^{* * *} \mathrm{P}<0.001$. 


\subsection{Função Hepática}

Para verificar alterações na função hepática, foram determinados os níveis plasmáticos de ALT, AST e GGT em diferentes tempos de experimento utilizando $30 \mathrm{mg} / \mathrm{dia}$ de indinavir.

Ao analisar os níveis de ALT, observou-se um aumento significante no primeiro mês de tratamento nos animais submetidos à dieta hiperlipídica e tratados com indinavir quando comparado com todos os outros grupos: animais submetidos à dieta hiperlipídica e sem tratamanto $(P<0.001)$, animais submetidos à dieta normal tratados com indinavir $(\mathrm{P}<0.01)$ e sem tratamento $(P<0.05)$ (Figura 13B).

No segundo mês de tratamento, pôde ser observado um aumento significativo nos níveis de ALT nos animais submetidos à dieta hiperlipídica e tratados com indinavir em relação aos animais submetidos à dieta normal e sem tratamento $(P<0.05)$. Também observou-se um aumento significativo nos animais submetidos à dieta hiperlipídica e sem tratamento quando comparados com os animais submetidos à dieta normal e tratados com indinavir $(P<0.05)$ e sem tratamento $(P<0.01)$ (Figura 13C).

No terceiro mês, observou apenas um aumento significante dos níveis de ALT nos animais não tratados quando comparado o grupo submetido à dieta hiperlipídica com o grupo de dieta normal $(P<0.05)$ (Figura 13D). 

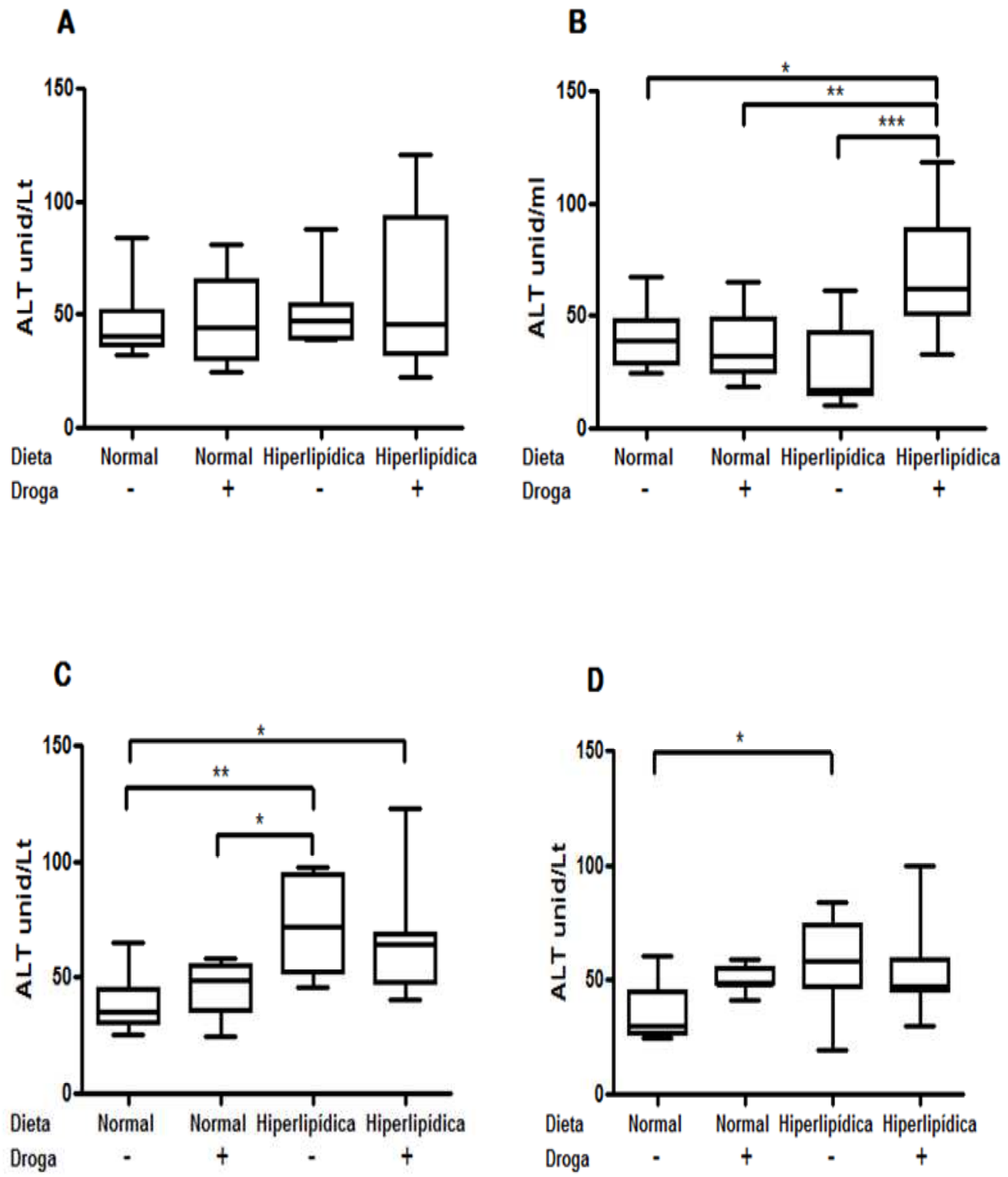

Figura 13. Níveis plasmáticos de alanina transaminase (ALT) em diferentes tempos de experimento, em hamsteres submetidos a dieta normal ou hiperlipídica, com ou sem tratamento com a droga, inibidor de protease indinavir ( $30 \mathrm{mg} / \mathrm{dia})$, mantidas durante todo o período do experimento. Tempos: A) zero; B) primeiro mês; C) segundo mês D) terceiro mês. ${ }^{*} \mathrm{P}<0.05,{ }^{\star \star} \mathrm{P}<0.01,{ }^{* \star} \mathrm{P}<0.001$. 
Em relação aos níveis de AST plasmáticos, foi observada diferença significativa apenas no primeiro e terceiro mês de tratamento.

No primeiro mês de tratamento, observou-se um aumento significante nos animais submetidos à dieta hiperlipídica e tratados com indinavir em relação aos animais tratados com indinavir e submetidos à dieta normal $(\mathrm{P}<0.05)$ (Figura 14B).

No terceiro mês, os níveis de AST dos grupos tratados com indinavir, apresentaram diferença significante com respeito a seus controles $(P<0.001$, $P<0.01)$. Essa significância também foi observada nos animais submetidos à dieta hiperlipídica sem tratamento em relação aos animais com dieta normal e tratados com a droga $(P<0.001)$ (Figura 14D). 
A

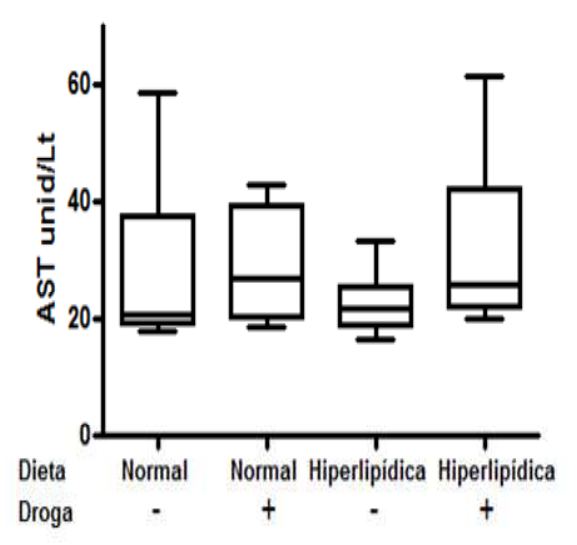

C

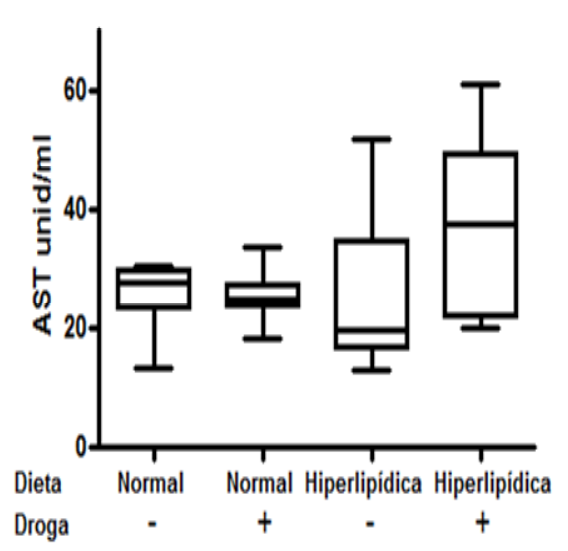

B

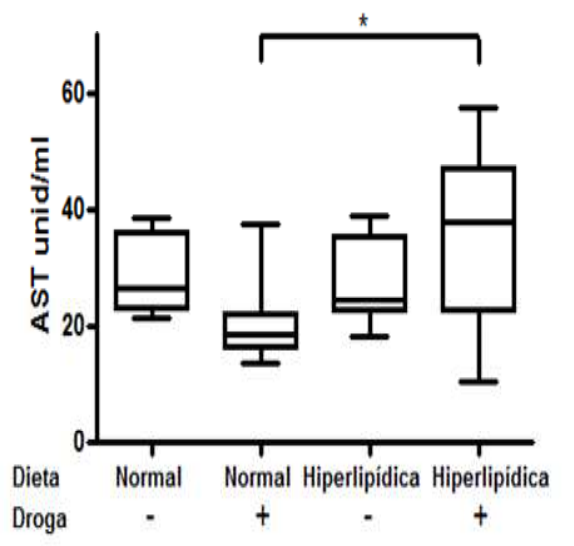

D

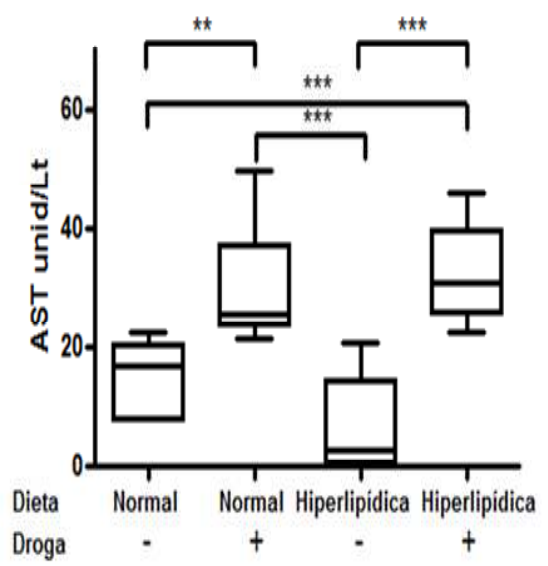

Figura 14. Níveis plasmáticos de aspartato aminotransferase (AST) em diferentes tempos de experimento, em hamsteres submetidos a dieta normal ou hiperlipídica, com ou sem tratamento com a droga, inibidor de protease indinavir $(30 \mathrm{mg} / \mathrm{dia})$, mantidas durante todo o período do experimento. Tempos: A) zero; B) primeiro mês; C) segundo mês D) terceiro mês. ${ }^{*} \mathrm{P}<0.05,{ }^{*} \mathrm{P}<0.01,{ }^{* \star *} \mathrm{P}<0.001$. 
Os níveis de GGT plasmáticos também foram analisados para visualização de alterações na função hepática.

No primeiro mês e no segundo mês de tratamento, observou-se um aumento significante nos níveis de GGT nos animais submetidos à dieta hiperlipídica e tratados com indinavir quando comparados com todos os outros grupos $(\mathrm{P}<0.001)$ (Figura 15B e $\mathrm{C})$.

Enquanto que no terceiro mês de tratamento, observou-se apenas um aumento nos níveis de GGT nos animais submetidos à dieta hiperlipídica e tratados com indinavir em relação aos animais com dieta normal e tratados $(P<0.05)$ (Figura 15D). 
A

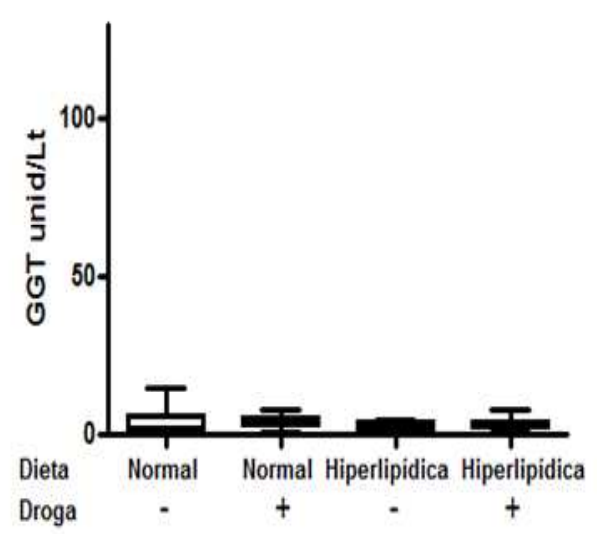

C

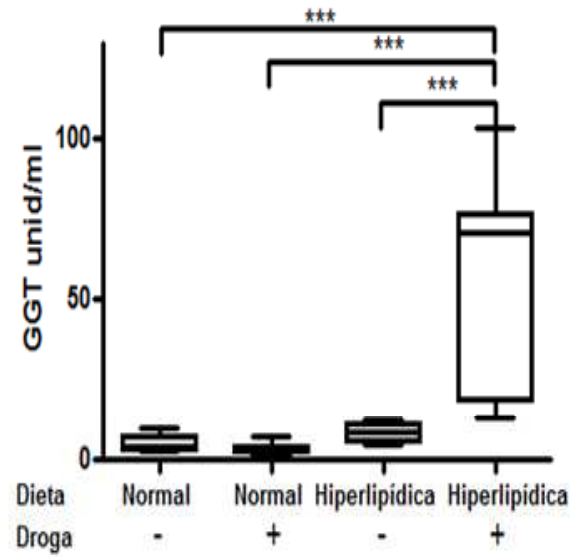

B

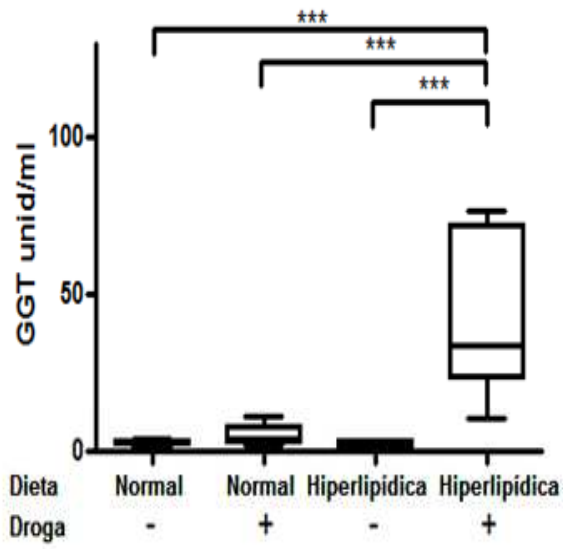

D

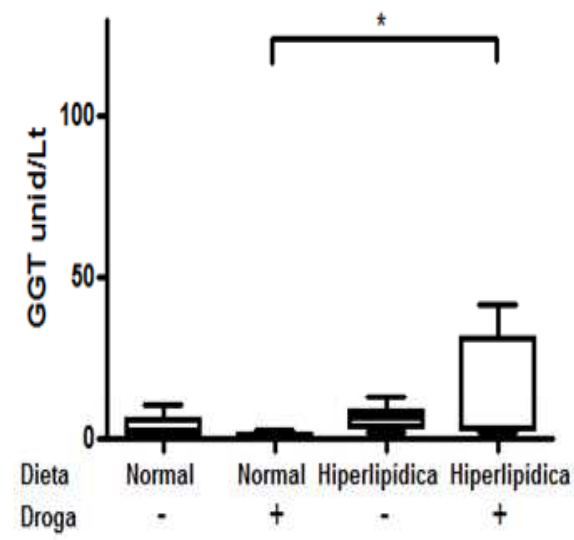

Figura 15. Níveis plasmáticos de gama glutamil transferase (GGT) em diferentes tempos de experimento em hamsteres submetidos a dieta normal ou hiperlipídica, com ou sem tratamento com a droga, inibidor de protease indinavir $(30 \mathrm{mg} / \mathrm{dia})$, mantidas durante todo o período do experimento. Tempos: A) zero; B) primeiro mês; C) segundo mês; D) terceiro mês ${ }^{*} \mathrm{P}<0.05,{ }^{* *} \mathrm{P}<0.001$. 


\subsection{Função Renal}

A determinação da função renal se deu pela quantificação plasmática de uréia e creatinina em diferentes tempos de experimento utilizando $30 \mathrm{mg} / \mathrm{dia}$ de indinavir.

No primeiro mês de tratamento, observou-se uma diminuição nos níveis de uréia plasmática nos animais submetidos à dieta hiperlipídica com ou sem tratamento com indinavir em relação aos animais com dieta normal e não tratados $(P<0.001)$. Também pôde ser observado uma diminuição significante nos animais submetidos à dieta hiperlipídica sem tratamento quando comparado com os animais com dieta normal e tratados com indinavir $(P<0.05)$ (Figura 16B). Não foi observado diferença significativa entre os grupos no segundo mês de tratamento (Figura 16C).

Já no terceiro mês, observou-se apenas uma diminuição dos níveis de uréia entre os grupos de animais submetidos à dieta hiperlipídica em relação aos grupos com dieta normal, independentemente do uso da droga $(P<0.01)$ (Figura 16D). 
A

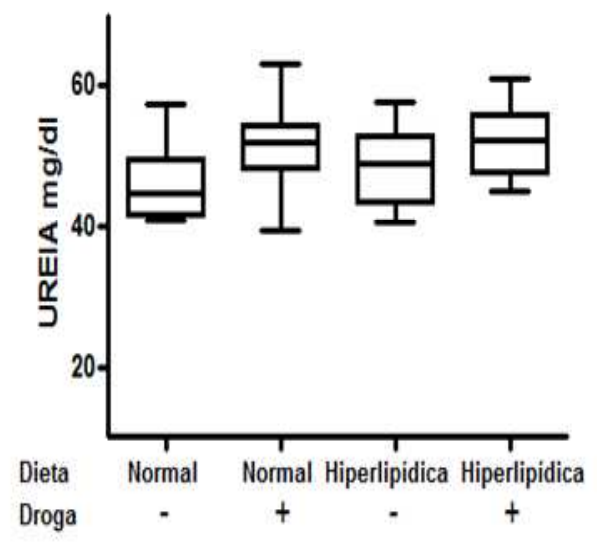

C

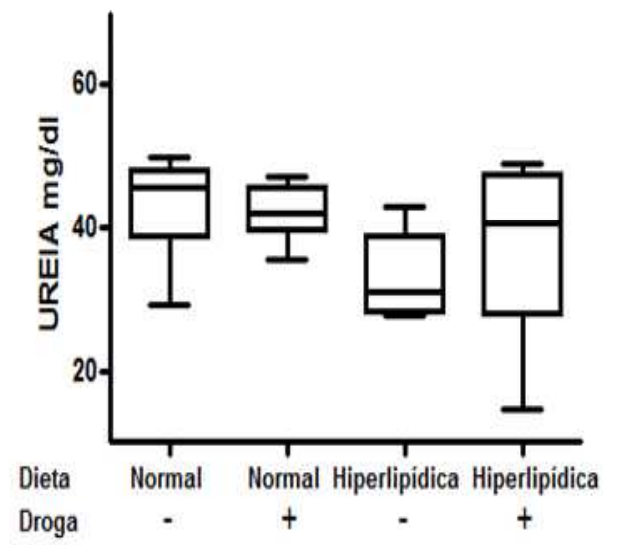

B

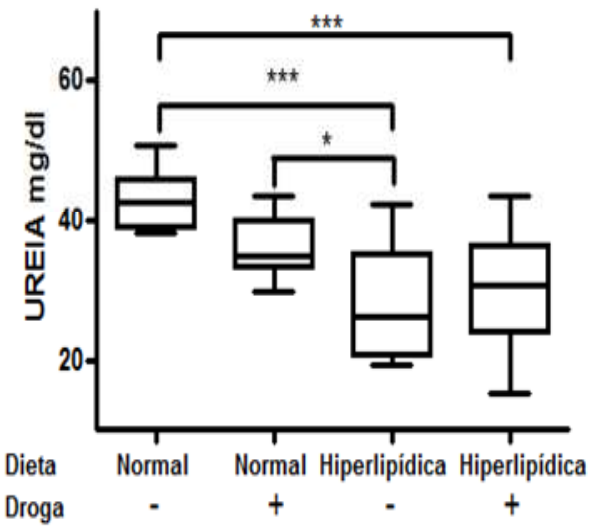

D

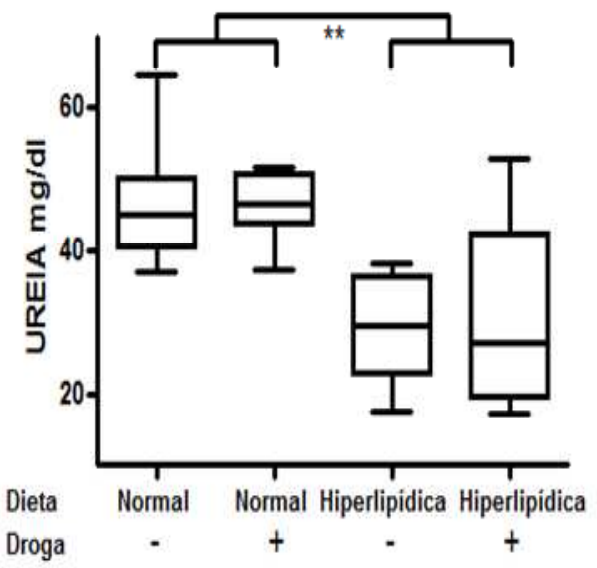

Figura 16. Níveis plasmáticos de uréia em diferentes tempos de experimento, em hamsteres submetidos a dieta normal ou hiperlipídica, com ou sem tratamento com a droga, inibidor de protease indinavir $(30 \mathrm{mg} / \mathrm{dia})$, mantidas durante todo o período do experimento. Tempos: A) zero; B) primeiro mês; C) segundo mês D) terceiro mês. ${ }^{*} P<0.05,{ }^{* *} P<0.01$, ${ }^{* * *} \mathrm{P}<0.001$. 
Analisando os níveis plasmáticos de creatinina, observou-se uma diminuição significante nos animais submetidos à dieta hiperlipídica e tratados com indinavir em relação aos animais submetidos à dieta hiperlipídica e sem tratamento $(P<0.01)$, no primeiro mês de tratamento (Figura 17B).

No segundo mês de tratamento, foi observado um aumento significante nos níveis de creatinina nos animais tratados com indinavir e submetidos a dieta hiperlipídica ou dieta normal quando comparados aos animais com dieta normal e não tratados $(P<0.001)$ (Figura 17C).

Já no terceiro mês, observou-se um aumento significante nos níveis de creatinina nos animais submetidos à dieta hiperlipídica e sem tratamento em relação aos animais com dieta normal e não tratados $(P<0.01)$ (Figura 17D). 
A

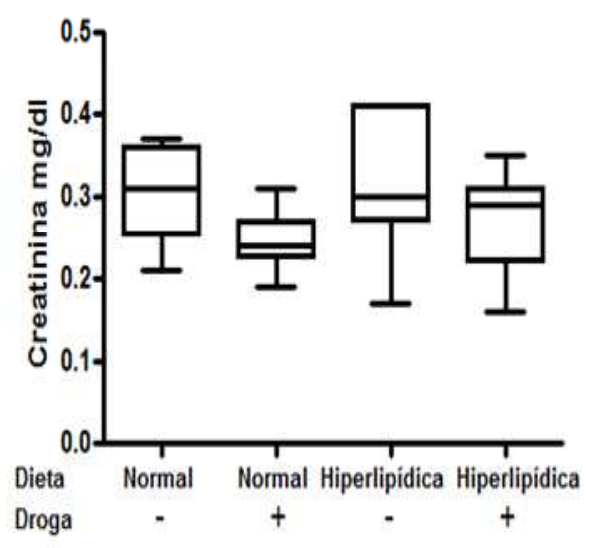

C

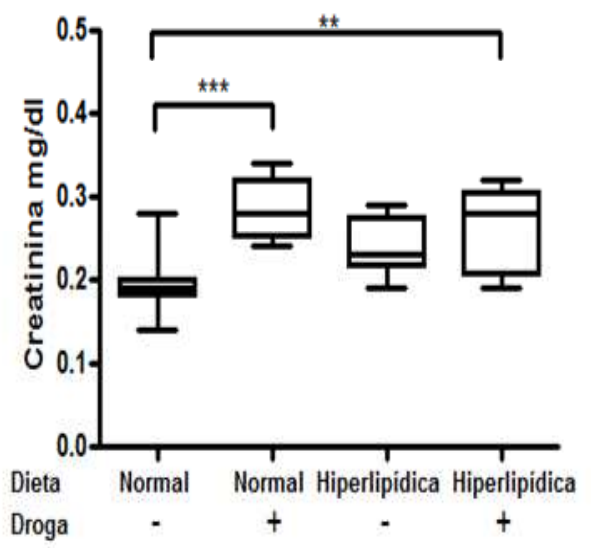

B

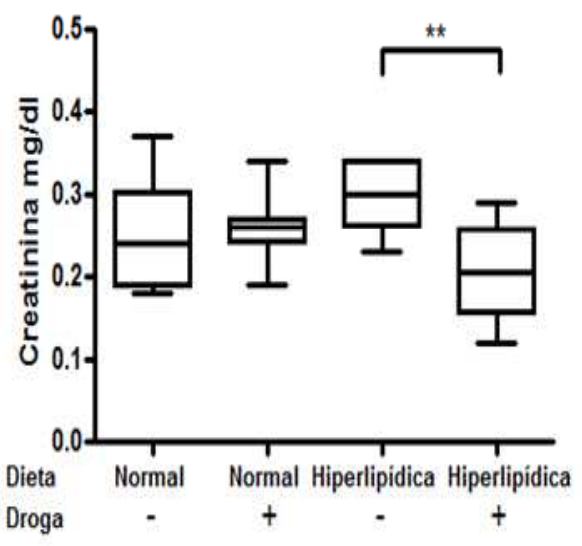

D

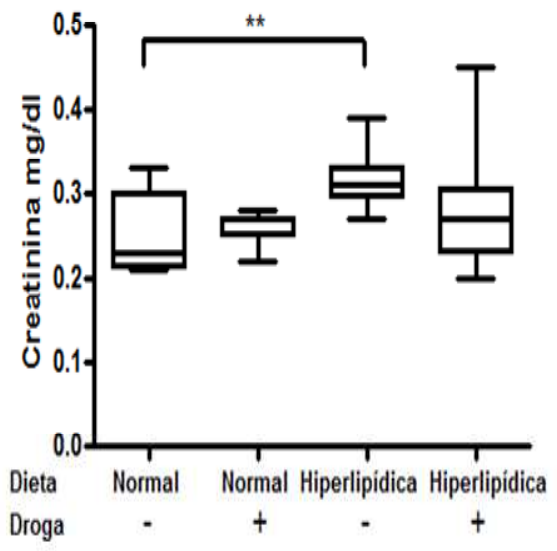

Figura 17. Níveis plasmáticos de creatinina em diferentes tempos de experimento, em hamsteres submetidos a dieta normal ou hiperlipídica, com ou sem tratamento com a droga, inibidor de protease indinavir $(30 \mathrm{mg} / \mathrm{dia})$, mantidas durante todo o período do experimento. Tempos: A) zero; B) primeiro mês; C) segundo mês D) terceiro mês. ${ }^{* *} \mathrm{P}<0.01,{ }^{* *} \mathrm{P}<0.001$. 


\subsection{Detecção de anticorpos anti-ox-LDL e apo-B-D}

Para o teste de ELISA para detecção de anticorpos anti-oxLDL, foi necessária a padronização do tempo de oxidação de LDL de hamster para utilizar como antígeno neste ensaio, pois o tempo de oxidação divergiu um pouco da encontrada em LDL humana que é de 18 horas segundo 0 padronizado no nosso laboratorio (Fernvick et al., 2004). De fato, o pico de oxidação ocorreu ao redor de 12 a 16 horas, que foi detectado pela medida do TBARS e formação de dienos. No presente estudo escolheu-se o tempo de 14 horas de oxidação da LDL para obtenção do antígeno.

Níveis séricos de anticorpos anti-ox-LDL em hamsteres no experimento com 6mg/dia de Indinavir não distinguiram significantemente nos dois primeiros meses (Figura 18B e C). Contudo, no terceiro mês de tratamento observou-se uma diminuição nos grupos tratados com indinavir $(P<0.001)$ e nos animais submetidos à dieta hiperlipídica $(\mathrm{P}<0.01)$ com relação aos animais com dieta normal e sem tratamento. Também foi observada uma diminuição significante nos animais submetidos à dieta hiperlipídica e tratados com indinavir quando comparados com seu grupo controle $(P<0.05)$ (Figura 18D).

Os níveis séricos de anticorpos anti-ox-pepD nos hamsteres, não se diferiram entre os grupos com indinavir a $6 \mathrm{mg} /$ dia (Figura 19). 
A

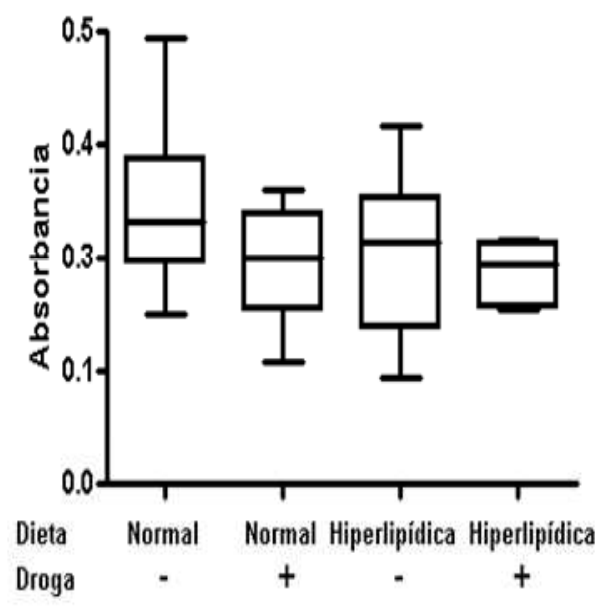

B

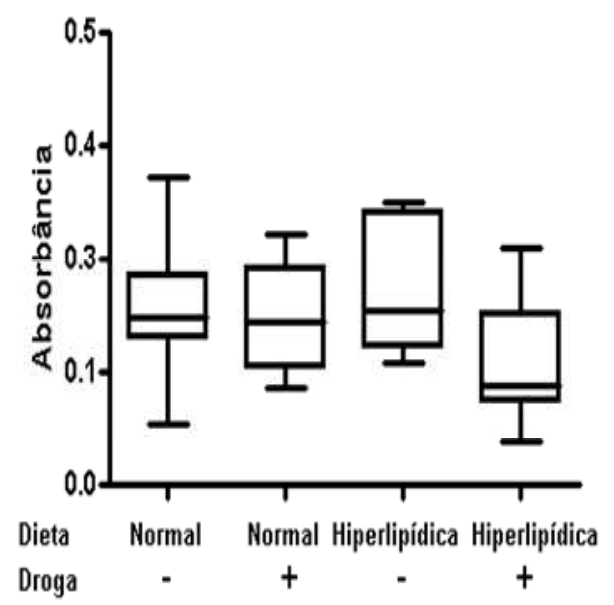

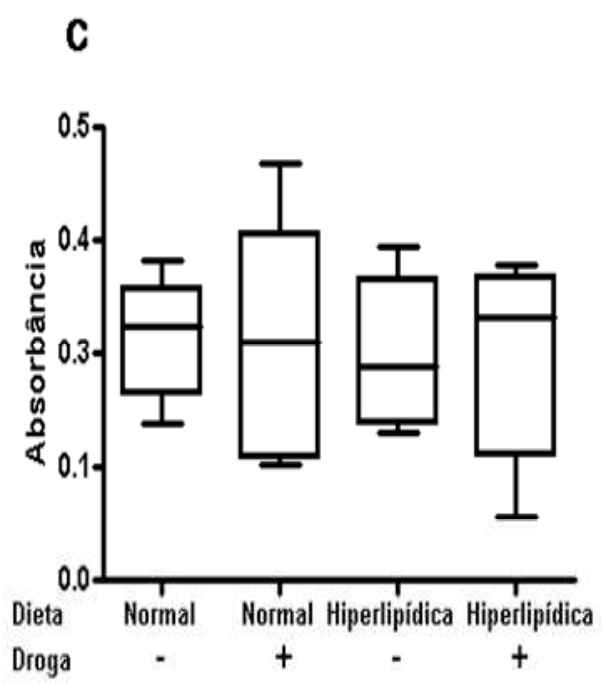

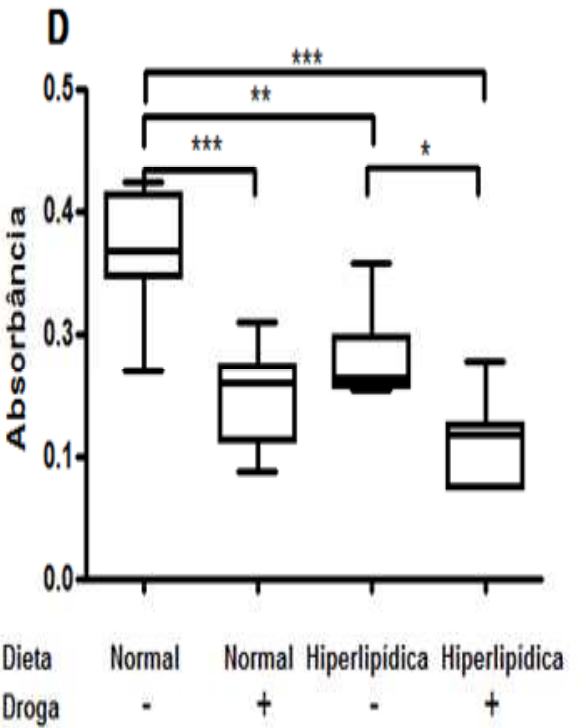

Figura 18. Níveis séricos de anticorpos anti-ox-LDL em diferentes tempos de experimento, em hamsteres submetidos a dieta normal ou hiperlipídica, com ou sem tratamento com a droga, inibidor de protease indinavir (6mg/dia), mantidas durante todo o período do experimento. Tempos: A) zero; B) primeiro mês; C) segundo mês $D)$ terceiro mês. ${ }^{*} P<0.05,{ }^{*} \mathrm{P}<0.01$, ${ }^{* * *} \mathrm{P}<0.001$ 

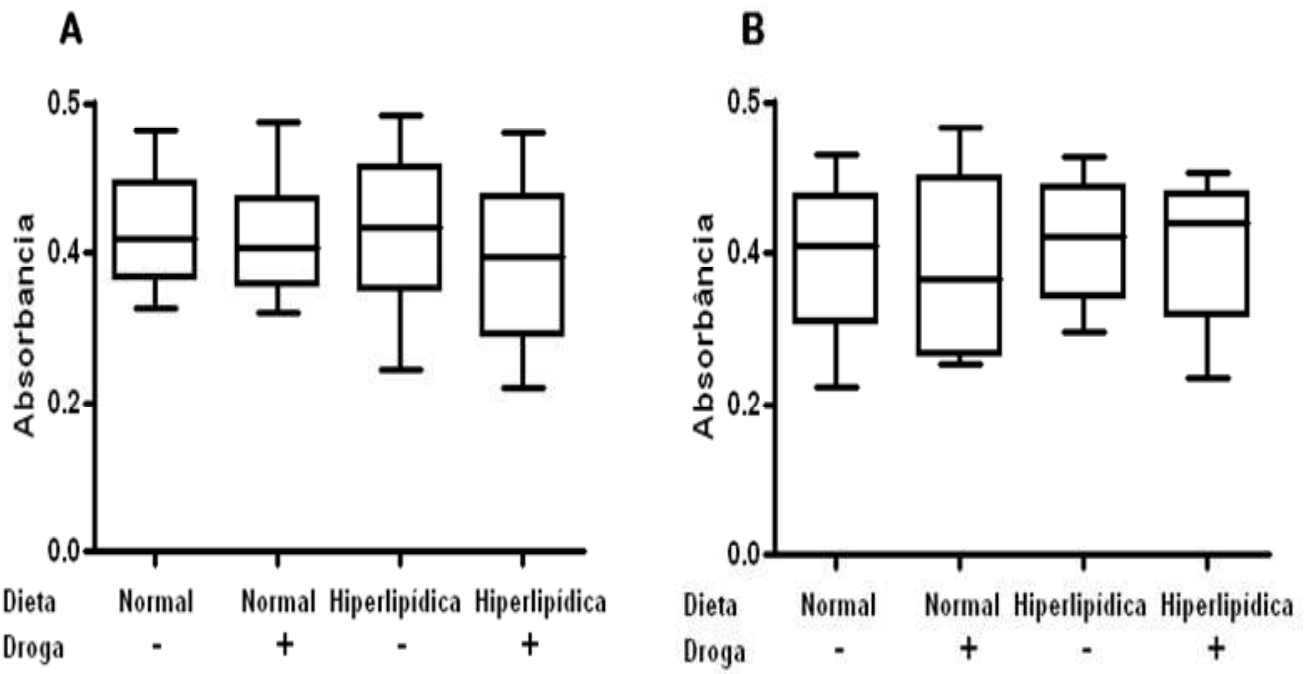

\section{C}

D
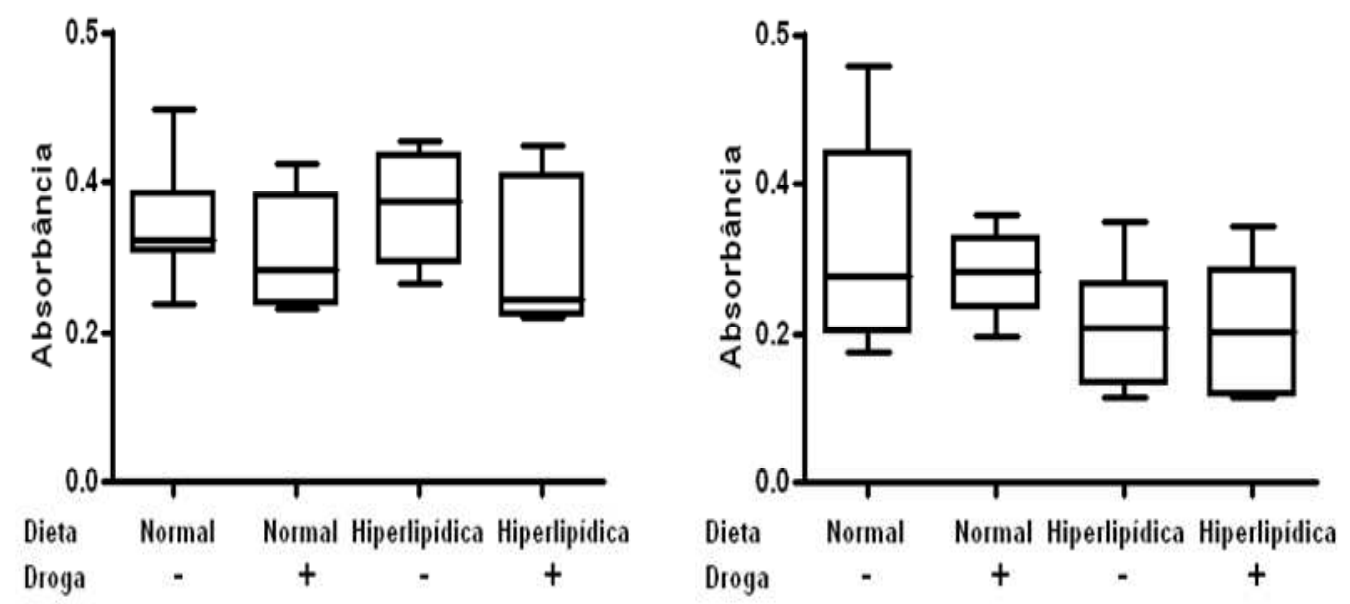

Figura 19. Níveis séricos de anticorpos anti-ox-pepD em diferentes tempos de experimento, em hamsteres submetidos a dieta normal ou hiperlipídica , com ou sem tratamento com a droga, inibidor de protease indinavir (6mg/dia), mantidas durante todo o período do experimento. Tempos: A) zero; B) primeiro mês; C) segundo mês D) terceiro mês. 
No experimento com indinavir na dose $12 \mathrm{mg} /$ dia, os níveis séricos de anticorpos anti-ox-LDL no primeiro mês de tratamento pôde ser observado um aumento significante no grupo sob dieta normal e tratados com indinavir em relação ao grupo submetido a dieta hiperlipídica e sem tratamento $(P<0.01)$. Não se notou diferença significativa no segundo mês de tratamento (Figura 20B e C).

Já no terceiro mês de tratamento, observou-se aumento significante do nível de anticorpo anti-ox-LDL no grupo sob dieta normal e sem tratamento quando comparado com todos os outros grupos (Figura 20D). No quarto mês do experimento, nos grupos que receberam dieta hiperlipídica, com e sem tratamento, observaram-se níveis significantemente diminuídos de anticorpos anti-ox-LDL em relação aos grupos sob dieta normal, independentemente da administração da droga ( $P<0.001)$ (Figura 20E).

Os níveis séricos de anticorpos anti-ox-pepD com indinavir na dose de $12 \mathrm{mg} /$ dia, não se diferiram entre os grupos no primeiro, segundo e terceiro mês do tratamento (Figura 21B, C e D). No quarto mês do experimento, nos grupos que receberam dieta hiperlipídica, com e sem tratamento, observaramse níveis significantemente diminuídos de anticorpos anti-ox-pepD em relação aos grupos sob dieta normal, independentemente da administração da droga $(P<0.001)$ (Figura 21E). 

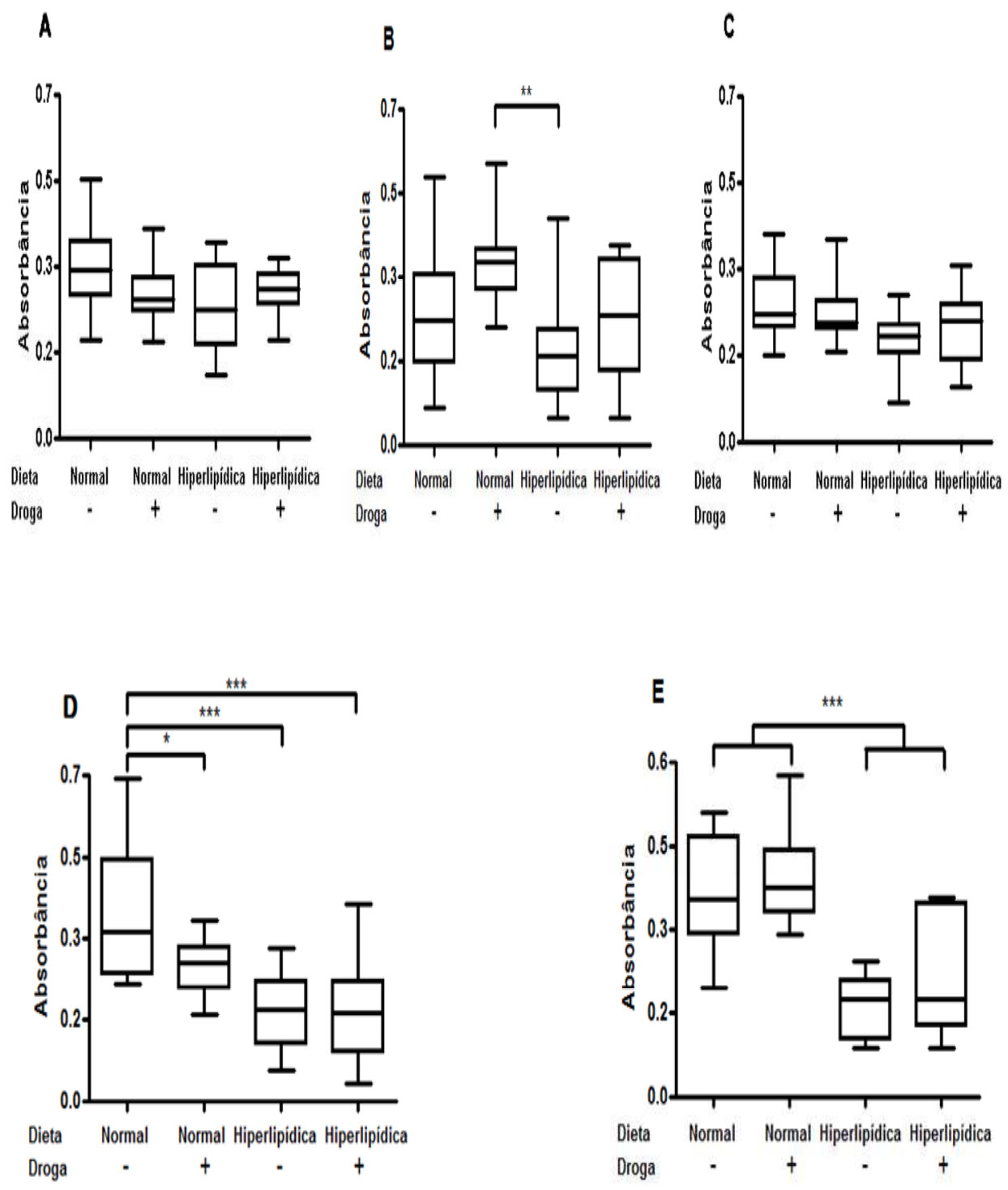

Figura 20. Níveis séricos de anticorpos anti-ox-LDL em diferentes tempos de experimento, em hamsteres submetidos a dieta normal ou hiperlipídica , com ou sem tratamento com a droga, inibidor de protease indinavir (12mg/dia), mantidas durante todo o período do experimento. Tempos: A) zero;B) primeiro mês;C)segundo mês;D)terceiro mês;E)quarto mês. ${ }^{*} P<0.05,{ }^{\star \star} P<0.01,{ }^{* \star *} P<0.001$. 

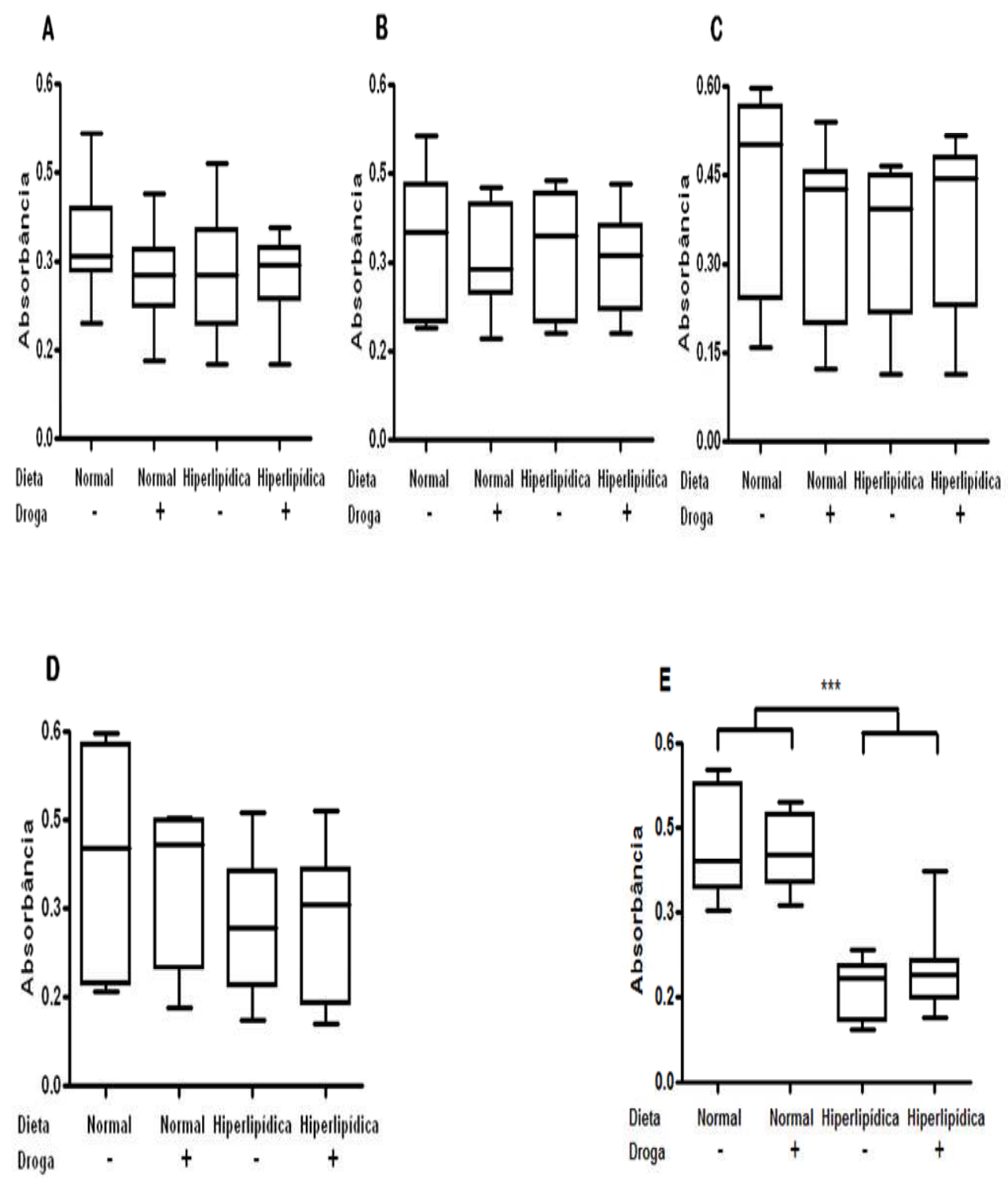

Figura 21. Níveis séricos de anticorpos anti-ox-pepD em diferentes tempos de experimento, em hamsteres submetidos a dieta normal ou hiperlipídica , com ou sem tratamento com a droga, inibidor de protease indinavir (12mg/dia), mantidas durante todo o período do experimento. Tempos: A) zero; B) primeiro mês; C) segundo mês; D) terceiro mês; E) quarto mês. ${ }^{* *} \mathrm{P}<0.001$. 
Níveis séricos de anticorpos anti-ox-LDL em hamsteres com indinavir na dose de $30 \mathrm{mg} / \mathrm{dia}$, não se diferiram entre os grupos nos dois primeiros meses (Figura 22B e C). Já no terceiro mês de tratamento, encontrou-se redução significante dos níveis de anticorpos nos animais sob tratamento com indinavir e submetidos à dieta normal $(P<0.05)$ ou dieta hiperlipídica $(P<0.01)$, em relação aos seus respectivos controles (Figura 22D). Também foi observada diferença significante entre os grupos submetidos à dieta normal e dieta hiperlipidica sem o tratamento com indinavir $(\mathrm{P}<0.01)$.

Os níveis séricos de anticorpos anti-ox-pepD em hamsteres com indinavir na dose de $30 \mathrm{mg} / \mathrm{dia}$, não se observou diferença significante entre os tratamentos nos diferentes tempos (Figura 23). 

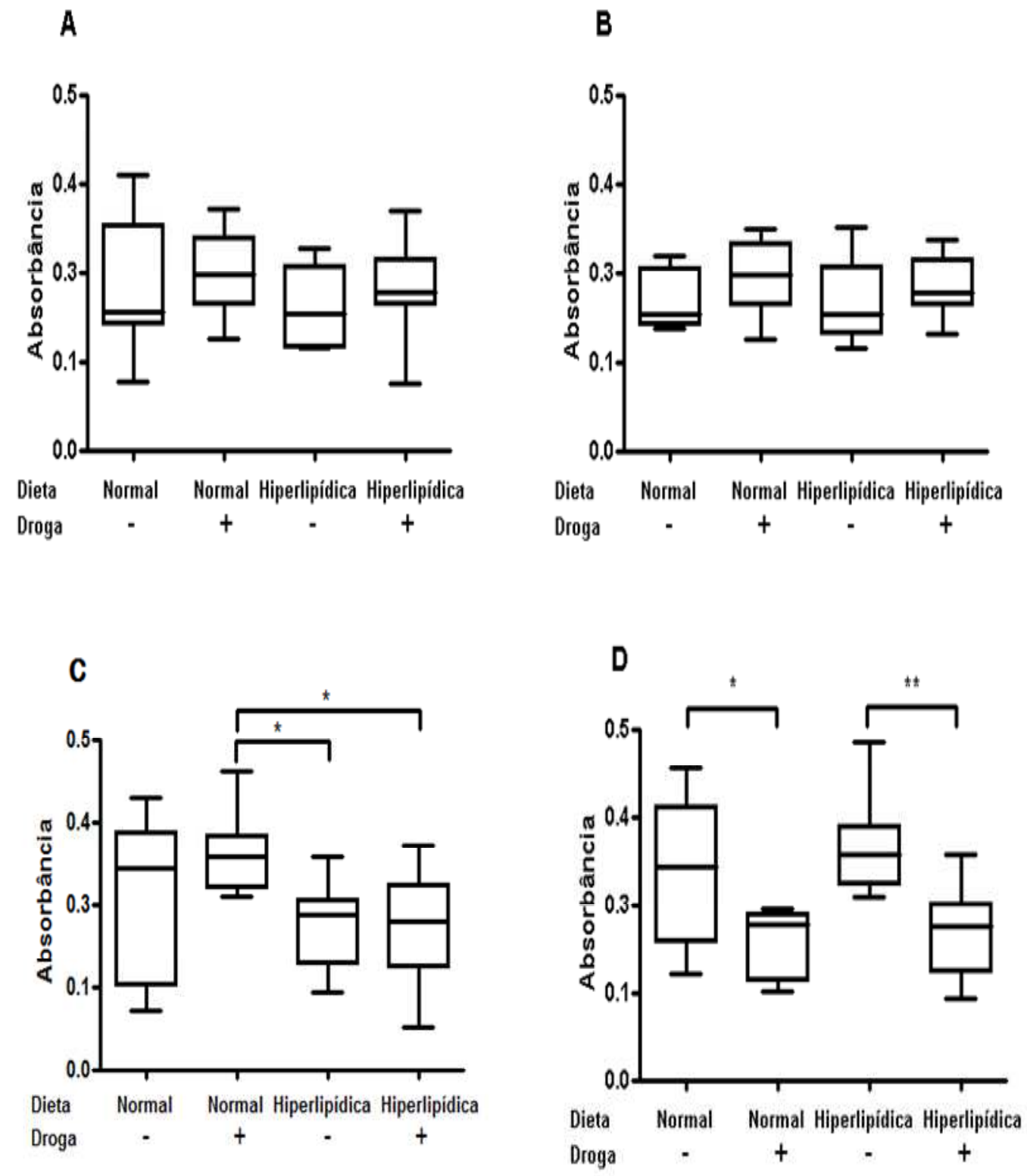

Figura 22. Níveis séricos de anticorpos anti-ox-LDL em diferentes tempos de experimento, em hamsteres submetidos a dieta normal ou hiperlipídica , com ou sem tratamento com a droga, inibidor de protease indinavir (30mg/dia), mantidas durante todo o período do experimento. Tempos: A) zero; B) primeiro mês; C) segundo mês; D) terceiro mês. ${ }^{*} P<0.05$, ${ }^{* *} \mathrm{P}<0.01$. 
A

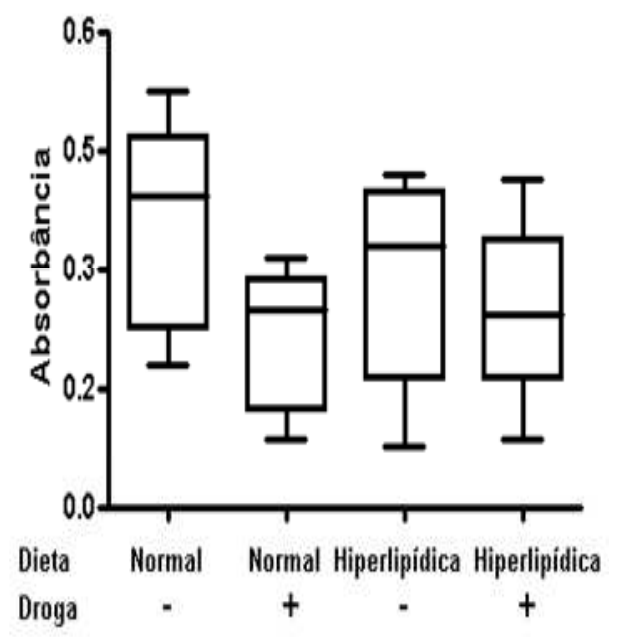

C

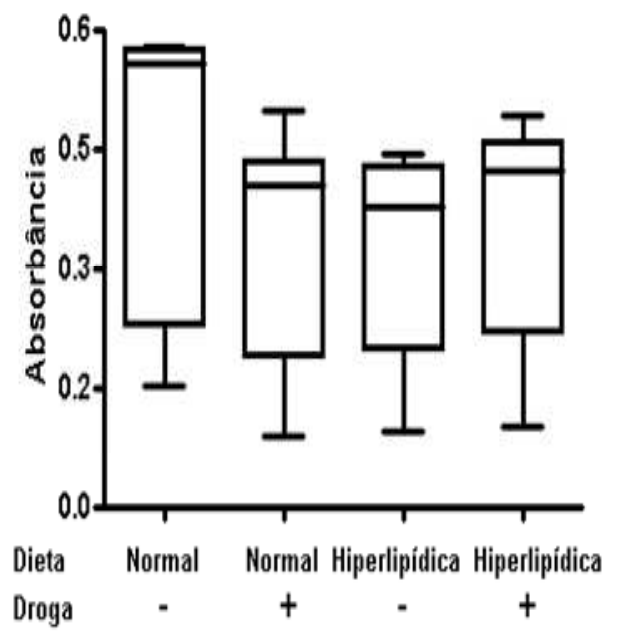

B

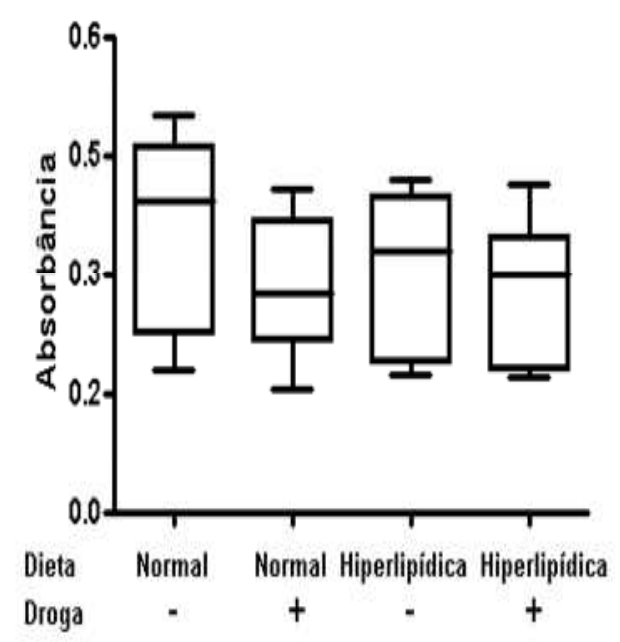

D

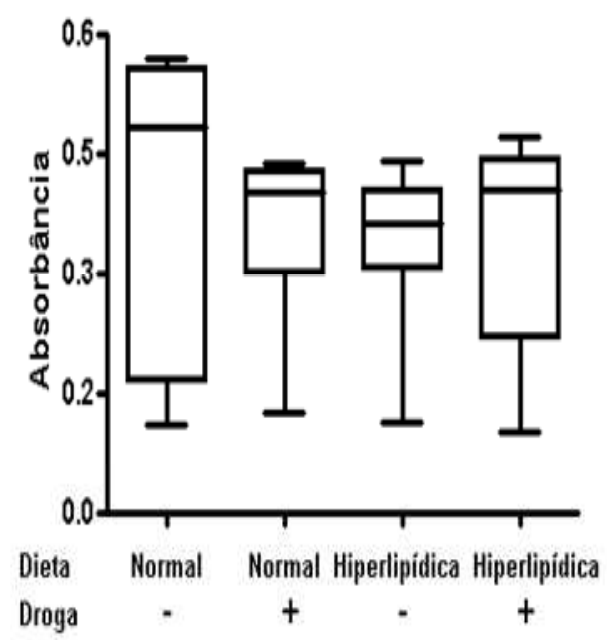

Figura 23. Níveis séricos de anticorpos anti-ox-pepD em diferentes tempos de experimento, em hamsteres submetidos a dieta normal ou hiperlipídica , com ou sem tratamento com a droga, inibidor de protease indinavir (30 mg/dia), mantidas durante todo o período do experimento. Tempos: A) zero; B) primeiro mês; C) segundo mês; D) terceiro mês. 
4.10 Análise das concentrações plasmáticas de glicose, uréia, creatinina, aspartato transaminase, alanina transaminase, gama glutamil transferase, triglicérides, colesterol, lipoproteína de baixa densidade e da lipoproteína de alta densidade

Os dados das concentrações plasmáticas de glicose, uréia, creatinina, aspartato transaminase, alanina transaminase, gama glutamil transferase, triglicérides, colesterol, lipoproteína de baixa densidade e da lipoproteína de alta densidade nos diferentes momentos estão apresentados nas tabelas 1 a 4. 
Tabela 1. Valores basais das concentrações plasmáticas nos diferentes grupos.

\begin{tabular}{c|c|c|c|c}
\hline & G1 & G2 & G3 & G4 \\
\hline Glicose & $136,9 \pm 13,69^{\mathrm{a}}$ & $133 \pm 15,67^{\mathrm{a}}$ & $118,8 \pm 11,94^{\mathrm{a}}$ & $123,4 \pm 18,49^{\mathrm{a}}$ \\
\hline Uréia & $46,03 \pm 5,17^{\mathrm{a}}$ & $51,28 \pm 6,63^{\mathrm{a}}$ & $49,26 \pm 5,64^{\mathrm{a}}$ & $51,92 \pm 5,35^{\mathrm{a}}$ \\
\hline Creatinina & $0,303 \pm 0,056^{\mathrm{a}}$ & $0,245 \pm 0,034^{\mathrm{a}}$ & $0,312 \pm 0,074^{\mathrm{a}}$ & $0,27 \pm 0,059^{\mathrm{a}}$ \\
\hline Colesterol & $113 \pm 22,27^{\mathrm{a}}$ & $110,9 \pm 9,562^{\mathrm{a}}$ & $106,4 \pm 9,501^{\mathrm{a}}$ & $103,3 \pm 16,64^{\mathrm{a}}$ \\
\hline AST & $27,95 \pm 14,27^{\mathrm{a}}$ & $29,01 \pm 9,639^{\mathrm{a}}$ & $22,57 \pm 4,985^{\mathrm{a}}$ & $31,78 \pm 13,99^{\mathrm{a}}$ \\
\hline HDL & $61,29 \pm 5,504^{\mathrm{a}}$ & $67,22 \pm 8,831^{\mathrm{a}}$ & $65,54 \pm 7,534^{\mathrm{a}}$ & $61,82 \pm 13,18^{\mathrm{a}}$ \\
\hline LDL & $16,37 \pm 22,2^{\mathrm{a}}$ & $11,45 \pm 8,198^{\mathrm{a}}$ & $7,403 \pm 5,991^{\mathrm{a}}$ & $9,881 \pm 7,256^{\mathrm{a}}$ \\
\hline Triglicerides & $146.8 \pm 46.29^{\mathrm{a}}$ & $124.3 \pm 18.36^{\mathrm{a}}$ & $152.3 \pm 62.73^{\mathrm{a}}$ & $101.5 \pm 32.62^{\mathrm{a}}$ \\
\hline GGT & $4.111 \pm 4.556^{\mathrm{a}}$ & $3.711 \pm 2.095^{\mathrm{a}}$ & $2.64 \pm 1.307^{\mathrm{a}}$ & $3.24 \pm 1.949^{\mathrm{a}}$ \\
\hline ALT & $46,02 \pm 15,89^{\mathrm{a}}$ & $46,69 \pm 19,00^{\mathrm{a}}$ & $52,33 \pm 16,38^{\mathrm{a}}$ & $59,38 \pm 35,18^{\mathrm{a}}$ \\
\hline
\end{tabular}

Letras diferentes indicam $\mathrm{P}<0,05$

G1: dieta Balanceada

G2: dieta Balanceada + indinavir $30 \mathrm{mg} / \mathrm{dia}$

G3: dieta hiperlipêmica

G4: dieta hiperlipêmica + indinavir $30 \mathrm{mg} / \mathrm{dia}$

AST: aspartato transaminase

HDL: lipoproteína de alta densidade

LDL: lipoproteína de baixa densidade

GGT: gama glutamil transferase

ALT: alanina transaminase 
Tabela 2. Valores das concentrações plasmáticas após o primeiro mês de tratamento nos diferentes grupos.

\begin{tabular}{c|c|c|c|c}
\hline & G1 & G2 & G3 & G4 \\
\hline Glicose & $92.33+/-6.543^{\mathrm{a}}$ & $94.15+/-7.493^{\mathrm{a}}$ & $98.42+/-14.4^{\mathrm{ab}}$ & $111+/-17.82^{\mathrm{b}}$ \\
\hline Uréia & $42,94 \pm 4,29^{\mathrm{a}}$ & $36,36 \pm 4,48^{\mathrm{ab}}$ & $27,59 \pm 8,41^{\mathrm{c}}$ & $29,82 \pm 8,77^{\mathrm{bc}}$ \\
\hline Creatinina & $0,251 \pm 0,067^{\mathrm{ab}}$ & $0,256 \pm 0,039^{\mathrm{ab}}$ & $0,296 \pm 0,041^{\mathrm{a}}$ & $0,208 \pm 0,057^{\mathrm{b}}$ \\
\hline Colesterol & $113,3 \pm 54,14^{\mathrm{a}}$ & $87,85 \pm 9,59^{\mathrm{a}}$ & $212,5 \pm 25,99^{\mathrm{b}}$ & $261,5 \pm 60,25^{\mathrm{b}}$ \\
\hline AST & $28,48 \pm 6,75^{\mathrm{ac}}$ & $20,5 \pm 6,98^{\mathrm{ab}}$ & $27,46 \pm 7,24^{\mathrm{ac}}$ & $35,48 \pm 15,46^{\mathrm{c}}$ \\
\hline HDL & $54,33 \pm 20^{\mathrm{a}}$ & $45,03 \pm 7,65^{\mathrm{a}}$ & $76,9 \pm 12,11^{\mathrm{b}}$ & $82,45 \pm 13,75^{\mathrm{b}}$ \\
\hline LDL & $26,63 \pm 33,23^{\mathrm{a}}$ & $17,84 \pm 4,29^{\mathrm{a}}$ & $75,01 \pm 29,51^{\mathrm{b}}$ & $102,2 \pm 41,77^{\mathrm{b}}$ \\
\hline Triglicerides & $222.6 \pm 21.81^{\mathrm{a}}$ & $229.3 \pm 22.98^{\mathrm{a}}$ & $216.8 \pm 35.54^{\mathrm{a}}$ & $243.7 \pm 39.88^{\mathrm{a}}$ \\
\hline GGT & $2.725 \pm 0.8172^{\mathrm{a}}$ & $5.018 \pm 2.802^{\mathrm{a}}$ & $2.113 \pm 1.222^{\mathrm{a}}$ & $42.51 \pm 24.53^{\mathrm{b}}$ \\
\hline ALT & $40,45 \pm 13,74^{\mathrm{a}}$ & $35,25 \pm 14,47^{\mathrm{a}}$ & $27,79 \pm 17,41^{\mathrm{a}}$ & $68,6 \pm 27,23^{\mathrm{b}}$ \\
\hline
\end{tabular}

Letras diferentes indicam $\mathrm{P}<0,05$

G1: dieta Balanceada

G2: dieta Balanceada + indinavir $30 \mathrm{mg} / \mathrm{dia}$

G3: dieta hiperlipêmica

G4: dieta hiperlipêmica + indinavir $30 \mathrm{mg} / \mathrm{dia}$

AST: aspartato transaminase

HDL: lipoproteína de alta densidade

LDL: lipoproteína de baixa densidade

GGT: gama glutamil transferase

ALT: alanina transaminase 
Tabela 3. Valores das concentrações plasmáticas após o segundo mês de tratamento nos diferentes grupos.

\begin{tabular}{c|c|c|c|c}
\hline & G1 & G2 & G3 & G4 \\
\hline Glicose & $87,48 \pm 12,46^{\mathrm{a}}$ & $96,52 \pm 13,43^{\mathrm{ab}}$ & $92,46 \pm 11,45^{\mathrm{a}}$ & $110,6 \pm 13,2^{\mathrm{b}}$ \\
\hline Uréia & $43,2 \pm 7,24^{\mathrm{a}}$ & $42,16 \pm 4,10^{\mathrm{a}}$ & $32,96 \pm 5,97^{\mathrm{a}}$ & $37,38 \pm 11,96^{\mathrm{a}}$ \\
\hline Creatinina & $0,195 \pm 0,039^{\mathrm{a}}$ & $0,285 \pm 0,035^{\mathrm{bc}}$ & $0,24 \pm 0,034^{\mathrm{ac}}$ & $0,263 \pm 0,051^{\mathrm{bc}}$ \\
\hline Colesterol & $107,3 \pm 18,04^{\mathrm{a}}$ & $92,43 \pm 10,16^{\mathrm{a}}$ & $324 \pm 72,32^{\mathrm{b}}$ & $316,8 \pm 68,16^{\mathrm{b}}$ \\
\hline AST & $25,85 \pm 5,67^{\mathrm{a}}$ & $25,55 \pm 4,15^{\mathrm{a}}$ & $25,12 \pm 13,70^{\mathrm{a}}$ & $37,75 \pm 13,9^{\mathrm{a}}$ \\
\hline HDL & $53,78 \pm 12,53^{\mathrm{a}}$ & $47,43 \pm 7,50$ & $83,18 \pm 14,71^{\mathrm{b}}$ & $91,21 \pm 18,8^{\mathrm{b}}$ \\
\hline LDL & $23,55 \pm 18,03^{\mathrm{a}}$ & $15,05 \pm 6,78^{\mathrm{a}}$ & $181,6 \pm 78,93^{\mathrm{b}}$ & $155,6 \pm 51,72^{\mathrm{b}}$ \\
\hline Triglicerides & $140.8 \pm 23.14^{\mathrm{a}}$ & $191.9 \pm 44.97^{\mathrm{ab}}$ & $262.1 \pm 52.79^{\mathrm{bc}}$ & $321.7 \pm 95.05^{\mathrm{c}}$ \\
\hline GGT & $5 \pm 2.734^{\mathrm{a}}$ & $3.32 \pm 1.76^{\mathrm{a}}$ & $8.413 \pm 3.116^{\mathrm{a}}$ & $53.56 \pm 33.06^{\mathrm{a}}$ \\
\hline ALT & $38,68 \pm 12,73^{\mathrm{a}}$ & $44,29 \pm 12,14^{\mathrm{a}}$ & $71,63 \pm 20,01^{\mathrm{b}}$ & $65,33 \pm 4,25^{\mathrm{a}}$ \\
\hline
\end{tabular}

Letras diferentes indicam $\mathrm{P}<0,05$

G1: dieta Balanceada

G2: dieta Balanceada + indinavir 30 mg/dia

G3: dieta hiperlipêmica

G4: dieta hiperlipêmica + indinavir $30 \mathrm{mg} /$ dia

AST: aspartato transaminase

HDL: lipoproteína de alta densidade

LDL: lipoproteína de baixa densidade

GGT: gama glutamil transferase

ALT: alanina transaminase 
Tabela 4. Valores das concentrações plasmáticas após o terceiro mês de tratamento nos diferentes grupos.

\begin{tabular}{c|c|c|c|c}
\hline & G1 & G2 & G3 & G4 \\
\hline Glicose & $77,74 \pm 6,20^{\mathrm{a}}$ & $92,87 \pm 8,71^{\mathrm{b}}$ & $90,89 \pm 9,71^{\mathrm{ab}}$ & $107,5 \pm 16,59^{\mathrm{c}}$ \\
\hline Uréia & $46,3 \pm 8,56^{\mathrm{a}}$ & $46,69 \pm 4,2^{\mathrm{a}}$ & $29,03 \pm 7,37^{\mathrm{b}}$ & $30,59 \pm 13,42^{\mathrm{b}}$ \\
\hline Creatinina & $0,254 \pm 0,048^{\mathrm{a}}$ & $0,26 \pm 0,017^{\mathrm{ab}}$ & $0,316 \pm 0,034^{\mathrm{b}}$ & $0,281 \pm 0,070^{\mathrm{ab}}$ \\
\hline Colesterol & $88,14 \pm 17,28^{\mathrm{a}}$ & $99,6 \pm 14,52^{\mathrm{a}}$ & $257,2 \pm 32,16^{\mathrm{b}}$ & $318 \pm 60,18^{\mathrm{c}}$ \\
\hline AST & $15,5 \pm 5,77^{\mathrm{a}}$ & $30,29 \pm 9,05^{\mathrm{b}}$ & $7,06 \pm 7,83^{\mathrm{a}}$ & $32,41 \pm 7,91^{\mathrm{b}}$ \\
\hline HDL & $45,42 \pm 13,29^{\mathrm{a}}$ & $51,18 \pm 5,50^{\mathrm{a}}$ & $88,88 \pm 13,46^{\mathrm{b}}$ & $106,7 \pm 25,96^{\mathrm{b}}$ \\
\hline LDL & $17,60 \pm 15,20^{\mathrm{a}}$ & $16,6 \pm 6,68^{\mathrm{a}}$ & $119,3 \pm 25,14^{\mathrm{b}}$ & $127,2 \pm 24,83^{\mathrm{b}}$ \\
\hline Triglicerides & $160 \pm 14.92^{\mathrm{a}}$ & $233 \pm 55.38^{\mathrm{b}}$ & $272.1 \pm 35.91^{\mathrm{b}}$ & $351.7 \pm 83.62^{\mathrm{c}}$ \\
\hline GGT & $4.129 \pm 3.269^{\mathrm{ac}}$ & $0.85 \pm 0.9006^{\mathrm{a}}$ & $6.311 \pm 3.371^{\mathrm{ac}}$ & $14.34 \pm 16.39^{\mathrm{ac}}$ \\
\hline ALT & $35,44 \pm 13,04^{\mathrm{a}}$ & $49,86 \pm 5,62^{\mathrm{ab}}$ & $57,85 \pm 18,17^{\mathrm{b}}$ & $54,12 \pm 19,27^{\mathrm{ab}}$ \\
\hline
\end{tabular}

Letras diferentes indicam $\mathrm{P}<0,05$

G1: dieta Balanceada

G2: dieta Balanceada + indinavir $30 \mathrm{mg} / \mathrm{dia}$

G3: dieta hiperlipêmica

G4: dieta hiperlipêmica + indinavir $30 \mathrm{mg} / \mathrm{dia}$

AST: aspartato transaminase

HDL: lipoproteína de alta densidade

LDL: lipoproteína de baixa densidade

GGT: gama glutamil transferase

ALT: alanina transaminase 


\subsection{Alteração cardíaca}

O eletrocardiograma de hamster apresenta um traçado diferente do humano, com intervalo $\mathrm{PQ}$ menor e o complexo QRS tendendo ao alargamento, nos limites do 0,12 mseg (Figura 24).

Os animais sob dieta normal que receberam indinavir apresentaram alargamento do complexo QRS, evidentes nas derivações D1, aVR e aVL (Figura 25) ou desnivelamento do segmento ST nas derivações D2, D3 e aVF (Figura 26).

Nos animais sob dieta hiperlipídica não se observou diferença em relação ao traçado no tempo basal (Figura 27).

Os animais sob dieta hiperlipídica que receberam indinavir apresentaram alterações mais acentuadas, com alargamento do complexo QRS, evidentes nas derivações $\mathrm{D} 1$ e aVL e desnivelamento do segmento ST nas derivações D2, D3 e aVF (Figuras 28Ae B).

Estas alterações foram confirmadas por histopatologia na coloração específica de Masson mostrando fibrose e confirmando áreas inativas no coração (Figura 29). Porém, sinais de aterosclerose não foram identificados.

Não foram observadas mudanças na anatomia (histopatologia) da aorta na coloração HE aumento do microscópio $40 \mathrm{X}$ nem acúmulo de gordura na coloração específica para marcar lipídeos Oil-red (Figura 30), nos grupos de animais alimentados com dieta normal e tratados com a droga (indinavir) e dieta Hiperlipídica tratados com droga (indinavir), o que nos diz que não tem presença e desenvolvimento de aterosclerose, o que não era esperado, pois segundo a literatura os IPs aumentam aterosclerose ou a aceleram. 

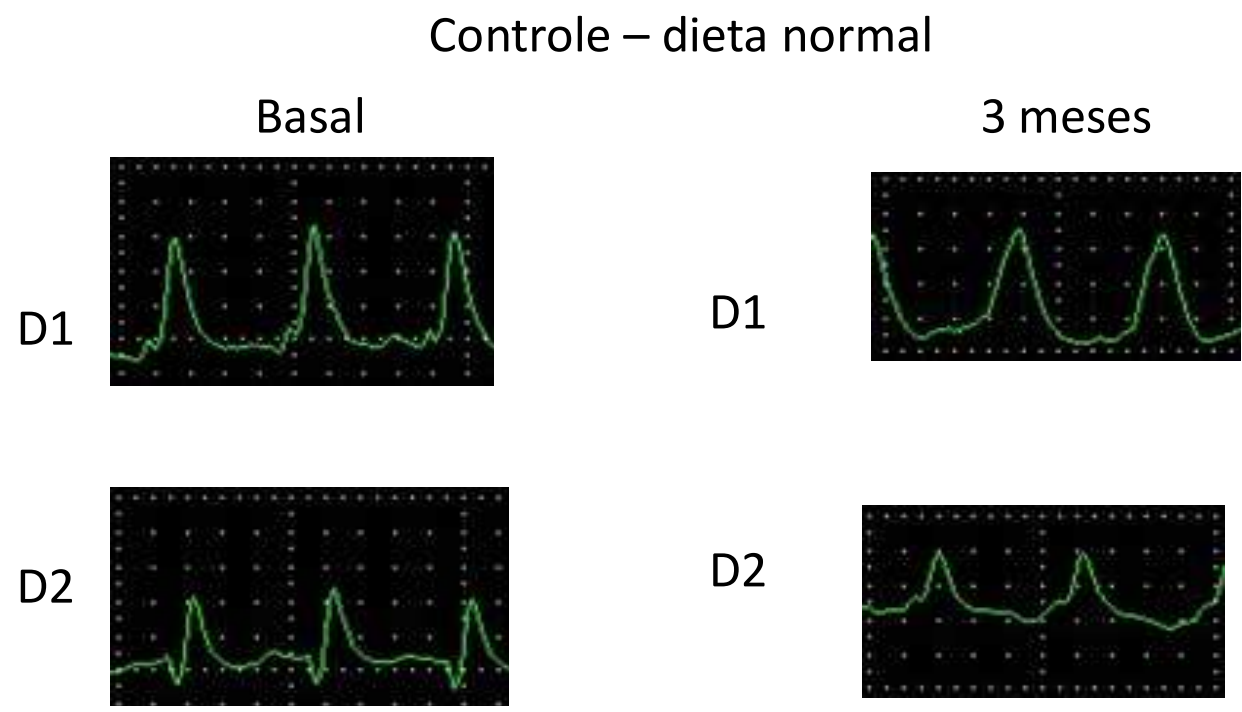

D2
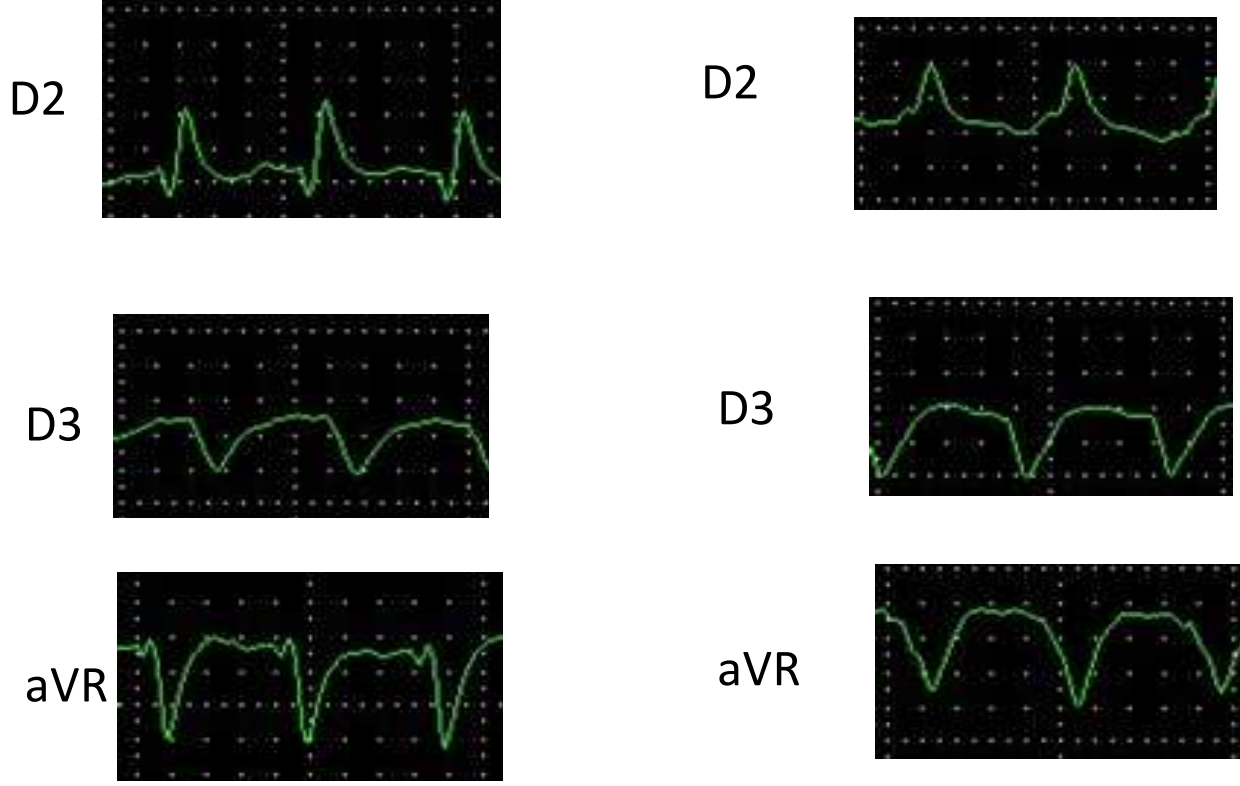

D3
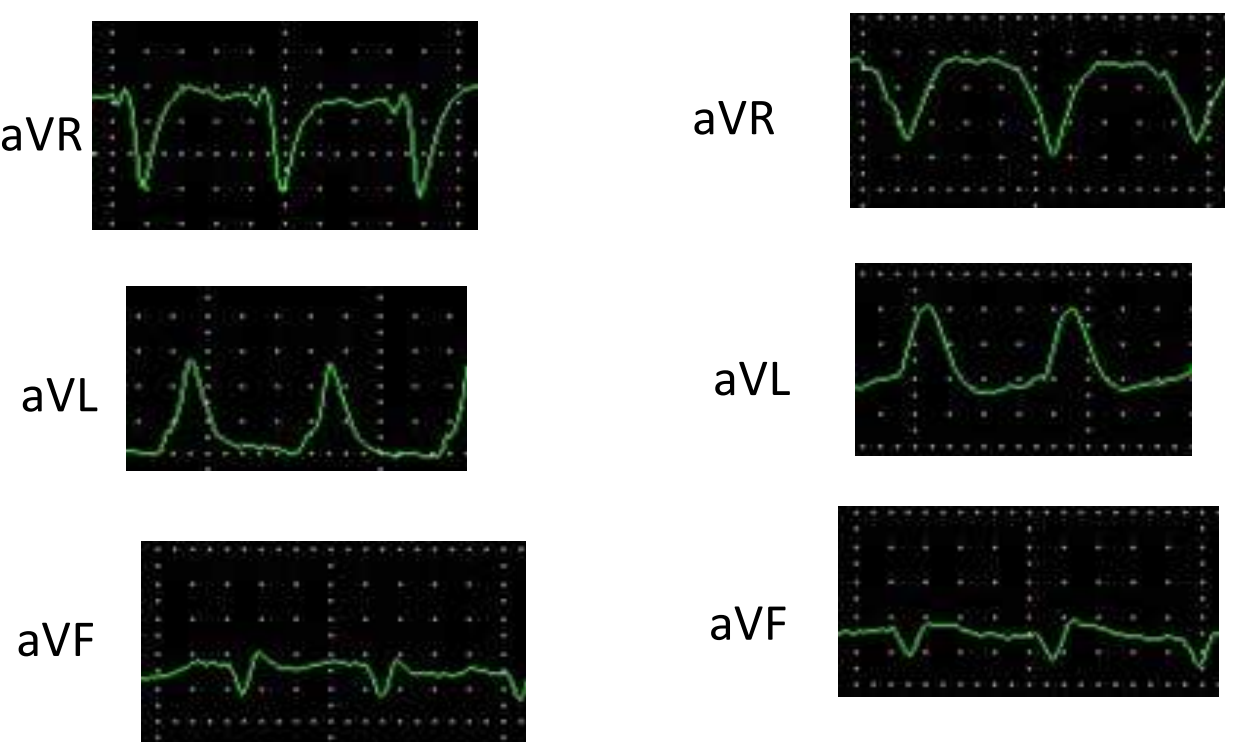

aVF

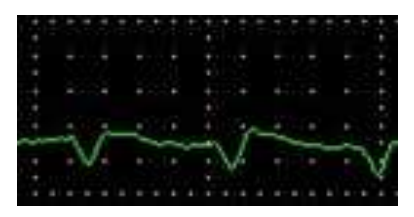

Figura 24. Eletrocardiograma de animal representativo do grupo controle dieta normal. 
Tratado com indinavir - dieta normal

Basal

D1

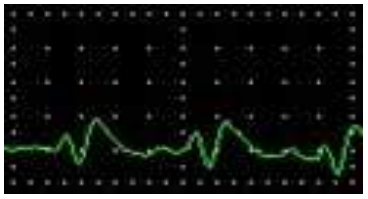

D2

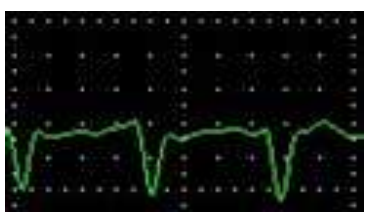

D3

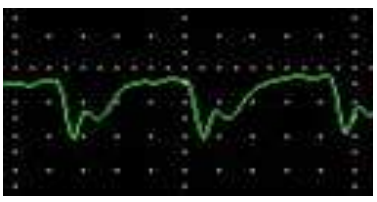

$\mathrm{aVR}$

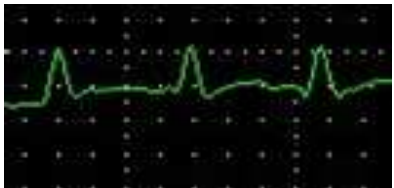

$\mathrm{aVL}$

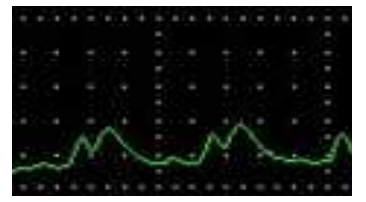

aVF

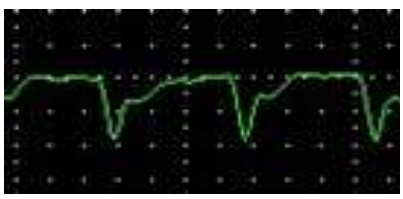

3 meses

D1

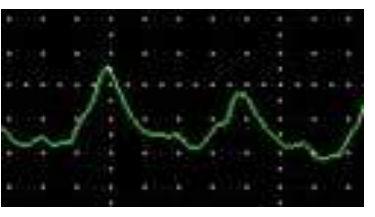

D2

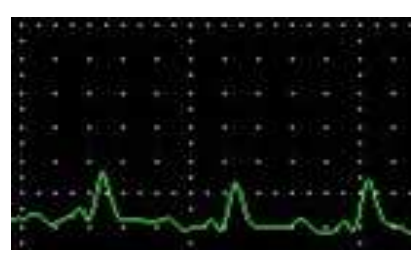

D3

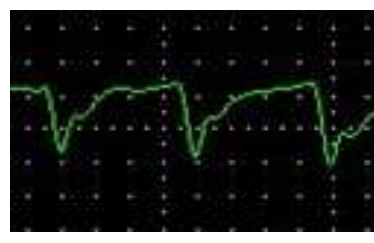

aVR

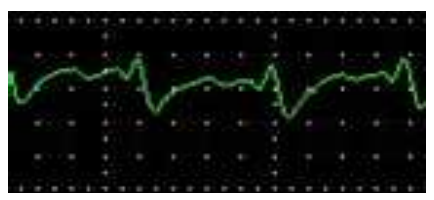

$\mathrm{aVL}$

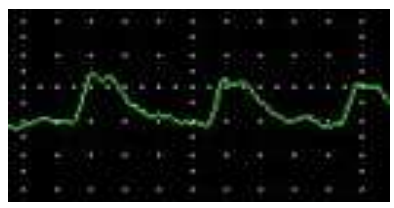

aVF

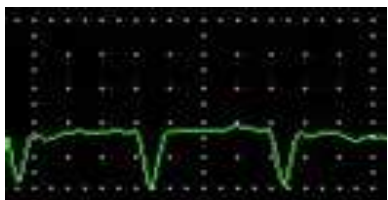

Figura 25. Eletrocardiograma de animal representativo do grupo submetido a dieta normal e sob tratamento com indinavir. 
Tratado com Indinavir- dieta normal

Basal

D1

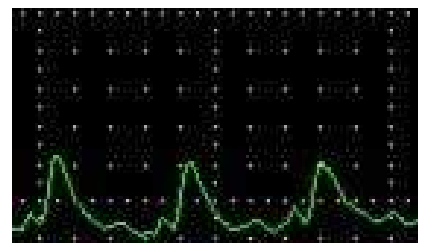

D2

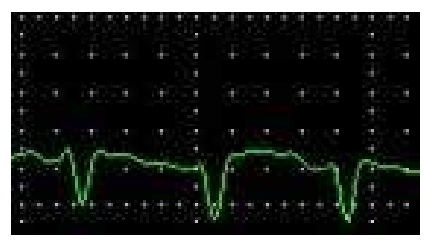

D2

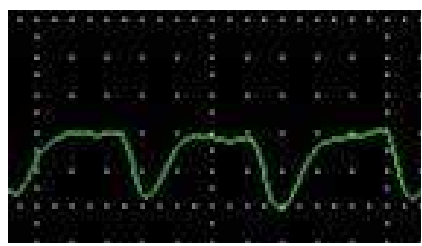

D3
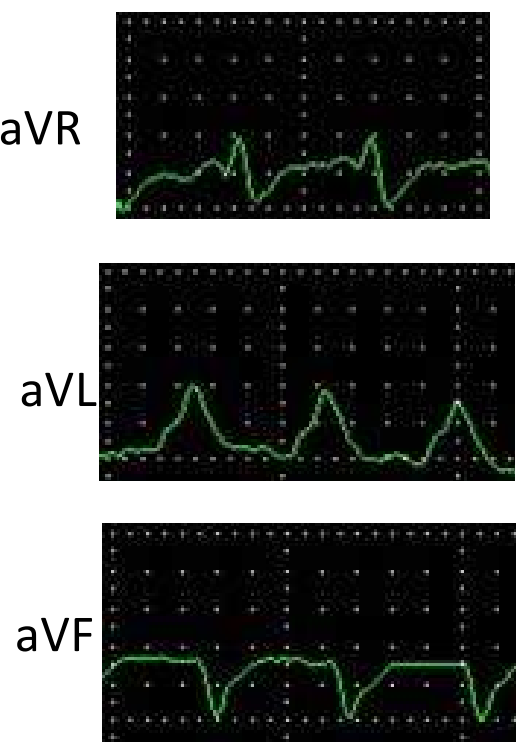

D1

3 meses
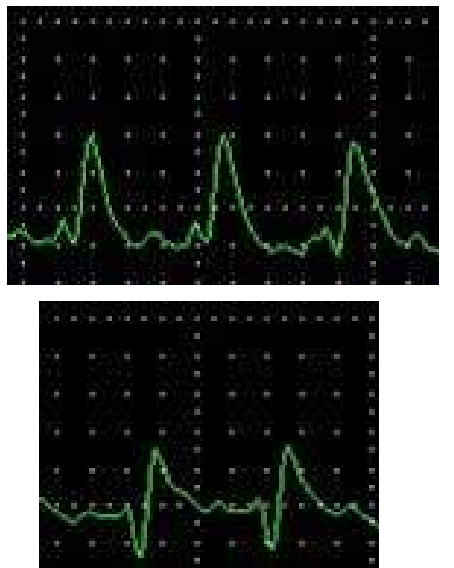

D3

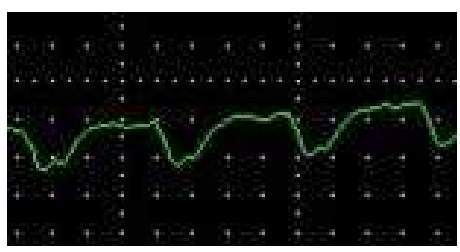

$\mathrm{aVR}$

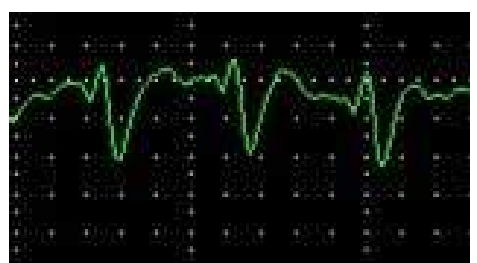

$\mathrm{aVL}$

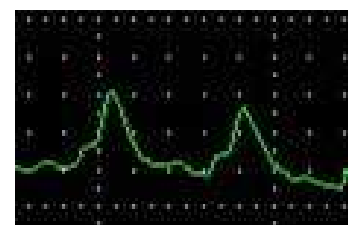

aVF

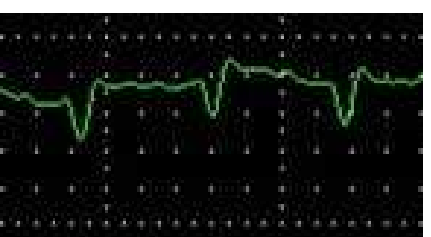

Figura 26. Eletrocardiograma de animal representativo do grupo submetido a dieta normal e tratado com indinavir. 
Controle - dieta hiperlipídica

Basal

D1

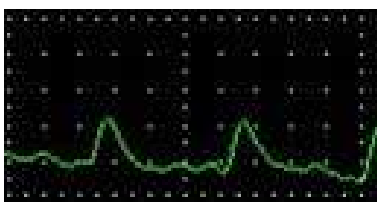

D2

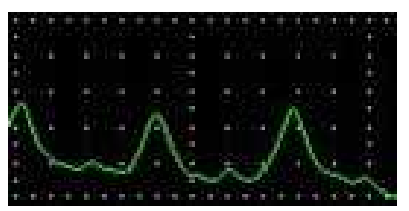

D1

D2

D3

D3

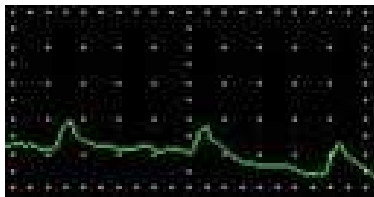

aVR

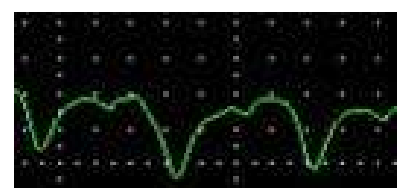

aVR

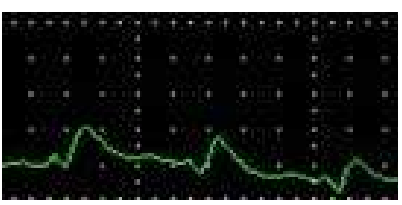

aVL

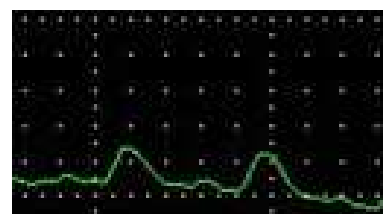

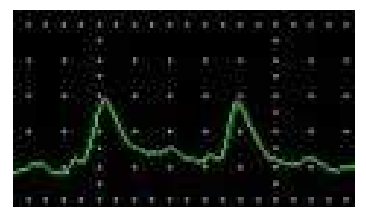

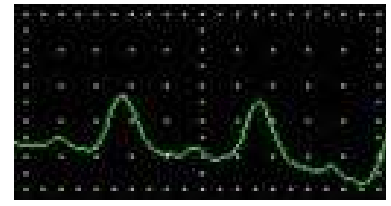

$\mathrm{aVL}$

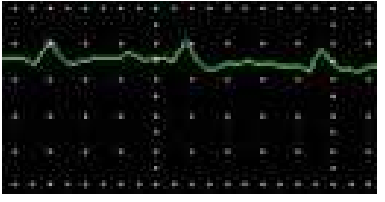

3 meses

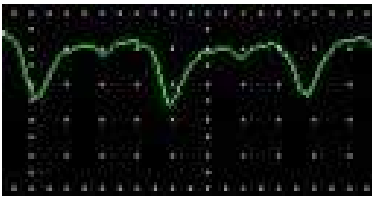

aVF
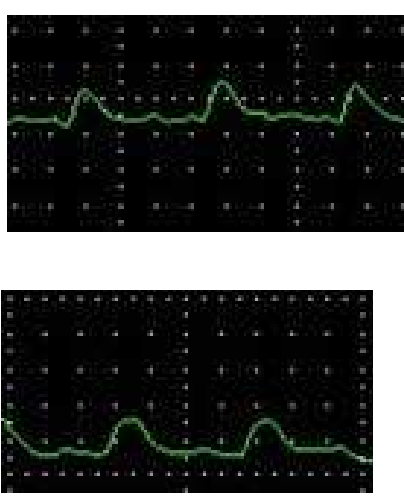

Figura 27. Eletrocardiograma de animal representativo do grupo controle dieta hiperlipídica. 
Tratado com Indinavir- dieta hiperlipídica

Basal

D1
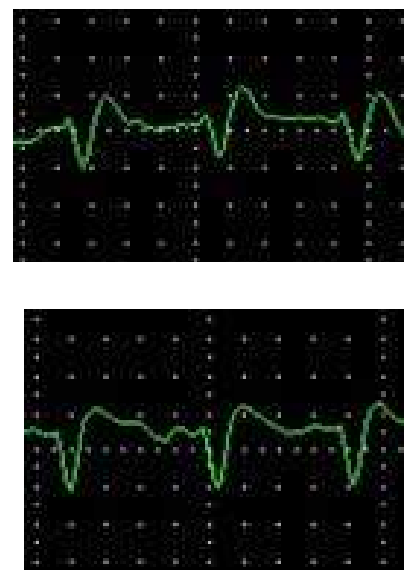

D2

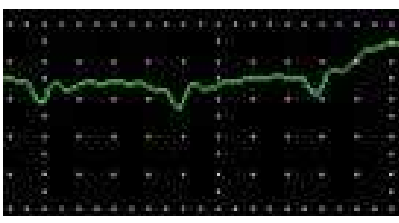

D3

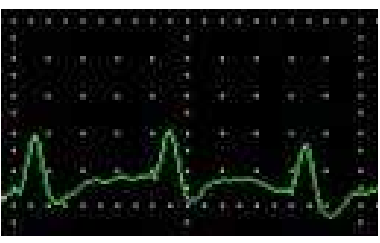

aVL

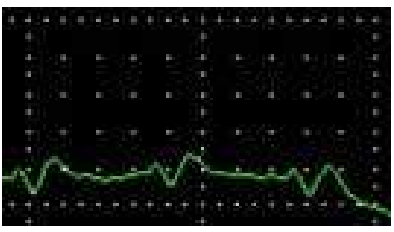

aVF

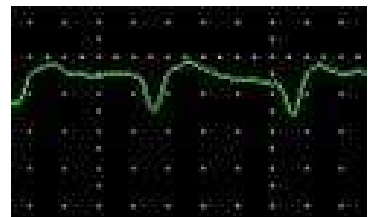

D1

3 meses

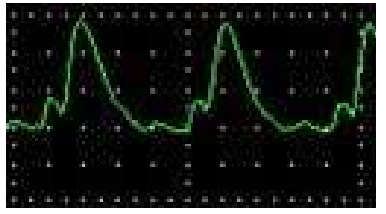

D2

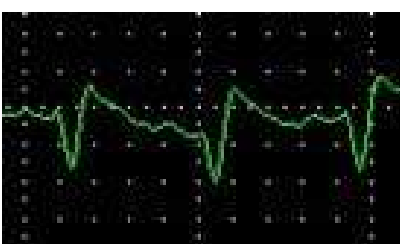

D3

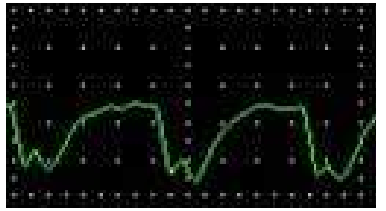

$\mathrm{aVR}$

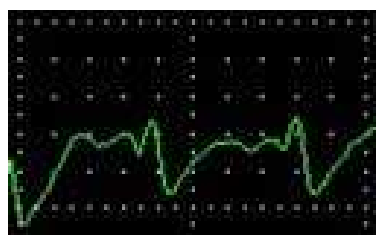

$\mathrm{aVL}$

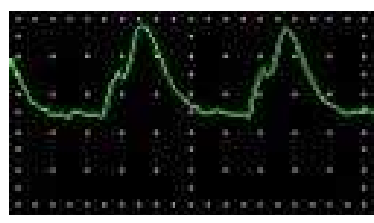

aVF

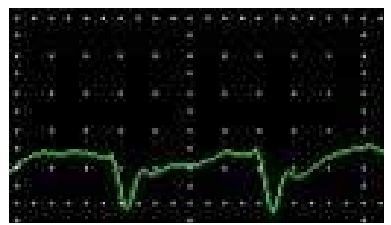

Figura 28A. Eletrocardiograma de animal representativo do grupo submetido a dieta hiperlipídica e tratado com indinavir. 
Tratado com Indinavir- dieta hiperlipídica

Basal

D1

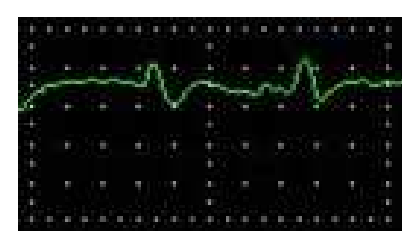

D1

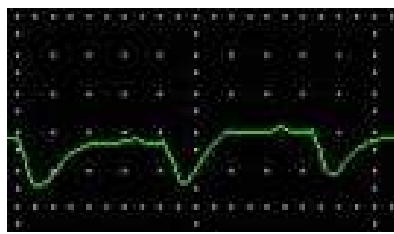

D2

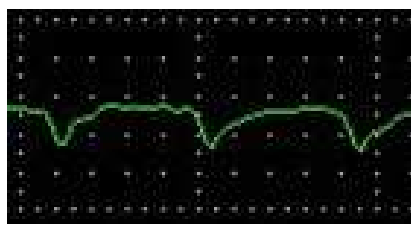

D3

D2

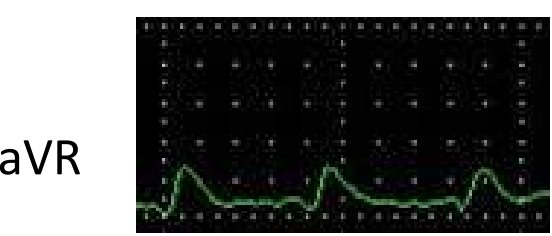

aVR

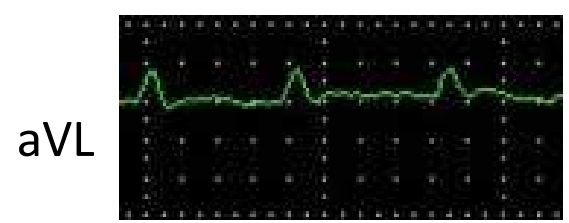

aVR

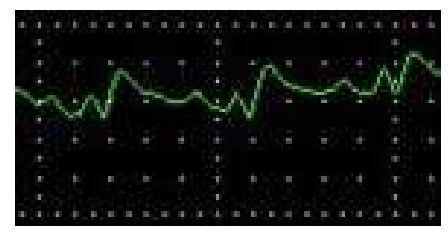

D3
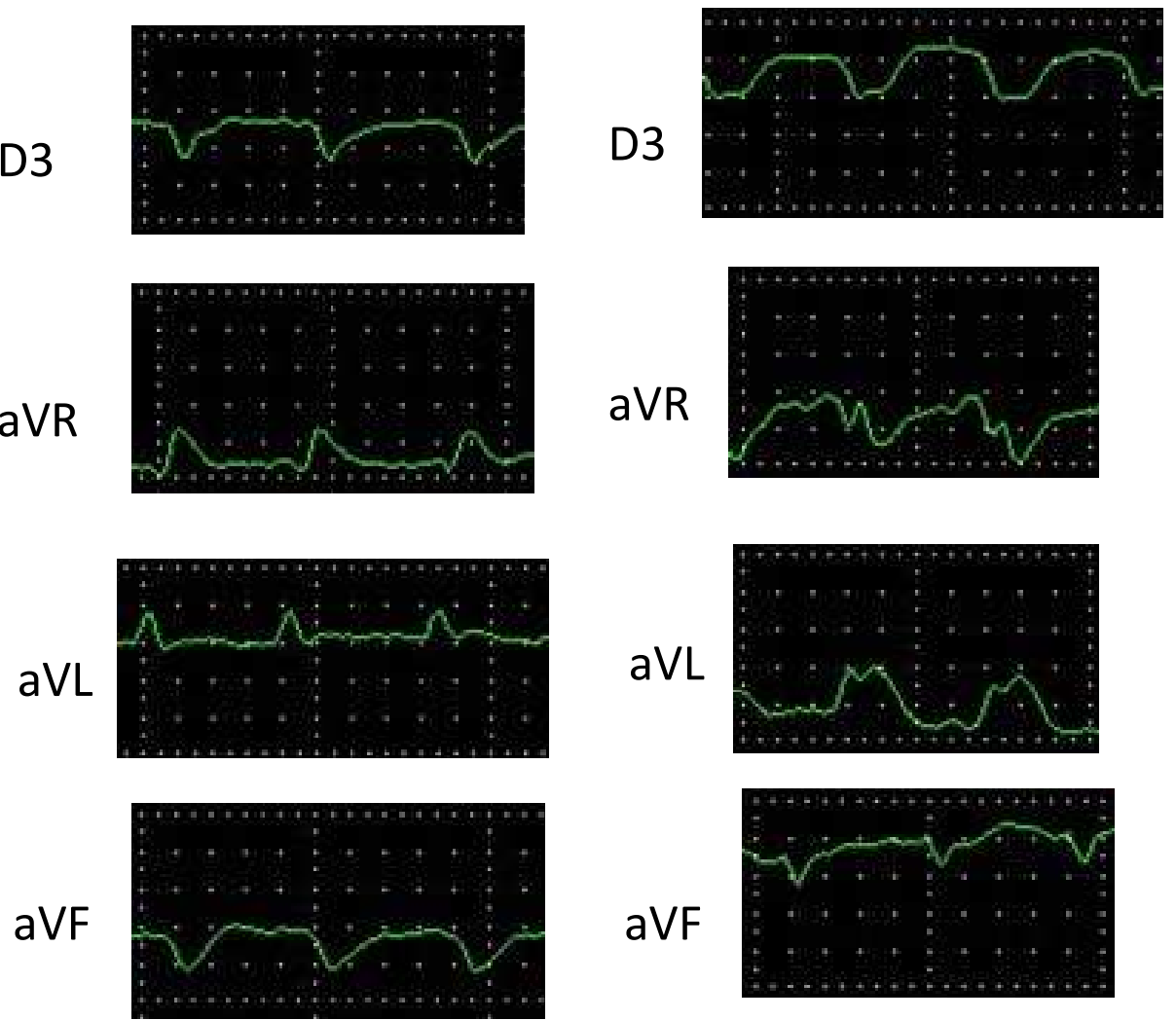

$\mathrm{aVL}$

3 meses
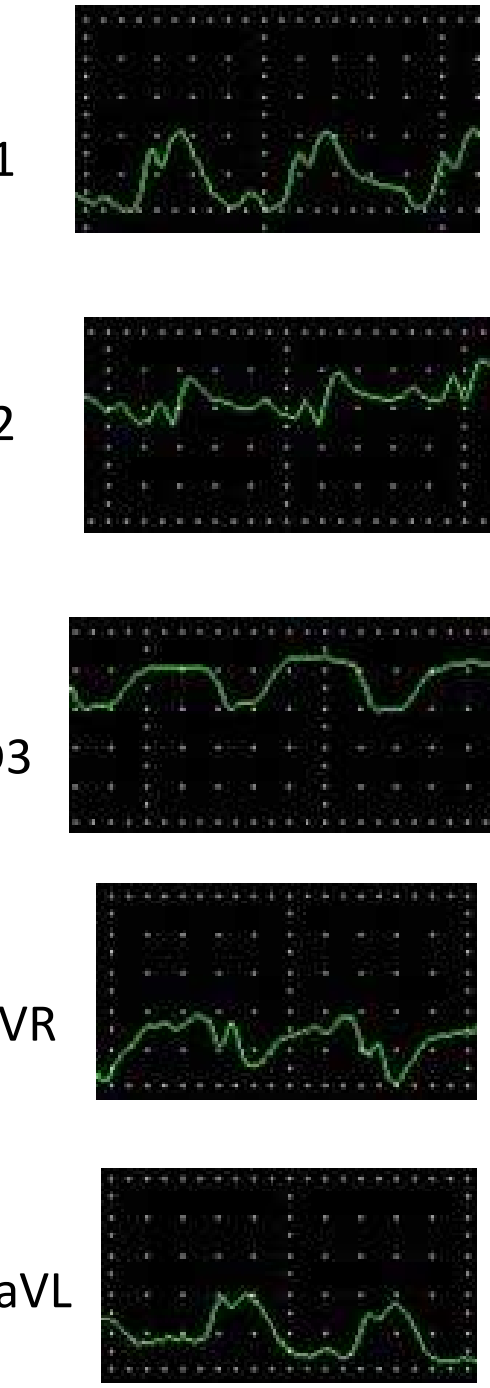

aVF

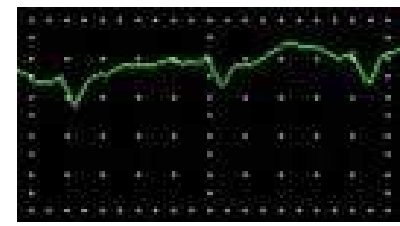

Figura 28B. Eletrocardiograma de animal representativo do grupo submetido a dieta hiperlipídica e tratado com indinavir. 

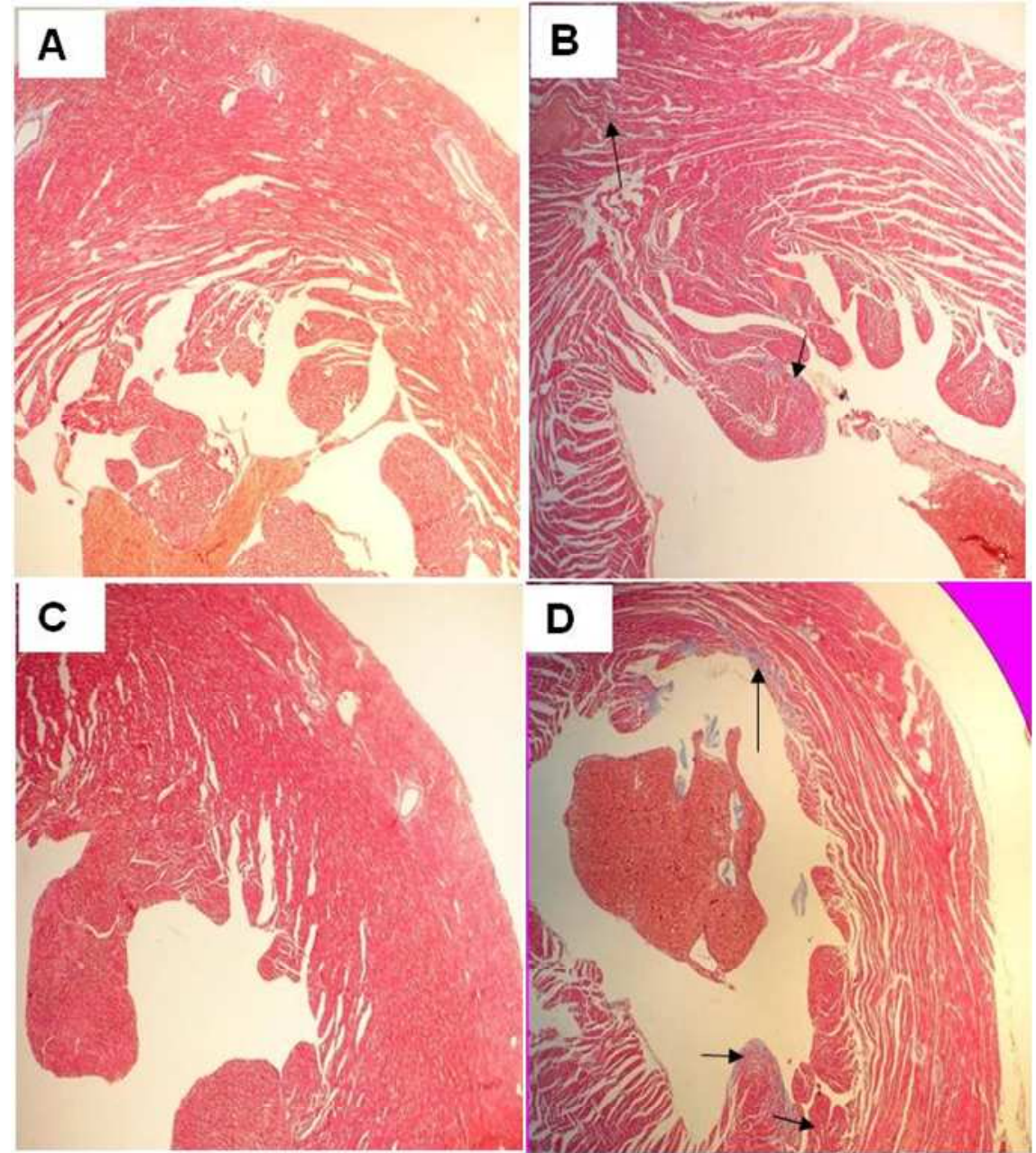

Figura 29. Coração de hamsteres mantidos com dieta normal ou hiperlipídica e tratados ou não com Indinavir $30 \mathrm{mg} / \mathrm{dia}$, no quinto mês do experimento. A - dieta normal, B -dieta normal e Indinavir , C - dieta hiperlipídica , D - dieta hiperlipídica e Indinavir. Observa-se presença de fibrose em azul (seta). Masson 40X. 

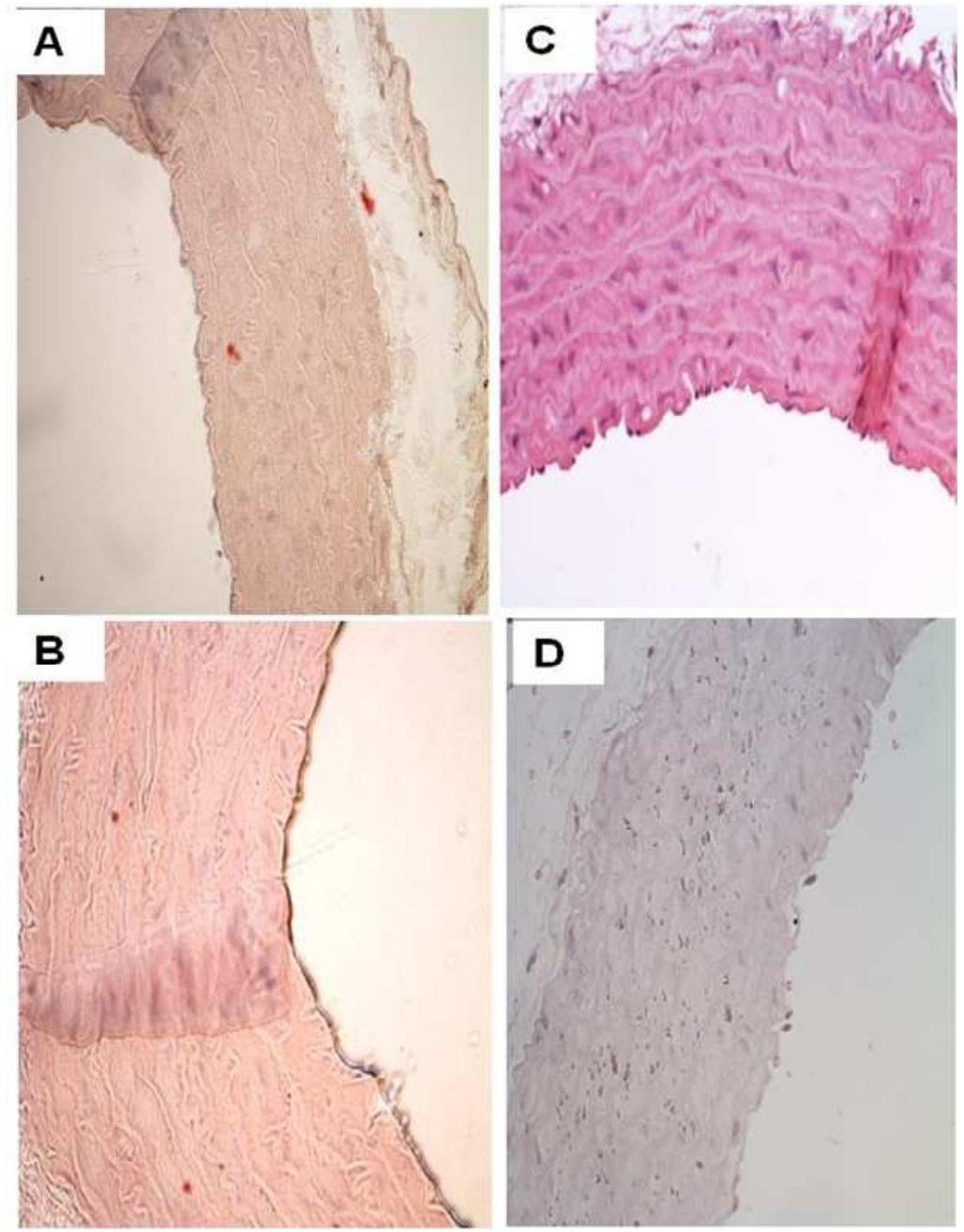

Figura 30. Aorta de hamsteres mantidos com dieta normal ou hiperlipídica e tratados com Indinavir $30 \mathrm{mg} / \mathrm{dia}$, no quinto mês do experimento. A e C - dieta normal e Indinavir, B e D - dieta hiperlipídica e Indinavir. Não se observa alteração histopatológica e não se nota a presença de gordura. HE - 40 x (A e B). Oil-red 40X (C e D). 


\subsection{Alteração renal}

Nos cortes histológicos do rim direito se efetuou a coloração Hematoxilina- Eosina aumento 40X observando-se hipercelularidade e diminuição da Cápsula de Bowman nos grupos submetidos à dieta normal e tratados com indinavir, ou dieta Hiperlipídica e tratados com droga (Figura 31B e D). Esta patologia poderia ser devido a litíase, porém não observou-se a presença de cristais ou cálculos, mas na literatura esta descrita falha crônica renal e o indinavir é insolúvel a $\mathrm{PH}$ 6,0. Já nos grupos tratados com dieta normal e dieta Hiperlipídica sem tratamento não foi observado hipercelularidade ou diminuição da cápsula de Bowman ou outras alterações patológicas ou glomerulares (Figura 31A e C).

Nos cortes histológicos de rim direito com coloração específica Masson aumento 40X observou-se fibrose que aparece na cor azulada e diminuição da Cápsula de Bowman nos grupos submetidos à dieta normal ou dieta hiperlipídica e tratados com indinavir (Figura 32B e D). Já nos grupos tratados com dieta Normal e dieta Hiperlipídica sem tratamento não foi observado fibrose ou diminuição da cápsula de Bowman nem outras alterações histopatológicas (Figura 32A e C).

Nos cortes histológicos de rim direito com coloração específica de PAMS aumento 40X observou-se espessamento da parede capilar e diminuição da Cápsula de Bowman nos grupos submetidos à dieta normal e tratados com indinavir, ou dieta Hiperlipídica e tratados com a droga, sendo menor no grupo submetido à dieta normal e droga (Figura 33B e C). No grupo submetido à dieta normal e sem tratamento não observou-se espessamento da parede capilar ou diminuição da cápsula de Bowman nem outras alterações histopatológicas (Figura 33A). 

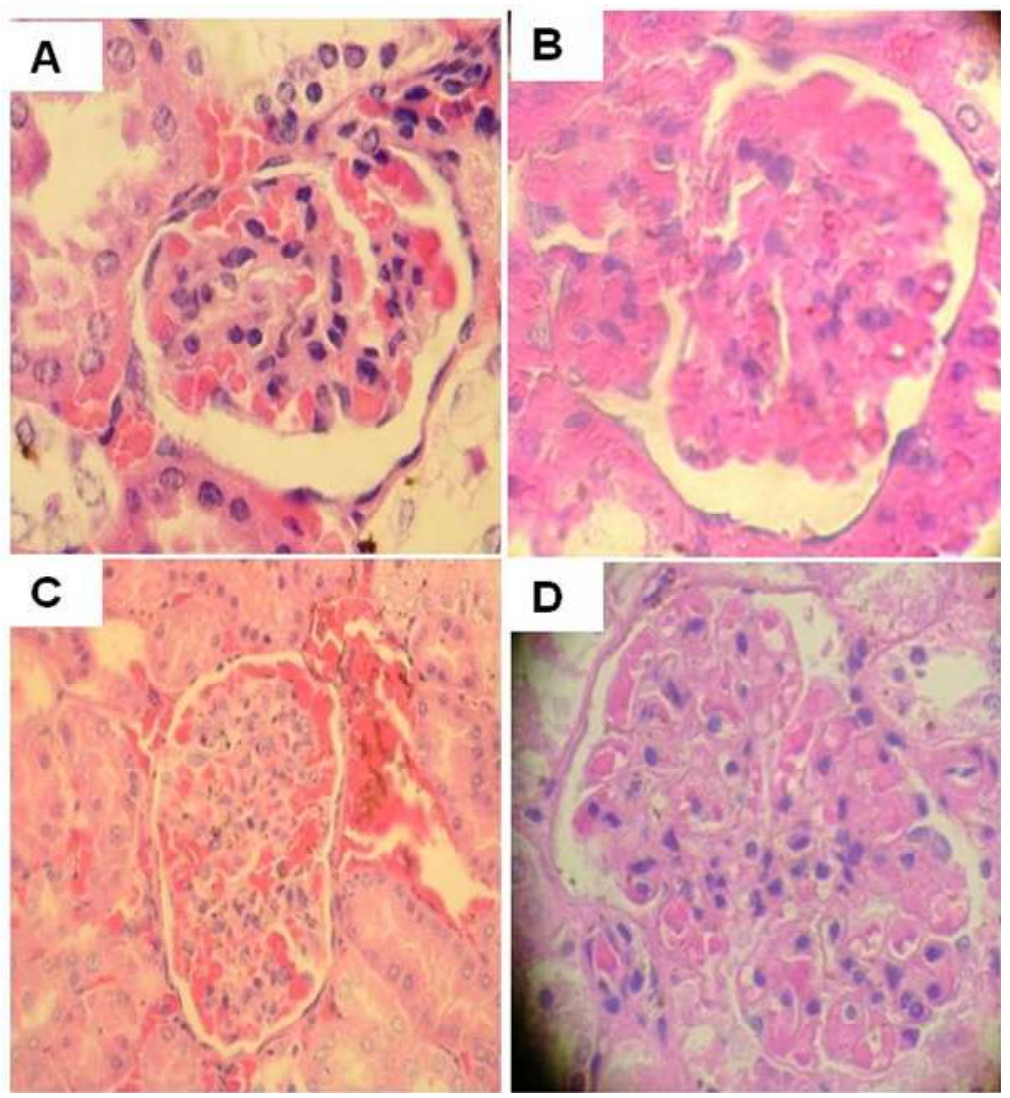

D

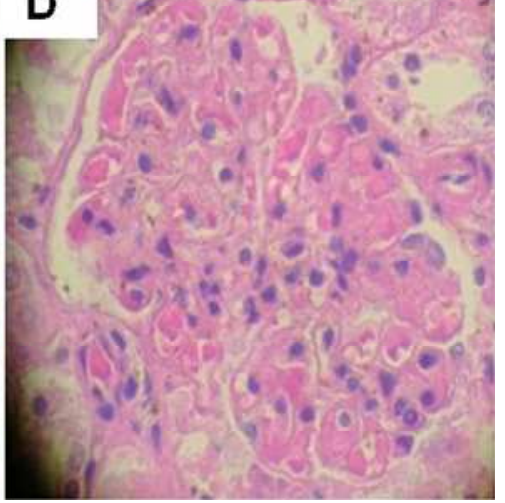

Figura 31. Rim de hamsteres mantidos com dieta normal ou hiperlipídica e tratados ou não com Indinavir $30 \mathrm{mg} / \mathrm{dia}$, no quinto mês do experimento. A - dieta normal, B -dieta normal e Indinavir ,C - dieta hiperlipídica D - dieta hiperlipídica e Indinavir. Observa-se hipercelularidade e diminuição da cápsula de Bowman nos animais tratados com a droga, independente do tipo da dieta (B e D). He 40X. 

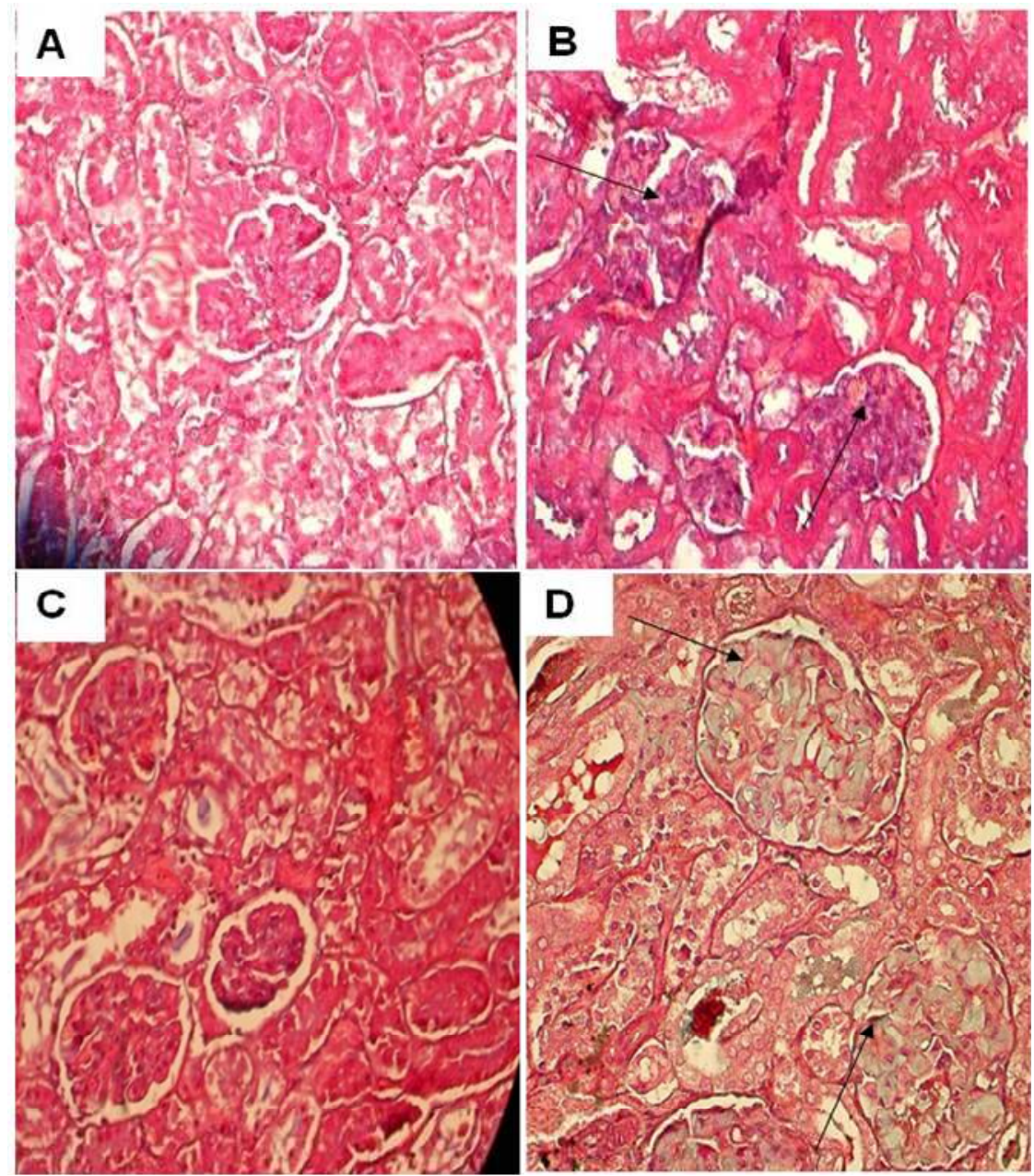

Figura 32. Rim de hamsteres mantidos com dieta normal ou hiperlipídica e tratados ou não com Indinavir $30 \mathrm{mg} / \mathrm{dia}$, no quinto mês do experimento. A - dieta normal, B -dieta normal e Indinavir , C - dieta hiperlipídica, D - dieta hiperlipídica e Indinavir. Observa-se fibrose e diminuição da cápsula de Bowman assinaldas pelas setas nos animais tratados com a droga. Masson 40X. 

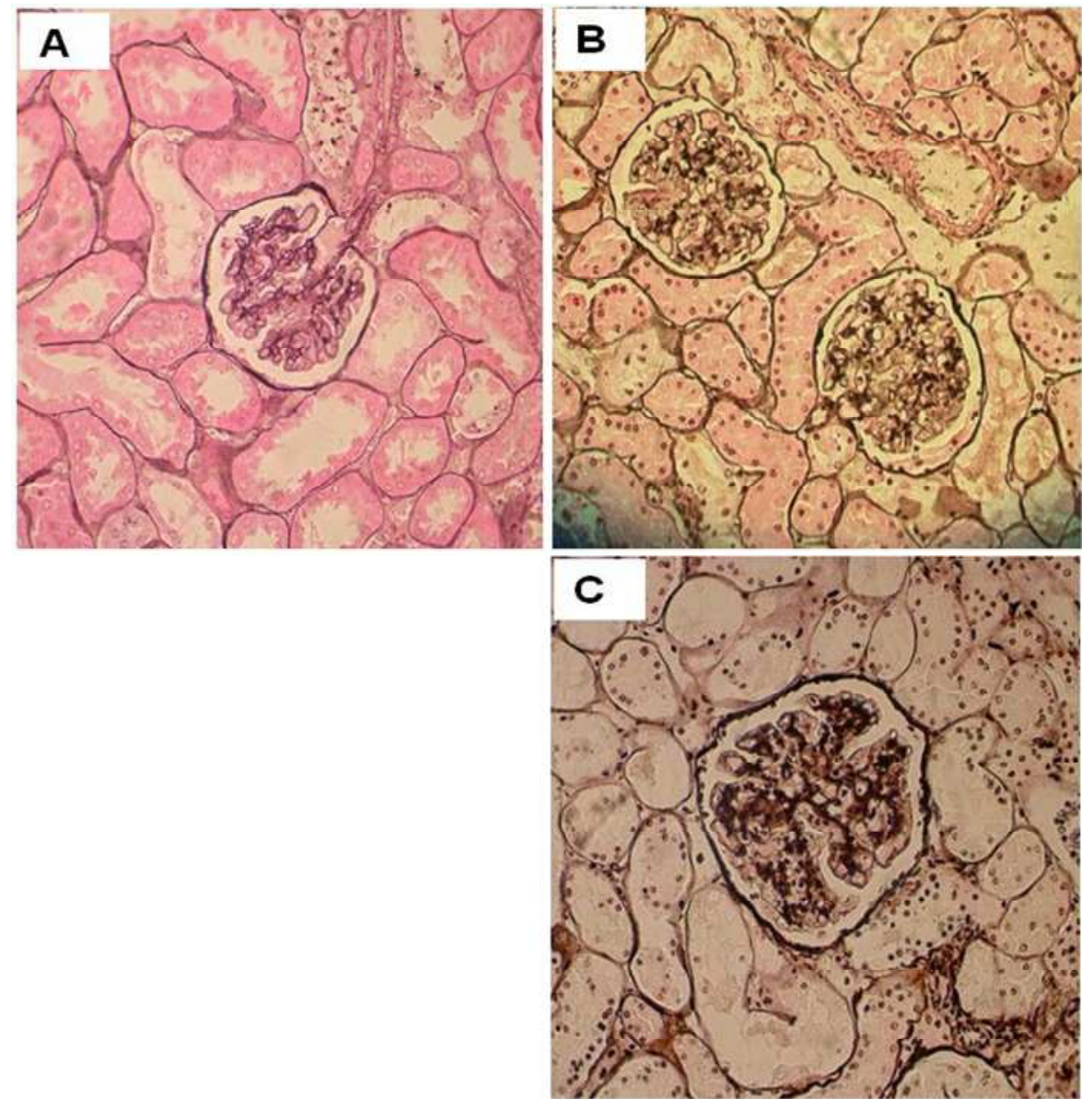

Figura 33. Rim de hamsteres mantidos com dieta normal ou hiperlipídica e tratados ou não com Indinavir $30 \mathrm{mg} / \mathrm{dia}$, no quinto mês do experimento. A - dieta normal, B -dieta normal e Indinavir , C - dieta hiperlipídica e Indinavir. Observa-se espessamento da parede capilar e diminuição da cápsula de Bowman nos animais tratados com a droga. PAMS 40X. 


\section{DISCUSSÃO}

Com a introdução de novos e potentes inibidores de proteases para 0 tratamento do HIV observou-se significante redução da mortalidade com concomitante aumento na sobrevida dos pacientes infectados. No entanto, têm-se descrito vários efeitos secundários em seres humanos associados ao uso destes medicamentos como a resistência à insulina (CARON et al., 2001), nefropatias, litíase, aumento do risco de infarto do miocárdio (NOOR et al., 2002; COLLIN et al., 2007; ESCUDERO et al., 2008), entre doenças cardíacas dado por efeitos secundários como a hiperlipidemia, lipodistrofia (redistribuição anormal da gordura corporal), diminuição dos níveis séricos de HDL (CALZA et al., 2004), entre outros.

Alguns destes efeitos colaterais estão associados a desordens no metabolismo de lipídios e no metabolismo de glicose. Assim, alterações no metabolismo são utilizadas como indicadores do prognóstico para doenças cardíacas ou risco cardíaco já que estão associadas a doenças cardíacas principalmente se mantidas por um longo período de tempo (HOLMBERG et al., 2002 ; FRIIS-MOLLER, 2003). Espera-se que a incidência de doenças cardíacas e cardiovasculares prematuras aumente devido ao elevado risco cardiovascular e ao aumento da expectativa de vida dos indivíduos infectados com o HIV (FISHER, 2001; NEUMANN, 2002). Por isso, o diagnóstico e a terapêutica das doenças cardiovasculares associadas ao HIV deve tornar-se parte integrante dos atuais conceitos terapêuticos da infecção pelo HIV.

A grande dificuldade no estudo destes efeitos colaterais é devido à complexidade com que eles se apresentam, e que se podem apresentar tanto isolados ou em conjunto. Ademais, algumas drogas afetam mais 0 metabolismo de lipídios e outras o metabolismo de glicose, o que indica que cada droga atua por metabolismos distintos, apesar da existência de certa controvérsia neste aspecto, mas tanto o metabolismo de lipídios quanto o de glicose estão interligados, e o balanço de um afeta o do outro. Além disso, a 
prevalência das síndromes metabólicas associadas ao uso destes medicamentos varia de estudo a estudo, por exemplo, a lipodistrofia varia de 11-83\% (GRINSPOON; CARR, 2005; CARR, 1998), a hipertrigliceridemia de 40-80\%, a hipercolesterolemia de 10-50\%, a hipercolesterolemia e a hipertrigliceridemia juntas de 10-40\% (CALZA et al., 2004), e a hiperinsulinemia de $30-40 \% \quad(C A R R, 1998)$. Todas estas variáveis ou fatores de risco exploradas e observadas nos diferentes estudos nos sugere que é resultante de complexas interações entre o paciente, o vírus e as drogas, o que demonstra a importância do desenvolvimento de um modelo experimental para os estudos destes efeitos colaterais e suas inter-relações.

Como esperado, considerando o supracitado, foi encontrado aumento das concentrações plasmáticas de glicose nos animais submetidos ao tratamento com indinavir (30 mg/dia) (CALZA et al., 2004; CARPER et al., 2008; ZHANG et al., 2009), que segundo Zhang et al (2009) está associado ao aumento da apoptose de células beta pancreáticas e a concominante redução de insulina em modelo com a linhagem celular 832/13INS-1. O mesmo foi observado nas concentrações plasmáticas de triglicérides como descrito por outros pesquisadores (CALZA et al., 2004; ANASTOS et al., 2007; CALZA et al., 2008). No entanto, no presente estudo não foi observado aumento das concentrações plasmáticas de LDL e HDL pela administração da droga, sendo apenas evidenciada nos animais submetidos à dieta hiperlipídica. Congruente a isso, aumentos leves a moderados têm sido reportados com a administração de inibidores de proteases, mas o mesmo não pode ser aplicado com o uso de indinavir (CALZA et al., 2008). Neste contexto, deve-se considerar que o próprio vírus do HIV pode interferir no metabolismo de lípides, o que dificulta o estabelecimento de uma correlação entre o tratamento com IPs e o aumento na incidência de doenças cardiovasculares e demais efeitos colaterais.

Recentemente (MUJAWAR et al., 2006), foi descrito possíveis mecanismos pelo qual o HIV pode interferir no metabolismo de lípides. Por exemplo, foi demontrado o sequestro de colesterol pelo HIV através da 
proteína citoplasmática Nef, proteína integrante do HIV que seqüestra partículas de colesterol pela supressão pós-transcricional da proteína ABCA1 e pela relocalização da mesma proteína para a membrana celular. A ABCA1 citoplasmática participa no efluxo celular de colesterol e fosfolípides inserindo lípides na apoA-1, que é a porção protéica da HDL, e como consequência a lipidificação do HDL é afetada juntamente com o efluxo de fosfofolípides em macrófagos e linhagens celulares (HeLa). Deste modo, ocasionaria a formação de células espumosas, que explicaria o aumento dos casos de aterosclerose e doenças cardiovasculares em pacientes infectados pelo HIV. Isto também pode explicar a redução da HDL nos pacientes com HIV dependente da carga viral. Enfatiza-se neste caso, que o tratamento em pacientes infectados com o HIV ocasiona simultaneamente redução da carga viral, e consequentemente ocasiona concomitantemente aumento dos níveis de HDL.

Atualmente, não se tem modelo experimental animal para predizer ou acompanhar o desenvolvimento de efeitos colaterais ou secundários do tratamento com drogas da classe dos inibidores de protease, em especial o indinavir.

A mortalidade expressiva observada no presente estudo após administração de $12 \mathrm{mg} /$ dia de indinavir, sendo mais acentuada em dietas hiperlipídicas, demonstra o importante papel da dieta no desenvolvimento das doenças cardiovasculares associado ao aumento dos níveis de colesterol e triglicérides (SPADY; DIETSCHY, 1985). No entanto, com a administração de $30 \mathrm{mg} / \mathrm{dia}$, não se identificou efeito da dieta, apesar da maior taxa de mortalidade. Este fato indica que a mortalidade é dose dependente, efeito já descrito em casos de nefrolitíase aguda em humanos (COLLIN et al., 2007), sendo possível que os demais efeitos adversos podem apresentar a mesma correlação. Todas estas alterações podem ser explicadas pelos efeitos citotóxicos em diferentes tipos celulares, através de um mecanismo de toxicidade mitocondrial, que ocasiona disfunção endotelial que pode resultar em tromboembolia e hipercoagulação, e ainda em apoptose de adipócitos e de 
células endoteliais vasculares. É ainda relatado aumento dos níveis de fibrinogênio sangüíneo, o que pode implicar em aumento dos riscos cardiovasculares descritos acima (MIN et al., 2004; JIANG et al., 2006).

Alterações no perfil lipídico são freqüentemente relatadas em humanos sob tratamento com IPs. Todavia, pode-se notar que ao extrapolar a dose de indinavir utilizada em humanos, o que resultaria em dose aproximada de 3 a 6 mg/dia não observou-se alterações histopatológicas cardíacas e renais, e somente na dose $6 \mathrm{mg} / \mathrm{dia}$ identificou-se discretas alterações no perfil lipídico, o que não refletiria de forma satisfatória os efeitos secundários reportados em humanos. No entanto, ao aumentar a dose para $12 \mathrm{mg} / \mathrm{dia}$, já pode-se identificar a presença de alterações mais evidentes no perfil lipídico.

Deste modo, optou-se por tentar uma dose de $30 \mathrm{mg} / \mathrm{dia}$, já que não se havia até então observado alterações histopatológicas, ademais o tempo necessário para o desenvolvimento das alterações lipídicas no tratamento com $12 \mathrm{mg} /$ dia foi de aproximadamente 5 meses, o que não conduziria com 0 tempo de tratamento ideal de um modelo experimental.

Salienta-se ainda que ao utilizar a dose de 6 e 12 mg/dia observou que alguns animais apresentavam níveis de lípides aumentados. Esse aumento no perfil lipídico não foi mantido o que indicaria que os animais conseguem reverter o quadro clínico. Este aumento dos níveis de colesterol e triglicérides, e posterior decréscimo foi reportado recentemente em humanos sadios que receberam a droga (ROSENKANZ et al., 2007), porém os mecanismos envolvidos ainda não foram completamente elucidados. No entanto, ao utilizar a dose de $30 \mathrm{mg} /$ dia observou aumento significativo das concentrações séricas de triglicérides e colesterol, sem posterior redução dos seus níveis como notado nas doses de 6 e $12 \mathrm{mg} / \mathrm{dia}$. Sugere-se que devido ao menor tempo de tratamento ocasionado principalmente pela maior taxa de mortalidade, a posterior redução dos níveis de triglicérides e colesterol não foi identificada.

Como esperado, foi observado aumento dos níveis plasmáticos de glicose nos animais sob tratamento com indinavir (30 mg/dia). O aumento na 
glicemia tem sido frequentemente reportado por outros autores, associados muitas vezes ao desenvolvimento de resistência à insulina em pacientes infectados (RUDICH et al., 2005), ou até mesmo em voluntários sadios sob tratamento (NOOR et al., 2002; LEE et al., 2007).

As formas oxidadas e modificadas da LDL (ox-LDL e m-LDL) têm sido associadas como agente etiológico de doenças de origem inflamatória e imunológica, que incluem artrite reumatóide e a aterosclerose, e muitos mecanismos de ação tem sido investigados, já que a ox-LDL e a m-LDL têm capacidade de ser imunogênica, estimular o sistema imune, ou mesmo apresentar atividade citotóxica em diversos tipos celulares como células endoteliais e macrófagos (FROSTEGARD et al., 1992 ; FROSTEGARD et al., 1996 ; STEMME et al., 1995). No entanto, muitos estudos têm explorado estas propriedades como a geração de repertório de auto-anticorpos contra a ox-LDL e m-LDL, onde dependendo do grau e localização da modificação ou oxidação dos diferentes epítopos desta partícula podem indicar distintas condições fisiopatológicas. Desta forma, estudos explorando os níveis destes autoanticorpos vêm sendo correlacionados com 0 desenvolvimento da aterosclerose e doenças cardiovasculares em estudos clínicos como naqueles ensaios de aterosclerose experimental (SHOENFELD et al., 2000; PALINSKI et al., 1990; BUl et al., 1996;PUURUNEN et al., 1994; DAMASCENO et al., 2000), mas os achados são contraditórios, pois a presença de anticorpos contra ox-LDL poderia ser desejável ou não, por exemplo altos títulos de anticorpos foram encontrados em pacientes com doença coronária, aterosclerose periférica e hipertensão (BUl et al., 1996; MAGGl et al., 1995; BERGMARK et al., 1995), por outro lado baixos níveis de anticorpos foram observados em estudos incluindo fumantes e pacientes com doença arteriocoronariana (DAC) sugerindo uma correlação inversa entre níveis de auto-anticorpos e risco de desenvolver doença (ZARATIN et al., 2002; SHOJI et al., 2000).

Em outros estudos não se demonstrou que a imunização com m-LDL 
produz auto-anticorpos desejáveis para o indivíduo (SHERER; SHOENFELD Y, 2002; DAMASCENO et al., 2000; UINT et al., 2003). Assim, decidiu-se observar as diferenças nos níveis séricos de autoanticorpos contra a ox-LDL e o peptídeo ApoB-D derivado da seqüência da apoB que é integrante da parte protéica da LDL. No presente estudo foram observadas diferenças na concentração dos níveis séricos de auto-anticorpos contra ox-LDL, porém não se encontrou diferenças significantes nos níveis de anticorpos contra ox-pepD. Este fato poderia ser explicado pelo design do peptídeo $D$ que foi desenhado a partir de parâmetros de predição de peptídeos imunogênicos, presença de regiões anfipáticas, probabilidade de ligação a moléculas do $\mathrm{MHC}$ e da apresentação dos sítios de clivagem para ação da tripsina. Este último parâmetro pode explicar o motivo de se encontrar diferenças significativas nos anticorpos contra ox-LDL e não contra o peptídeo $\mathrm{D}$, pois os inibidores de protease inibem o proteossomo de células hepáticas, macrófagos e outros tipos celulares inibindo especificamente a atividade tripsina-like $e$ quimotripsina-like do proteossomo de forma dose dependente (PATRICE et al., 1998; LIANG et al., 2001), e considerando o proteossomo um sistema de degradação protéica que está envolvido na produção de epítopos de células $T$, a inibição ou modulação na atividade do proteossomo vai gerar mudanças na apresentação de antígenos e na resposta de células T (PATRICE et al., 1998; SCHMIDTKE et al., 1999), assim a tendência dos anticorpos anti-ox-pepD é de se manter ou diminuir. Com respeito aos anticorpos anti-ox-LDL pode-se sugerir o surgimento de novos epítopos gerados a partir da modulação da atividade do proteossomo, onde um novo repertório de anticorpos que reconhecem a ox-LDL poderiam ser gerados, explicando assim as diferenças observadas nos níveis de anticorpos anti-ox-LDL .

Alterações metabólicas são associadas à terapia HAART principalmente ao uso de IPs, sendo correlacionadas ao aumento do risco de desenvolver doenças cardiovasculares tais como a aterosclerose e infarto do miocárdio. No presente estudo, não se encontrou desenvolvimento de aterosclerose 
possivelmente devido ao modelo experimental utilizado, já que o tempo necessário para induzir a aterosclerose por dieta é de aproximadamente nove meses, enquanto o tempo experimental utilizado não passou dos seis meses, o que justificaria a ausência de achados histopatológicos indicativos do desenvolvimento de aterosclerose.

Nos eletrocardiogramas realizados observou-se aumento do intervalo QRS e supradesnivelamento do intervalo ST nos animais tratados com indinavir que pode estar associado à fibrose ventricular que foi evidenciada na histologia dos animais sob tratamento. Isto também pode ser explicado pela inibição da metaloproteinase MMP9 por parte dos IPs (BOURLIER et al., 2004). A MMP9 apresenta a função de rearranjar a matriz celular e promover o reparo tecidual. A inibição desta enzima juntamente com aumento dos níveis séricos de TGF- $\beta$ relatado em pacientes sob terapia HAART e a toxicidade mitocondrial observada em adipócitos e células endoteliais vasculares onde a indução de apoptose é inibida (JIANG et al., 2007;2009; HEBERT et al., 2004; LEWIS et al., 2000), pode ocasionar um quadro de lesão a celulas endotelias de vasos cardíacos com reparo tecidual comprometido que fovoreceria a formação de tecido fibroso nestes vasos com conseqüente dano cardíaco.

No entanto, os inibidores de protease produzem anormalidades no ECG especificamente no aumento do intervalo QT, alteração no ECG que pode causar taquicardia "Torsade de pointes" (CASTILLO, 2002). Achados semelhantes foram relatados por Anson et al. (2005), onde descreveram uma elongação no intervalo QT e associaram ao uso de IPs, incluindo o indinavir. O aumento do intervalo QT, algumas vezes, ainda está associado a morte súbita devido a arritmia ventricular paroxística (SARAIVA et al., 2006).

Ademais, têm-se observado morte súbita relacionada principalmente ao infarto do miocárdio agudo em pacientes sob HAART (comunicação pessoal), além do aumento do risco cardiovascular em $26 \%$ a cada ano de terapia HAART, principalmente associado ao uso de IPS (FRIIS-MOLLER, 2003). Corrobora a isso, associação entre o uso de proteases, incluindo o indinavir, e 
prolongação do intervalo QT (ANSON et al., 2005).

Adicionalmente a isto, em outros estudos correlacionaram aumento da onda $\mathrm{P}$ ao uso de inibidores de protease. Deste modo, salienta-se que 0 aumento da onda $\mathrm{P}$ está correlacionado com o desenvolvimento da hipertrofia atrial, que por conseguinte está associada ao desenvolvimento de hipertensão pulmonar. Esta síndrome é frequentemente encontrada em pacientes infectados pelo HIV sob tratamento com inibidores de proteases (BARBARO, 2005).

A insuficiência renal aguda e crônica, ou declínio da função renal também tem sido reportado em pacientes sob tratamento com inibidores de protease (ROLING et al., 2006; SCHWARTZ et al.,2005). No caso específico do indinavir os efeitos adversos vão desde cristalúria, nefrolitíase aguda dose dependente, doença renal crônica, insuficiência renal crônica, precipitação intratubular, obstrução renal, nefropatia túbulo intersticial, fibrose intersticial, e hialinose (GAGNON et al., 2006; 2007; SAID et al., 2007; COLLIN et al., 2007; MOCROFT et al., 2007; CHEUNG et al., 2007; ESCUDERO et al., 2007).

De forma semelhante, no presente modelo, observou-se alterações histopatológicas como hipercelularidade e fibrose glomerular com conseqüente diminuição do lúmen da cápsula de Bowman, e hialinose apenas nos tratados com $30 \mathrm{mg} / \mathrm{dia}$ independente da dieta, o que ocorreu em aproximadamente $70 \%$ dos animais. No entanto, não identificou cristais de indinavir, o que seria de certa forma esperado já que o indinavir é insolúvel no $\mathrm{pH}$ de 6,0 o que condiz com $\mathrm{opH} 8$ da urina destes animais. Entretanto, até o presente momento não se tem publicações a respeito dos metabólitos derivados do indinavir.

Apesar dos indícios de insuficiência renal encontrada nos cortes histológicos reforçados pelos freqüentes relatos de aumento das concentrações creatinina e uréia plasmática em pacientes infectados com HIV sob tratamento com indinavir, no presente estudo não se observou alteração dos níveis plasmáticos de creatinina e uréia nos animais sob tratamento. 
Curiosamente, o aumento de uréia pode apenas ser observado nos animais submetidos à dieta hiperlipídica que pode ser devido ao fato de animais submetidos a dietas hiperlipídicas apresentarem aumento a oferta de ácidos graxos, o que ocasiona em uma adaptação no metabolismo de aminoácidos resultante de menor catabolismo de proteínas, e consequentemente menor formação de uréia (SERRA et al., 1991; TANG et al., 2001).

No tocante à avaliação das enzimas hepáticas, apesar de se observar diferenças significantes em alguns momentos entre os distintos grupos, não se pode predizer a presença de lesões hepáticas, pois as alterações discretas ou isoladas apresentam baixa sensibilidade e baixo valor preditivo. Embora a utilização da expressão "avaliação da função hepática", nenhuma das enzimas utlizadas como ferramenta para tal é específica para doenças hepáticas, podendo ainda estar alteradas em outras condições. Além disso, alterações destas enzimas não têm sido uma constante em pacientes infectados pelo HIV sob tratamento (MERAVIGLIA et al., 2002).

Os resultados do presente estudo demonstraram a viabilidade da utilização do Mesocricetus auratus como ferramenta para a avaliação dos efeitos adversos advindos do tratamento com inibidores de proteases, no caso o indinavir. Fato que merece especial atenção dado a liberação precoce das drogas recém desenvolvidas que foram liberadas ainda na segunda fase do ensaio clínico e aos recentes relatos de efeitos adversos advindos do uso destas drogas devido ao aumento da sobrevida dos pacientes infectados com o HIV. Assim, este estudo abre campo para novos estudos onde poderão ser estabelecidos mecanismos que levam ao desenvolvimento de tais síndromes. 


\section{Conclusões}

Pode-se concluir que:

- $\mathrm{Na}$ concentração $20 \mu \mathrm{M}$ de $\mathrm{CuSO}_{4}$ são gerados produtos antigênicos que podem ser reconhecidos por auto-anticorpos, e que a produção destes aumentam em relação ao tempo

- Animais que não receberam tratamento apresentam uma maior concentração de auto-anticorpos ox-LDL quando comparado com os animais tratados com Inibidores de protease.

- As concentrações do inibidor de protease indinavir afeta o metabolismo de glicose e triglicérides.

- As concentrações de glicose e triglicérides estão aumentados em animais tratados com droga e dieta hiperlipídica quando comparado com os animais submetidos a dieta normal.

- Animais submetidos apenas a dieta hiperlipídica sem droga também apresentaram aumento nos níveis de glicose e triglicérides.

- Níveis de protease causam aumento nos níveis de colesterol nos animais tratados com dieta hiperlipidica e droga.

- Não foi possível acompanhar diminuição da função renal nos grupos dosando apenas os níveis de creatinina e uréia, mesmo observando fibrose renal na histologia.

- Houve aumento drástico da mortalidade após o $100^{\circ}$ dia de tratamento nos animais tratados com IP independente da dieta

- Os animais submetidos à droga e a dieta hiperlipídica assim como os animais apenas tratados com a droga apresentaram diferenças no segmento QRS e supradesnivelamento ST após análise dos eletrocardiogramas.

- Os animais submetidos a dieta normal e tratados com droga e nos animais submetidos a dieta hiperlipídica e tratados com droga apresentaram alterações de fibrose. 
- Presença de hipercelularidade e fibrose no rim de animais tratado com IPS em comparação com animais submetidos a dieta normal.

- O modelo Hamster apresentou como um modelo viável que nos permite explorar os efeitos cardiotóxicos do IPs, no caso o indoinavir (e potencialmente outras drogas) e os mecanismos patogênicos causadores de alterações cardiovasculares que levam ao AMI. 


\section{REFERÊNCIAS BIBLIOGRÁFICAS}

ALEXAKI, A. et al. Hamsters fed diets high in saturated fat have increased cholesterol accumulation and cytokine production in the aortic arch compared with cholesterol-fed hamsters with moderately elevated plasma non-HDL cholesterol concentrations. J. Nutr., v. 134, p. 410-415, 2004.

ANASTOS, K. et al. Association of serum lipid levels with HIV serostatus specific antiretroviral agents and treatment regimens. J. Acquir. Immune Defic. Syndr., v. 45, n.1, p. 34-42, 2007.

ANSON, B. D. et al. Blockade of HERG channels by HIV protease inhibitors. Lancet, v. 395, n. 9460, p. 682-686, 2005.

ARSHAD, A. et al. Cardiac complications of human immunodeficiency virus infection: diagnostic and therapeutic considerations. Heart Dis., v. 2, n. 2, p. 133-145, 2000.

BARBARO, G. Cardiovascular manifestations of HIV infection. Circulation, v. 106, n. 11, p. 1420-1425, 2002.

BARBARO, G. Reviewing the cardiovascular complications of HIV infection after the introduction of highly active antiretroviral therapy. Curr. Drug Targets Cardiovasc. Haematol. Disord., v. 5, n. 4, p. 337-343, 2005.

BARTLETT, J. G. et al. HAART: one of the most cost effective therapies of the past decade.In: WORLD AIDS CONFERENCE, 12., 24380, 1998, Geneva. Abstract..., Geneva, 1998.

BARTLETT, J. G.; MOORE, R. Are protease inhibitors cost effective? Hopkins HIV report, v. 8, n. 4, p. 1-2, 1996.

BASTARD, J. P. et al. Association between altered expression of adipogenic factor SREBP1 in lipoatrophic adipose tissue from HIV-1-infected patients and abnormal adipocyte differentiation and insulin resistance. Lancet, v. 359, n. 9311, p. 1026-1031, 2002.

BECKER, D. M. et al. Case report: Venous thromboembolism in AIDS. Am. J. Med. Sci., v. 303, n. 6, p. 395-397, 1992.

BECKMAN, J. A. et al. Diabetes and atherosclerosis: epidemiology, pathophysiology and management. JAMA, v. 287, n. 19, p. 2570-2580, 2002.

BERGMARK, C. et al. Patients with early-onset peripheral vascular disease

* De acordo com:

ASSOCIAÇÃO BRASILEIRA DE NORMAS TÉCNICAS. NBR 6023: Informação e documentação: referências: elaboração. Rio de Janeiro, 2002. 
have increased levels of autoantibodies against oxidized LDL. Arterioscler. Thromb. Vasc. Biol., v. 15, p. 441-445, 1995.

BOURLIER, V. et al. Involvement of matrix metalloproteinase- 9 in human adipocyte differentiation. J. Pharmacol. Exp. Ther., v. 312, n. 3, p. 1272-1279, 2004.

BROCHERIOU, I. et al. Expression of platelet-activating factor receptor in human carotid atherosclerotic Plaques relevance to progression of Atherosclerosis. Circulation, v. 102, n. 21, p. 2569-2575, 2000.

BROWN, M. S. et al. The scavenger cell pathway for lipoprotein degradation: specificity of the binding site that mediates the uptake of negatively-charged LDL by macrophages. J. Supramol. Struct., v. 13, n. 1, p. 67-81, 1980.

BUI, M. N. et al. Autoantibody titers to oxidized low-density lipoprotein in patients with coronary atherosclerosis. Am. Heart J., v. 131, n. 4, p. 663-667, 1996.

CALZA, L. et al. Dyslipidaemia associated with antiretroviral therapy in HIVinfected patients. J. Antimicrob. Chemother., v. 53, p. 10-14, 2004.

CALZA, L. et al. Risk of premature atherosclerosis and ischemic heart disease associated with HIV infection and antiretroviral therapy. J. Infect., v. 57, n. 1, p. 16-32, 2008.

CARON, M. et al. The HIV protease inhibitor indinavir impairs sterol regulatory element-binding protein-1 intranuclear localization, inhibits preadipocyte differentiation, and induces insulin resistance. Diabetes, v. 50, p. 1378-1388, 2001.

CARPER, M. J. et al. HIV-protease inhibitors induce expression of suppressor of cytokine signaling-1 in insulin-sensitive tissues and promote insulin resistance and type 2 diabetes mellitus. Am. J. Physiol. Endocrinol. Metab., v. 294, n. 3, p. 558-567, 2008.

CARR, A. et al. Pathogenesis of HIV-1 protease inhibitor-associated peripheral lipodystrophy, hyperlipidaemia and insulin resistance. Lancet, v. 351, n. 9119, p. $1881-1883,1998$.

CARR, A. et al. A syndrome of peripheral lipodystrophy, hyperlipidaemia and insulin resistance in patients receiving HIV protease inhibitors. AIDS, v. 12, n. 7, p. 51-8, 1998. 
CASTILLO, R. et al. Efavirenz-associated QT prolongation and Torsade de Pointes arrhythmia. Ann. Pharmacother., v. 36, p. 1006-1008, 2002.

CHEUNG, C. Y. et al. Prevalence of chronic kidney disease in Chinese HIVinfected patients. Nephrol. Dial. Transplant., v. 22, n. 11, p. 3186-3190, 2007.

COHEN J. R. et al. Deep venous thrombosis in patients with AIDS. N. Y. State J. Med., v. 90, n. 3, p. 159-161, 1990.

COLLIN, F. et al. Indinavir trough concentration as a determinant of early nephrolithiasis in HIV-1-infected adults.Ther. Drug Monit., v. 29, n. 2, p. 164170, 2007.

CONCORDE: MRC/ANRS randomised double-blind controlled trial of immediate and deferred zidovudine in symptom-free HIV infection. Concorde coordinating committee. Lancet, v. 343, n. 8902, p. 871-881, 1994.

DAMASCENO, N. R. T. et al. Soy protein isolate reduces the oxidizability of LDL and generation of oxidized LDL autoantibodies in rabbits with diet-induced atherosclerosis. J. Nutr., v. 130, p. 2641-2647, 2000.

DELTA: a randomised double-blind controlled trial comparing combinations of zidovudine plus didanosine or zalcitabine with zidovudine alone in HIV-infected individuals. Delta coordinating committee. Lancet, v. 348, n. 9023, p. 283-291, 1996.

DENG, H. K. et al. Expression cloning of new receptors used by simian and human immunodeficiency viruses. Nature, v. 388, n. 6639, p. 296-300, 1997.

DOMINGO, P. et al. Subcutaneous adipocyte apoptosis in HIV-1 protease inhibitor-associated lipodystrophy. AIDS, v. 13, n. 16, p. 2261-2267, 1999.

EDWARDS, T. G. et al. Relationships between CD4 independence, neutralization sensitivity, and exposure of a CD4-induced epitope in a human immunodeficiency virus type 1 envelope protein. J. Virol., n. 75, v. 11, p.52305239, 2001.

EGGER, M. et al. Impact of a new antiretroviral combination therapies in HIV infected patients in Switzerland: prospective multicenter study. Swiss HIV cohort study. BMJ, v. 315, n. 7117, p. 1194-1199, 1997.

EMESON, E. E. et al. Inhibition of atherosclerosis in CD4 T-cell-ablated and nude (nu/nu) C57BL/6 hyperlipidemic mice. Am. J. Pathol., v. 149, n. 2, p. 675-685, 1996. 
ERON, J. J. et al. Treatment with lamivudine, zidovudine, or both in HIV-positive patients with 200 to 500 CD4+ cells per cubic millimeter. North American HIV working party. N. Eng. J. Med., v. 333, n. 25, p. 1662-1669, 1995.

ESCUDERO, J. U. J. et al. Litiasis medicamentosa em pacientes HIV+ em tratamiento com indinavir. Arch. Esp. Urol., v. 61, n. 1, p. 35-40, 2008.

FERNVICK, E. C. et al. The autoantibody repertoire against copper-or macrophagemodified LDL differs in normolipidemics and hypercholesterolemic patients. J. Clin. Immunol., v. 24, n. 2, p. 170-176, 2004.

FISHER, S.D. et al. Epidemiology of cardiovascular involvement in HIV disease and AIDS. Ann. N. Y. Acad. Sci., v. 946, p. 13-22, 2001.

FISCHL, M. A. et al. The efficacy of azidothymidine (AZT) in the treatment of patients with AIDS and AIDS-related complex. A double-blind, placebo-controlled trial. $\mathbf{N}$. Engl. J. Med., v. 317, n. 4, p. 185-191, 1987.

FISCHL, M. A. et al. A randomized controlled trial of a reduced daily dose of zidovudine in patients with the acquired immunodeficiency syndrome. The AIDS clinical trials group. N. Engl. J. Med., v. 323, n. 15, p. 1009-1014, 1990.

FRISS-MOLLER, $\mathrm{N}$. et al. Combination antiretroviral therapy and the risk of myocardial infarction. N. Engl. J. Med., v. 349, n. 21, p. 1993-2003, 2003.

FROSTEGARD, J. et al. Oxidized low density lipoprotein induces differentiation and adhesion of human monocytes and the monocytic cell line U937. PNAS, v. 87, n. 3, p. 904-908, 1990.

FROSTEGARD, J. et al. Induction of T-cell activation by oxidized low density lipoprotein. Arterioscler. Thromb., v. 12, p. 461-467, 1992.

FROSTEGARD, J. et al. Induction of heat shock protein in monocytic cells by oxidized low density lipoprotein. Atherosclerosis, v. 121, n. 1, p. 93-103, 1996.

GAGNON, R. F. et al. Indinavir crystalluria. Kydney Int., v. 70, n. 12, p. 2047, 2006.

GAGNON, R. F. et al. Indinavir-associated tubulointerstitial renal disease. Nephrol. Ther., v. 3, n. 7, p. 461-462, 2007.

GALLANT, J. E. Strategies for long-term success in the treatment of HIV infection. JAMA, v. 283, n. 10, p. 1329-1334, 2000. 
GALLI, F. C.; CHEITLIN, M. D. Pericardial disease in AIDS. Frequency of tamponade and therapeutic and diagnostic use of pericardio-centesis. J. Am. Coll. Cardiol., v. 19, p. 226A, 1992.

GENG, Y. J. et al. Expression of the macrophage scavenger receptor in atheroma. Relationship to immnune activation and the $\mathrm{T}$ cell cytokine interferon gamma. Arterioscler. Thromb. Vasc. Biol., v. 15, n. 11, p. 1995-2002, 1995.

GRAHAM, N. M. Metabolic disorders among HIV-infected patients treated with protease inhibitors: a review. J. Acquir. Defic. Syndr., v. 25, Suppl 1, p. S4$11,2000$.

GRINSPOON, S.; CARR, A. Cardiovascular risk and body-fat abnormalities in HIVinfected adults. N. Engl. J. Med., v. 1, n. 352, p. 48-62, 2005.

GRUNFELD, C. et al. Lipids, lipoproteins, triglyceride clearance, and cytokines in human immunodeficiency virus infection and the acquired immunodeficiency syndrome. J. Clin. Endocrinol. Metab., v. 74, n. 5, p. 1045-1052, 1992.

HADIGAN, C. et al. Metabolic abnormalities and cardiovascular disease risk factors in adults with human immunodeficiency virus infection and lipodystrophy. Clin. Infect. Dis., v. 32, n. 1, p. 130-139, 2001.

HALLIWELL, B. et al. Free radicals, antioxidants, and human disease: where are we now? J. Lab. Clin. Med., v. 119, n. 6, p. 598-620, 1992.

HANSSON, G. K. Cell-mediated immunity in atherosclerosis. Curr. Opin. Lipidol., v. 8, p. 301-311, 1997.

HARA, $H$. et al. Induction of acetylated low density lipoprotein receptor and suppression of low density lipoprotein receptor on the cells of human monocytic leukemia cell line (THP-1 cell). Biochem. Biophys. Res. Commun., v. 146, n. 2, p. 802-808, 1987.

HARMON, W. G. et al. Myocardial and pericardial disease in HIV. Curr. Treat. Options Cardiovasc. Med., v. 4, n. 6, p. 497-509, 2002.

HASSALL, D. G. Three probe flow cytometry of a human foam-cell forming macrophage. Cytometry, v. 13, n. 4, p. 381-388, 1992.

HAVEL, R. J. The formation of LDL: mechanisms and regulation. J. Lipid. Res., v. 25, p. 1570-1576, 1984.

HEBERT, V. Y. et al. Effects of HIV drug combinations on endothelin-1 and 
vascular cell proliferation. Cardiovasc. Toxicol., v. 4, n. 2, p. 117-131, 2004.

HEIDENREICH, P. A. et al. Pericardial effusion in AIDS. Incidence and survival. Circulation, v. 92, n. 11, p. 3229-3234, 1995.

HENGEL, R. L. et al. Bening symmetric lipomatosis associated with protease inhibitors. Lancet, v. 350, n. 9091, p. 1596, 1997.

HENRY, K. A randomized, controlled, double-blind study comparing the survival benefit of four different reverse transcriptase inhibitor therapies (three-drug, two-drug and alternating drug) for the treatment of advanced AIDS. J. Acquir. Immune Defic. Syndr. Hum. Retrovirol., v. 19, n. 4, p. 339-349, 1998.

HERRY, I. et al. Hypertrophy of the breasts in a patient treated with indinavir. Clin. Infect. Dis., v. 25, n. 4, p.937-938, 1997.

HOLMBERG, S. et al. Protease inhibitors and cardiovascular outcomes in patients with HIV-1. Lancet, v. 360, n. 9347, p. 1747-1748, 2002.

HOMMES, M. J. et al. Basal fuel homoeostasis in symptomatic human immunodeficiency virus infection. Clin. Sci., Lond., v. 80, n. 4, p. 359-365, 1991.

HRUZ, P. W. et al. Indinavir Induces Acute and Reversible Peripheral Insulin Resistance in Rats. Diabetes, v. 51, n. 5, p. 937-942, 2002.

HUI, D. Y. Effects of HIV protease inhibitor therapy on lipid metabolism. Prog. Lipid Res., v. 42, n. 2, p. 81-92, 2003.

JIANG, B. et al. Antiretrovirals induce direct endothelial dysfunction in vivo. J. Acquir. Immune Defic. Syndr., v. 42, p. 391-395, 2006.

JIANG, B. et al.HIV antiretroviral drug combination induces endothelial mitochondrial dysfunction and reactive oxygen species production, but not apoptosis. Toxicol. Appl. Pharmacol., v. 224, p. 60-71, 2007.

JIANG, B. et al. HIV-1 antiretrovirals induce oxidant injury and increase intimamedia thickness in an atherogenic mouse model.Toxicol. Lett., v. 187, p. 164$171,2009$.

JONASSON, L. et al. Regional accumulations of $\mathrm{T}$ cells, macrophages, and smooth muscle cells in the human atherosclerotic plaque. Arteriosclerosis, v. 6, n. 2, p. 131-138, 1986.

JUETTE, A. et al. Increased morbidity from severe coronary heart disease in HIV- 
patients receiving protease inhibitors. In: CONFERENCE ON RETROVIRUSES AND OPPORTUNISTIC INFECTIONS, 6., 656, 1999, Chicago. Abstract... Chicago, 1999.

KATLAMA, C. et al. Safety and efficacy of lamiduvine-zidovudine combination therapy in antiretroviral-naive patients. A randomized controlled comparison with zidovudine monotherapy. Lamivudine European HIV working group. JAMA, v. 276, n. 2, p. 118-125, 1996.

KATZENSTEIN, D. A. et al. The relation of virologic and immunologic markers to clinical outcomes after nucleoside therapy in HIV-infected adults with 200 to 500 CD4 cells per cubic millimetre. AIDS clinical trials group study 175 virology study team. N. Engl. J. Med., v. 335, n. 15, p. 1091-1098, 1996.

KILBY, J. M. et al. Potent suppression of HIV-1 replication in humans by T-20, a peptide inhibitor of gp41-mediated virus entry. Nat. Med., v. 4, n. 11, p. 13021307, 1998.

KLATZMANN, D. et al. T-lymphocyte T4 molecule behaves as the receptor for human retrovirus LAV. Nature, v. 312, n. 5996, p. 767-768, 1984.

$\mathrm{KOHL}, \mathrm{N}$. E. et al. Active human immunodeficiency virus protease is required for viral infectivity. Proc. Natl. Acad. Sci., v. 85, n. 13, p. 4686-4690, 1988.

KRIEGER, M. Molecular flypaper and atherosclerosis: structure of the macrophage scavenger receptor. Trends Biochem. Sci., v. 17, n. 4, p. 141$146,1992$.

LEE, G. A. et al. The metabolic effects of liponavir/ritonavir in HIV-negative men. AIDS, v. 18, n. 4, p. 641-649, 2004.

LEE, G. A. et al. Effects of ritonavir and amprenavir on insulin sensitivity in healthy volunteers. AIDS, v. 21, n. 16, p. 2183-2190, 2007.

LEVY, J. A. et al. Isolation of lymphocytopathic retroviruses from San Francisco patients with AIDS. Science, v. 225, n. 4664, p. 840-842, 1984.

LEWIS, W. et al. Cardiac dysfunction occurs in the HIV-1 transgenic mouse treated with zidovudine. Lab. Invest., v. 80, p. 187-197, 2000.

LEWIS, W. AIDS: cardiac findings from 115 autopsies. Prog. Cardiovasc. Dis., v. 32, n. 3, p. 207-215, 1989.

LIANG, J. S. et al. HIV protease inhibitors protect apolipoprotein B from degradation by the proteasome: a potential mechanism for protease inhibitor- 
induced hyperlipidemia. Nat. Med., v. 7, n. 12, p. 1327-133, 2001.

LIAO, F. et al. STRL33, A novel chemokine receptor-like protein, functions as a fusion cofactor for both macrophage-tropic and T cell line-tropic HIV-1. J. Exp. Med., v. 185, n. 11, p. 2015-2023, 1997.

LIBBY, P. et al. Cytokines regulate vascular functions related to stability of the atherosclerotic plaque. J. Cardiovasc. Pharmacol., v. 25, p. S9-12, 1995. Suppl. 2.

LIBBY, P. et al. Roles of infectious agents in atherosclerosis and restenosis an assessment of the evidence and need for future research. Circulation, v. 96, p. 4095-4103, 1997.

LIBBY, P. Changing concepts of atherogenesis. J. Intern. Med., v. 247, n. 3, p. 349-358, 2000.

LIU, S. X. et al. Lipoperoxidative injury to macrophages by oxidatively modified low density lipoprotein may play an important role in foam cell formation. Atherosclerosis, v. 121, n. 1, p. 55-61, 1996.

LO, J. C. et al. "Buffalo hump" in men with HIV-1 infection. Lancet, v. 351, n. 9106, p. 867-870, 1998.

LUSIS, A. J. Atherosclerosis. Nature, v. 407, p. 233-241, 2000.

MADDEN, E. et al. Association of Antiretroviral Therapy With Fibrinogen Levels in HIV-infection. AIDS, v. 22, p. 707-715, 2008.

MADGE, S. et al. Lipodystrophy in patients naive to HIV protease inhibitors. AIDS, v. 13, n. 6, p. 735-737, 1999.

MAGGI, E. et al. Presence of autoantibodies against oxidatively modified lowdensity lipoprotein in essential hypertension: a biochemical signature of an enhanced in vivo low-density lipoprotein oxidation. J. Hypertens., v. 13, n. 1, p. 129-138, 1995.

MARRY-KRAUSE, M. et al. Increased risk of myocardial infarction with duration of protease inhibitor therapy in HIV-infected men. AIDS, v. 17, n. 17, p. 24792486, 2003.

MATSUMURA, T. et al. Suppression of atherosclerotic development in watanabe heritable hyperlipidemic rabbits treated with an oral antiallergic drug, Tranilast. Circulation, v. 99, p. 919-924, 1999. 
MELMON, K. L.; GILMAN, A. G.; MAYER, S. E. Princípios da terapêuticaregulamentação e desenvolvimento dos medicamentos. In: Goodman e Gilman. As bases farmacológicas da terapêutica. 6. ed. Rio de Janeiro: Guanabara Koogan, 1983. p. 43-45.

MERAVIGLIA, P. et al. Risk factors for indinavir-related renal colic in HIV patients: predictive value of indinavir dose/body mass index. AIDS, v. 16, n. 15, p. 2089-2093, 2002.

MILLER, K. K. et al. Pseudo-cushing's syndrome in human immunodeficiency virus-infected patients. Clin. Infect. Dis., v. 27, n. 1, p. 68-72, 1998b.

MILLER, K. D. et al. Visceral abdominal-fat accumulation associated with use of indinavir. Lancet, v. 351, n. 9106, p. 871-875, 1998.

MIN, T. Q. et al. Improvement in endothelial progenitor cells from peripheral blood by ramipril therapy in patients with stable coronary artery disease. Cardiovasc. Drugs Ther., v. 18, n. 3, p. 203-209, 2004.

MINISTÉRIO DA SAÚDE. Coordenação Nacional de DST e Aids. Infecção pelo HIV em adultos e adolescentes: Recomendações para terapia Anti-retroviral. Brasília, DF, 1999.

MINISTÉRIO DA SAÚDE. Coordenação Nacional de DST e Aids. Infecção pelo HIV em adultos e adolescentes: Recomendações para terapia Anti-retroviral. Brasília, DF, 2004.

MIRELES-VIEYRA, M. P. et al. Long time retrospective study of comparation of monotherapy with AZT in comparation with combination of AZT + DOC, AZT + DDI and AZT +3TC. AIDS, v. 10, p. S26, 1996. Suppl. 2.

MOCROFT, A. et al. Chronic renal failure among HIV-1-infected patients. AIDS, v. 21, n. 9, p. 1119-1127, 2007.

MOCROFT, A. et al. AIDS across Europe, 1994-1998: the EuroSIDA study. Lancet, v. 356, n. 9226, p. 291-296, 2000.

MOCROFT A. et al. Changing patterns of mortality across Europe in patients with HIV-1.EuroSIDA study group. Lancet, v. 352, n. 9142, p. 1725-1730, 1998.

MOORE, $R$. et al. Decline in mortality rates and opportunistic disease with combination antiretroviral therapy. In: WORLD AIDS CONFERENCE, 12., 22374, 1998, Geneva. Abstract... Geneva, 1998.

MORENO, J. R. et al. Afectación cardiaca asociada a la infección por el virus 
de la inmunodeficiencia humana. Clin. Cardiovasc., v. 13, p. 31-39, 1995.

MUJAWAR, Z. et al. Human immunodeficiency virus impairs reverse cholesterol transport from macrophages. PLoS Biol., v. 4, n. 11, p. e365, 2006.

MULLIGAN, K. et al. Anabolic effects of recombinant human growth hormone in patients with wasting associated with human immunodeficiency virus infection. J. Clin. Endocrinol. Metab., v. 77, n. 4, p. 956-962, 1993.

MULLIGAN, K. et al. Hyperlipidemia and insulin resistance are induced by protease inhibitors independent of changes in body composition in patients with HIV infection. AIDS, v. 23, n.1, p. 35-43, 2000.

MURATA, $\mathrm{H}$. et al. The mechanism of insulin resistance caused by HIV protease inhibitor therapy. J. Biol. Chem., v. 275, n. 27, p. 20251-20254, 2000.

MYNARCIK, D. C. et al. Association of severe insulin resistance with both loss of limb fat and elevated serum tumor necrosis factor receptor levels in HIV lipodystrophy. J. Acquir. Immune Defic. Syndr., v. 24, n. 4, p. 312-321, 2000.

NEUMANN, T. et al. Kardiale manifestationen der HIV-infektion. Med. Klin., v. 97, p. 659-665, 2002.

NOOR, M. A. et al. Metabolic effects of indinavir in healthy HIV-seronegative men. AIDS, v. 15, n. 7, p. 11-18, 2001.

NOOR, M. A. et al. Indinavir acutely inhibits insulin-stimulated glucose disposal in humans: a randomized, placebo-controlled study. AIDS, v. 16, n. 5, p. F1-8, 2002.

PALELLA, F. J. Jr. et al. Declining morbidity and mortality among patients with advanced human immunodeficiency virus infection. HIV outpatient study investigators. N. Engl. J. Med., v. 338, n. 13, p. 853-860, 1998.

PALINSKI, W. et al. Immunological evidence for the presence of advanced glycosylation end products in Atherosclerotic lesions of euglycemic Rabbits. Arterioscler. Thromb. Vasc. Biol., v. 15, p. 571-582, 1995.

PALINSKI, W. et al. Antisera and monoclonal antibodies specific for epitopes generated during oxidative modification of low density lipoprotein. Arteriosclerosis, v. 10, n. 3, p. 325-335, 1990.

PATRICE, A. et al. An inhibitor of HIV-1 protease modulates proteasome activity, antigen presentation and $\mathrm{T}$ cell responses. Proc. Nat. Acad. Sci. 
United States of America, v. 95, n. 22, p. 13120-13124, 1998.

PAULSSON, G. et al. Oligoclonal T cell expansions in Atherosclerotic lesions of Apolipoprotein E-deficient mice. Arterioscler. Thromb. Vasc. Biol., v. 20, p. 10-17, 2000.

PUURUNEN, M. et al. Antibody against oxidized low-density lipoprotein predicting myocardial infarction. Arch. Intern. Med., v. 154, n. 22, p. 26052609, 1994.

REAVEN, P. et al. Effect of streptozotocin-induced hyperglycemia on lipid profiles, formation of advanced glycation end products in lesions, and extent of Atherosclerosis in LDL receptor-deficient mice. Arterioscler. Thromb. Vasc. Biol., v. 17, n. 10, p. 2250-2256, 1997.

ROLING, J. et al. HIV-associated renal diseases and highly active antiretroviral therapy-induced nephropathy. Clin. Infect. Dis., v. 42, n. 10, p. 1488-1495, 2006.

ROSENKRANZ, S. L. et al. Antiretroviral drug levels and interactions affect lipid, lipoprotein and glucose metabolism in HIV-1 seronegative subjects: A pharmacokinetic-pharmacodynamic analysis. Metab. Syndr. Relat. Disord., v. 5, n. 2, p. 163-173, 2007.

ROSS, R.; GLOMSET, J. A. The pathogenesis of atherosclerosis. N. Engl. J. Med., v. 295, p. 369-377, 1976.

$\mathrm{RUDICH}, \mathrm{A}$. et al. Mechanisms of insulin resistance, lipodystrophy and atherosclerosis induced by HIV protease inhibitors. Acta Physiol. Scand., v. 183, n. 1, p. 75-88, 2005.

SAID, S. M. et al. Nephrotoxicity of antiretroviral therapy in an HIV-infected patient. Kidney Int., v. 71, n. 10, p. 1071-1075, 2007.

SAINT-MARC, T. et al. A syndrome of lipodystrophy in patients receiving a stable nucleoside -anologue therapy. In: CONFERENCE ON RETROVIRUSES AND OPPORTUNISTIC INFECTIONS, 6., 653, 1999, Chicago. Abstract... Chicago, 1999.

SARAIVA, L. R. et al. The prolongation of the QT interval in the acute rheumatic carditis: an enigma. Arq. Bras. Cardiol., v. 87, n. 6, p. 254-256, 2006.

SCHMIDTKE, G. et al. How an inhibitor of the HIV-I protease modulates proteasome activity. J. Biol. Chem., v. 274, n. 50, p. 35734-35740, 1999. 
SCHWARTZ, E. J. et al. Highly active antiretroviral therapy and the epidemic of HIV+ end-stage renal disease. J. Am. Soc. Nephrol., v. 16, n. 8, p. 2412-2420, 2005.

SERRA, F. et al. Altered blood amino acid distribution in genetically obese mice. Biochim. Biophys. Acta, v. 1097, n. 4, p. 289-292, 1991.

SHERER, Y.; SHOENFELD, Y. Immunomodulation for treatment and prevention of atherosclerosis. Autoimmun. Rev., v. 1, n. 1, p. 21-27, 2002.

SHIKUMA, C. et al. Analysis of subcutaneous adipose tissue mitochondrial DNA from individuals with HAART- associated lipodystrophy. In: CONFERENCE ON RETROVIRUSES AND OPPORTUNISTIC INFECTIONS, 6., 1999, Chicago. Abstract... Chicago, 1999.

SHOENFELD, Y. et al. Autoantibodies associated with atherosclerosis. Ann. Med., v. 32, n. 1, p. 37-40, 2000.

SHOJI, T. et al. Inverse relationship between circulating oxidized low density lipoprotein (oxLDL) and anti-oxLDL antibody levels in healthy subjects. Atherosclerosis, v. 148, n. 1, p. 171-177, 2000.

SOHMA, Y. et al. Accumulation of plasma cells in atherosclerotic lesions of Watanabe heritable hyperlipidemic rabbits. PNAS, v. 92, n. 11, p. 4937-4941, 1995.

SPADY, D. K. et al. Dissociation oh hepatic cholesterol synthesis from hepatic low-density lipoprotein uptake and billiary cholesterol saturation in female and male hamsters of different ages. Biochim. Biophys. Acta, v. 753, n. 3, p. 381392, 1983.

SPADY, D. K.; DIETSCHY, J. M. Dietary saturated triacylgly cerols suppress hepatic low density lipoprotein receptor activity $n$ the hamster. PNAS, v.82, p. 4526-4530, 1985.

SPADY, D. K.; DIETSCHY, J. M. Interaction of dietary cholesterol and triglycerides in the regulation of hepatic low density lipoprotein lipoprotein transport in the hamster. J. Clin. Invest., v. 81, p. 300-309, 1988.

SPÓSITO, A. C. et al. The lipoprotein profile in HIV infected patients. Braz. J. Infect. Dis., v. 1, n.6, p. 275-283, 1997.

STEINBERG, D. et al. Beyond cholesterol. Modifications of low-density lipoprotein that increase its atherogenicity. N. Engl. J. Med., v. 320, n. 14, p. 915-924, 1989. 
STEMME, $S$ et al. T lymphocytes from human atherosclerotic plaques recognize oxidized low density lipoprotein. PNAS, v. 92, n. 9, p. 3893-3897, 1995.

TANG, V. et al. Dietary oleoyl-estrone delays the growth rate of young rats. Eur. J. Nutr., v. 40, n. 1, p.17-22, 2001.

UGAWA, T. et al. Experimental model of escape phenomenon in hamsters and the efectiveness of YM-53601 in the model. B. J. Pharmacol., v. 135, p. 1572-1578, 2002.

UINT, L. et al. Hormone replacement therapy increases levels of antibodies against heat shock protein 65 and certain species of oxidized low density lipoprotein. Braz. J. Med. Biol. Res., v. 364, p. 491-494, 2003.

VIRABEN, R.; AQUILINA, C. Indinavir-associated lipodystrophy. AIDS, v. 12, n. 6, p. 37-39, 1998.

VITTINGHOFF, E. et al. Combination antiretroviral therapy and recent declines in AIDS incidence and mortality. J. Infect. Dis., v. 179, n. 3, p. 717-720, 1999.

VOLBERDING P. A. et al. The duration of zidovudine benefit in persons with asymptomatic HIV infection. Prolonged evaluation of protocol 019 of the AIDS clinical trials group. JAMA, v. 272, n. 6, p. 437-442, 1994.

WICK, G. et al. Autoimmunity and atherosclerosis. Am. Heart J., v. 138, n. 5, p. S444-S449, 1999.

WITZTUM, J. L.; PALINSKI, W. Are immunological mechanisms relevant for the development of atherosclerosis? Clin. Immunol., v. 90, p.153, 1999.

YLA-HERTTUALA, S. Is oxidized low-density lipoprotein present in vivo?. Curr. Opin. Lipidol., v. 9, n. 4, p. 337-344, 1998.

YOKOTA, T.; HANSSON, G. K. Immunological mechanisms in atherosclerosis. J. Int. Med., v. 238, p. 479-489, 1995.

ZACK, J. A. et al. HIV-1 entry into quiescent primary lymphocytes: molecular analysis reveals a labile, latent viral structure. Cell, v. 61, n. 2, p. 213-222, 1990.

ZARATIN, A. et al. Antibodies against oxidized low-density lipoprotein in normolipidemic smokers. Am. J. Cardiol., v. 90, n. 6, p. 651-653, 2002.

ZHANG, S. et al.Protease inhibitors used in the treatment of HIV+ induce beta- 
cell apoptosis via the mitochondrial pathway and compromise insulin secretion. Am. J. Physiol. Endocrinol. Metab., v. 296, n. 4, p. 925-935, 2009.

ZHOU, X. et al. Transfer of $\mathrm{CD}^{+} \mathrm{T}$ Cells Aggravates Atherosclerosis in immunodeficient Apolipoprotein E knockout mice. Circulation, v. 102, n. 24, p. 2919-2922, 2000. 